\title{
Poly(vinylphenoxazine) as Fast-Charging Cathode Material for Organic Batteries
}

Fabian Otteny, ${ }^{1,6}$ Verena Perner, ${ }^{2,6}$ Daniel Wassy, ${ }^{1}$ Martin Kolek, ${ }^{2, *}$ Peter Bieker, ${ }^{2}$ Martin Winter ${ }^{2,3}$ and Birgit Esser ${ }^{1,4,5,7, *}$

${ }^{1}$ Institute for Organic Chemistry, University of Freiburg, Albertstraße 21, 79104 Freiburg, Germany

2 MEET Battery Research Center, Institute of Physical Chemistry, University of Münster, Corrensstraße 46, 48149 Münster, Germany

${ }^{3}$ Helmholtz-Institute Münster (HI MS), IEK-12, Forschungszentrum Jülich GmbH, Corrensstrasse 46, 48149 Münster, Germany

${ }^{4}$ Freiburg Materials Research Center, University of Freiburg, Stefan-Meier-Straße 19, 79104 Freiburg, Germany

${ }^{5}$ Cluster of Excellence livMatS @ FIT - Freiburg Center for Interactive Materials and Bioinspired Technologies, University of Freiburg, Georges-Köhler-Allee 105, 79110 Freiburg, Germany

${ }^{6}$ These authors contributed equally

${ }^{7}$ Lead contact

* Correspondence: besser@oc.uni-freiburg.de, martin.kolek@uni-muenster.de

Number of pages: 47

Number of figures: 36

Number of tables: 8 


\section{Contents}

1 Synthesis and characterization data of PVMPO and X-PVMPO

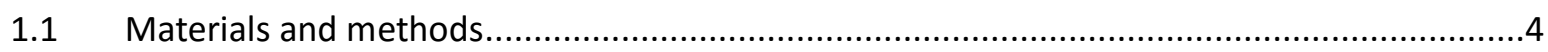

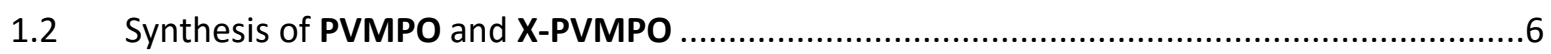

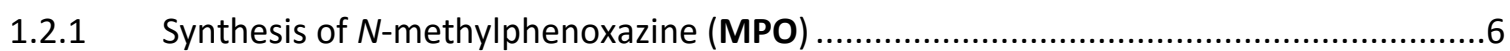

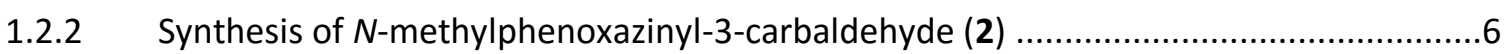

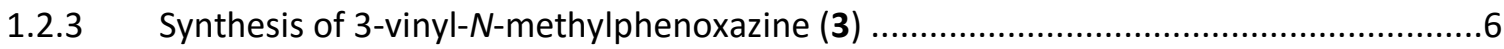

1.2.4 Synthesis of poly(3-vinyl- $N$-methylphenoxazine) (PVMPO) .........................................

1.2.5 Synthesis of 3,7-dibromo- $N$-methylphenoxazine (5) …............................................

1.2.6 Synthesis of 3,7-divinyl- $N$-methylphenoxazine (4) ................................................

1.2.7 Synthesis of crosslinked poly(3-vinyl-N-methylphenoxazine) (X-PVMPO).....................

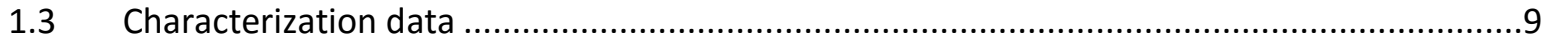

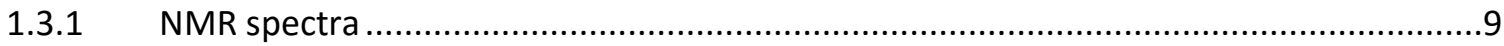

1.3.2 FTIR spectra of PVMPO and X-PVMPO

1.3.3 Thermal gravimetric analyses (TGA) of PVMPO and X-PVMPO

1.3.4 Differential scanning calorimetry (DSC) measurements of PVMPO and X-PVMPO .....15

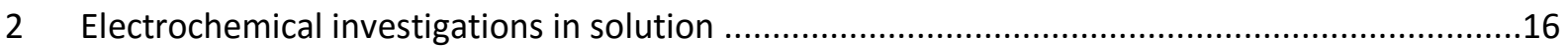

3 Investigations on (X-)PVMPO-based composite electrodes ......................................................19

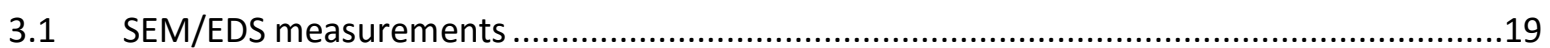

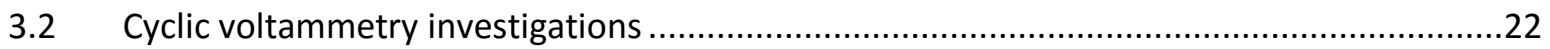

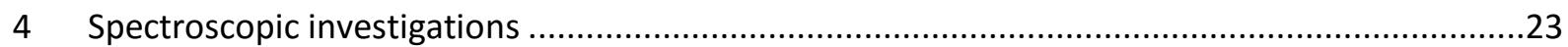

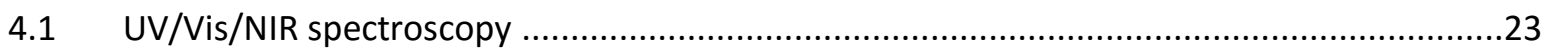

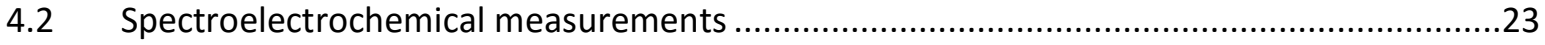

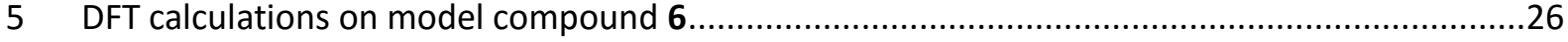

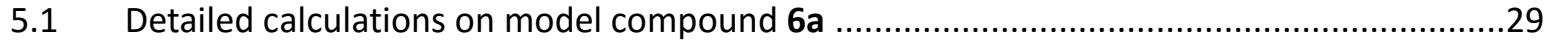

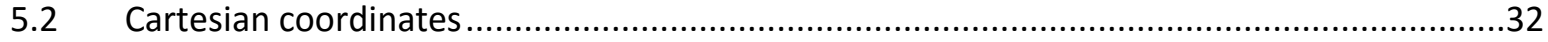

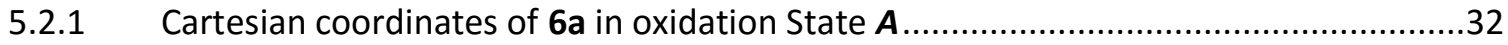

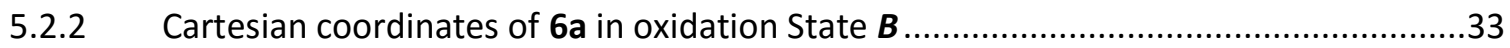

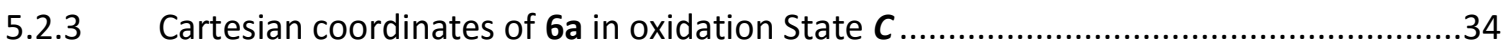

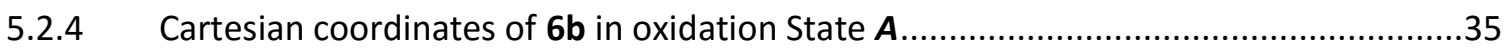

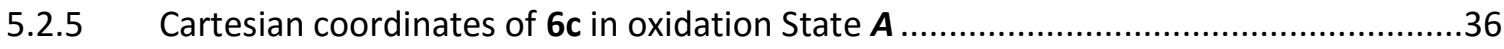

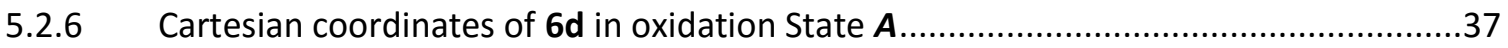

5.2.7 Cartesian coordinates of $\mathrm{N}$-methylphenoxazine (MPO) in oxidation State $\boldsymbol{A}$...............38

5.2.8 Cartesian coordinates of $\mathrm{N}$-methylphenoxazine (MPO) in oxidation State $\boldsymbol{B}$................39 
5.2.9 Cartesian coordinates of $\mathrm{N}$-methylphenoxazine (MPO) in oxidation State $C$..............40

5.2.10 Cartesian coordinates of $\mathrm{N}$-methylphenothiazine (MPT) in oxidation State $\boldsymbol{A}$.............41

5.2.11 Cartesian coordinates of $\mathrm{N}$-methylphenothiazine (MPT) in oxidation State $\boldsymbol{B}$.............42

5.2.12 Cartesian coordinates of $\mathrm{N}$-methylphenothiazine (MPT) in oxidation State $\mathrm{C}$.............43

6 Rate capability test and differential capacity plot of (X-)PVMPO-based composite electrodes...44

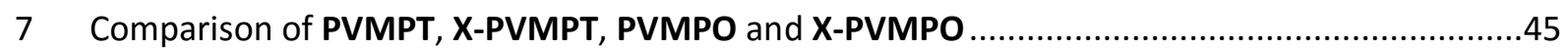

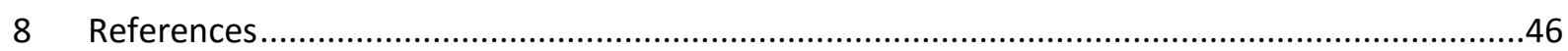




\section{Synthesis and characterization data of PVMPO and X-PVMPO}

\subsection{Materials and methods}

Commercially available chemicals were purchased from ACROS, CHEMPUR, FISHER CHEMICAL and SIGMAALDRICH and used without further purification unless otherwise noted. Solvents purchased in technical grade were distilled prior to use, analytical grade solvents were used as received. Anhydrous solvents were obtained from an M. BRAUN solvent purification system (MB-SPS-800) and stored over molecular sieves ( $3 \AA$ ) for a minimum duration of $72 \mathrm{~h}$. Air- and moisture-sensitive reactions were carried out under an argon atmosphere in glassware dried by heating under vacuum using standard Schlenk techniques (Argon 5.0 from SAUERSTOFFWERK FRIEDRICHSHAFEN).

Analytical thin layer chromatography was carried out by using silica gel-coated aluminium plates with a fluorescence indicator (MERCK $60 F_{254}$ ). Detection was carried out by using short-wave UV light $\left(\lambda_{\max }=254 \mathrm{~nm}\right.$ ). Flash column chromatography was carried out by using silica gel Silica 60 (grain size 40-63 $\mu \mathrm{m}, 230-400$ mesh) from MACHERY-NAGEL.

NMR spectra were recorded on BRUKER Avance III HD $\left({ }^{1} \mathrm{H}=500 \mathrm{MHz},{ }^{13} \mathrm{C}=125 \mathrm{MHz}\right)$, BRUKER Avance II $\left({ }^{1} \mathrm{H}=400 \mathrm{MHz},{ }^{13} \mathrm{C}=100 \mathrm{MHz}\right)$ and BRUKER Avance III HD $\left({ }^{1} \mathrm{H}=300 \mathrm{MHz}\right)$ spectrometers in deuterated solvent solution at $298 \mathrm{~K}$. Chemical shifts are reported in parts per million (ppm, $\delta$ scale) and are referenced to the residual solvent signal $\left(\mathrm{CDCl}_{3}: \delta_{\mathrm{H}} 7.26 \mathrm{ppm}, \delta_{\mathrm{C}}=77.16 \mathrm{ppm}\right)$. Analysis followed first order and data are presented as follows: chemical shift, multiplicity $(s=$ singlet, $d=$ doublet, $d d=$ doublet of doublet, $d d d=$ doublet of doublet of doublet, $m=$ multiplet), coupling constants $(J)$ in Hertz $[\mathrm{Hz}]$ and integration.

HRMS spectra were measured on a THERMO FISHER SCIENTIFIC Exactive spectrometer with orbitrap analyzer. For ionization $\mathrm{APCl}$ and ESI were used.

GC/MS spectra were measured on a THERMO SCIENTIFIC TRACE 1300 Gas Chromatograph combined with an ISQ LT Single Quadrupole Mass Spectrometer using electron impact ionization (EI).

FT-IR measurements were performed on a THERMO FISHER SCIENTIFIC Nicolet iS10 spectrometer equipped with a diamond-ATR module. Spectra were recorded at $298 \mathrm{~K}$ in the range of $4000-550 \mathrm{~cm}^{-1}$ with a resolution of $2 \mathrm{~cm}^{-1}$ and averaged over 64 scans. The THERMO FISHER SCIENTIFIC software OMNIC was used for acquiring data. All spectra were normalized to 1 and intensities are given as follows: vw = very weak $(<0.2), w=$ weak $(<0.4), m=$ medium $(<0.6), s=$ strong $(<0.8)$, vs = very strong $(\geq 0.8)$.

UV/Vis/NIR absorption spectra were measured with a Lambda 950 spectrometer from PERKINELMER using sealable Quartz Suprasil cuvettes from HeLLMA ANALYTICS.

Elemental analysis was performed on an ELEMENTAR vario MICRO cube using a thermal conductivity detector (TCD). 
GPC was performed on a SECCurity GPC System from PSS POLYMER STANDARDS SERVICE using components of the 1260 Infinity series from AGILENT TECHNOLOGIES. Measurements in THF were performed at $35{ }^{\circ} \mathrm{C}$ with a flow rate of $1 \mathrm{~mL} \mathrm{~min}{ }^{-1}$ and a set of three columns (PSS SDV, $8 \mathrm{~mm} \times 50 \mathrm{~mm}$ pre-column, $8 \mathrm{~mm}$ $\times 300 \mathrm{~mm}$ columns with a porosity of $1.000 \AA$ and $100.000 \AA$ ). For calibration, polystyrene standards by PSS were used.

TGA (thermogravimetric analysis) was performed on a NETZSCH STA 409 C and DSC (differential scanning calorimetry) on a NETZSCH DSC 204 F1 Phoenix. Evaluation of the data was perfomed with Proteus Thermal Analysis by NETZSCH.

Spectroelectrochemistry was performed using a combination of a VersaSTAT 4 potentiostat by PRINCETON APPLIED RESEARCH and a SPECORD S 300 VIS spectrometer by ANALYTIK JENA. Measurements were carried out in anhydrous dichloromethane $(10 \mathrm{mM}$ of analyte, referenced to the amount of redoxactive subunits) containing $n-\mathrm{Bu}_{4} \mathrm{NPF}_{6}(0.2 \mathrm{M})$ as supporting electrolyte. As working electrode (WE) a platinum net was used, as counter electrode (CE) a platinum rod and as reference electrode (RE) a $\mathrm{Ag} / \mathrm{AgNO}_{3}$ electrode containing a silver wire immersed in an inner chamber filled with $\mathrm{AgNO}_{3}(0.01 \mathrm{M})$ and $n-\mathrm{Bu}_{4} \mathrm{NPF}_{6}(0.1 \mathrm{M})$ in anhydrous acetonitrile. To apply the desired potential a chronoamperometric measurement was performed using the software VersaStudio to adjust the parameters. UV/Vis spectra were recorded at an interval of 30 seconds using the software WinASPECT. 


\subsection{Synthesis of PVMPO and X-PVMPO}

\subsubsection{Synthesis of $\mathbf{N}$-methylphenoxazine (MPO)}

A solution of phenoxazine $(\mathbf{1}, 1.00 \mathrm{~g}, 5.46 \mathrm{mmol})$ in dry THF $(20 \mathrm{~mL})$ was added to a solution of potassium tert-butoxide $(919 \mathrm{mg}, 8.19 \mathrm{mmol})$ in dry THF $(30 \mathrm{~mL})$ at $0{ }^{\circ} \mathrm{C}$. After stirring for $1 \mathrm{~h}$, methyl iodide $(0.68 \mathrm{~mL}, 10.9 \mathrm{mmol})$ was added to the solution. The mixture was stirred at room temperature for $42 \mathrm{~h}$. The reaction was quenched with water $(20 \mathrm{~mL})$, and the resulting mixture was extracted with ethyl acetate $(3 \times 50 \mathrm{~mL})$. The combined organic layers were washed with water and brine, dried over $\mathrm{MgSO}_{4}$, filtered and evaporated to dryness under reduced pressure. Column chromatography (silica gel, cyclohexane/ethyl acetate: 10/1) afforded $\mathrm{N}$-methylphenoxazine (MPO, $1.05 \mathrm{~g}, 5.35 \mathrm{mmol}$, 98\%) as a colorless oil. $R_{\mathrm{f}} 0.59$ (cyclohexane/ethyl acetate: 10/1); ${ }^{1} \mathrm{H}$ NMR $\left(300 \mathrm{MHz}, \mathrm{CDCl}_{3}\right): \delta 6.90-6.82(\mathrm{~m}$, $2 \mathrm{H}), 6.73-6.67(\mathrm{~m}, 4 \mathrm{H}), 6.53(\mathrm{~d}, J=7.7 \mathrm{~Hz}, 2 \mathrm{H}), 3.05(\mathrm{~s}, 3 \mathrm{H}) ;{ }^{13} \mathrm{C} \mathrm{NMR}\left(100 \mathrm{MHz}, \mathrm{CDCl}_{3}\right): \delta$ 145.8, 135.2, 123.9, 121.1, 115.4, 111.5, 31.0; HRMS (ESI+): $m / z$ calcd. for $\mathrm{C}_{13} \mathrm{H}_{11} \mathrm{NO} 197.0835$ [M] $]^{+}$, found 197.0835.

\subsubsection{Synthesis of $\boldsymbol{N}$-methylphenoxazinyl-3-carbaldehyde (2)}

Phosphoryl chloride $\left(\mathrm{POCl}_{3}, 0.42 \mathrm{~mL}, 4.46 \mathrm{mmol}\right)$ was added dropwise to dry DMF $(1.50 \mathrm{~mL}$, $19.5 \mathrm{mmol}$ ) at $0{ }^{\circ} \mathrm{C}$. A solution of $\mathrm{N}$-methylphenoxazine (MPO, $800 \mathrm{mg}, 4.06 \mathrm{mmol}$ ) in dry 1,2-dichloroethane $(9 \mathrm{ml})$ was added dropwise, and the reaction mixture was stirred at $0{ }^{\circ} \mathrm{C}$ for $1 \mathrm{~h}$, warmed to room temperature and then stirred for $24 \mathrm{~h}$ at $90^{\circ} \mathrm{C}$. After cooling to room temperature, saturated aq. $\mathrm{NaOAc}$ solution $(20 \mathrm{~mL})$ was added. The aqueous layer was extracted with dichloromethane $(3 \times$ $50 \mathrm{~mL}$ ). The combined organic layers were washed with water and brine, dried over $\mathrm{MgSO}_{4}$, filtered and evaporated to dryness under reduced pressure. Column chromatography (silica gel, cyclohexane/ethyl acetate: 4/1) afforded $N$-methylphenoxazinyl-3-carbaldehyde (2, $824 \mathrm{mg}$, $3.66 \mathrm{mmol}, 90 \%$ ) as a yellow solid. $R_{\mathrm{f}} 0.47$ (cyclohexane/ethyl acetate: $2 / 1$ ); ${ }^{1} \mathrm{H} \mathrm{NMR}\left(400 \mathrm{MHz}, \mathrm{CDCl}_{3}\right.$ ): $\delta 9.69(\mathrm{~s}, 1 \mathrm{H}), 7.35$ (dd, $J=8.2,1.9 \mathrm{~Hz}, 1 \mathrm{H}), 7.13(\mathrm{~d}, J=1.8 \mathrm{~Hz}, 1 \mathrm{H}), 6.87$ (ddd, J = 7.9, 7.4, $1.6 \mathrm{~Hz}, 1 \mathrm{H}$ ), 6.77 (ddd, J = 7.9, 7.8, 1.6 Hz, 1H), 6.71 (dd, J = 7.8, 1.6 Hz, 1H), $6.57(\mathrm{dd}, J=7.8,1.6 \mathrm{~Hz}, 1 \mathrm{H}), 6.55$ (d, J $=7.9 \mathrm{~Hz}, 1 \mathrm{H}), 3.11(\mathrm{~s}, 3 \mathrm{H}) ;{ }^{13} \mathrm{C} \mathrm{NMR}\left(100 \mathrm{MHz}, \mathrm{CDCl}_{3}\right): \delta 189.9,145.8,145.2,140.8,133.1,130.3,128.8$, 124.2, 122.7, 115.8, 114.3, 112.3, 110.9, 31.4; $\mathrm{HRMS}\left(\mathrm{APCl}+\right.$ ): $\mathrm{m} / \mathrm{z}$ calcd. for $\mathrm{C}_{14} \mathrm{H}_{12} \mathrm{NO}_{2} 226.0863[\mathrm{M}+\mathrm{H}]^{+}$, found 226.0865 .

\subsubsection{Synthesis of 3-vinyl- $N$-methylphenoxazine (3)}

Methyltriphenylphosphonium bromide $(2.08 \mathrm{~g}, 5.83 \mathrm{mmol})$ was added to a solution of potassium tertbutoxide $(747 \mathrm{mg}, 6.66 \mathrm{mmol})$ in dry THF $(15 \mathrm{~mL})$, and the solution was stirred at room temperature for $40 \mathrm{~min}$. N-Methylphenoxazinyl-3-carbaldehyde $(2,721 \mathrm{mg}, 3.20 \mathrm{mmol})$ was added to the solution, and the reaction mixture was stirred at room temperature for $24 \mathrm{~h}$. The reaction was quenched with water $(10 \mathrm{~mL})$ and extracted with ethyl acetate $(3 \times 100 \mathrm{~mL})$. The combined organic extracts were dried 
over $\mathrm{MgSO}_{4}$, filtered, and the solvent was removed under reduced pressure. Column chromatography (silica gel, cyclohexane/ethyl acetate: $8 / 1$ to $1 / 1$ ) yielded 3-vinyl- $N$-methylphenoxazine $(3,697 \mathrm{mg}$, $3.12 \mathrm{mmol}, 98 \%$ ) as a yellow solid. $R_{\mathrm{f}} 0.60$ (cyclohexane/ethyl acetate: $5 / 1$ ); ${ }^{1} \mathrm{H} \mathrm{NMR}\left(500 \mathrm{MHz}, \mathrm{CDCl}_{3}\right.$ ): $\delta 6.88-6.83(\mathrm{~m}, 2 \mathrm{H}), 6.82(\mathrm{~d}, J=2.0 \mathrm{~Hz}, 1 \mathrm{H}), 6.73-6.69(\mathrm{~m}, 2 \mathrm{H}), 6.54(\mathrm{dd}, J=17.5,10.8 \mathrm{~Hz}, 1 \mathrm{H}), 6.53(\mathrm{~d}$, $J=7.9 \mathrm{~Hz}, 1 \mathrm{H}), 6.46(\mathrm{~d}, J=8.1 \mathrm{~Hz}, 1 \mathrm{H}), 5.55(\mathrm{dd}, J=17.5,0.9 \mathrm{~Hz}, 1 \mathrm{H}), 5.09(\mathrm{dd}, J=10.8,0.9 \mathrm{~Hz}, 1 \mathrm{H}), 3.05$ $(\mathrm{s}, 3 \mathrm{H}) ;{ }^{13} \mathrm{CNMR}\left(125 \mathrm{MHz}, \mathrm{CDCl}_{3}\right): \delta 145.7,145.5,135.9,134.7,134.6,131.1,123.9,122.7,121.2,115.5$, 112.3, 111.6, 111.5, 111.2, 31.1; HRMS (ESI+): $\mathrm{m} / z$ calcd. for $\mathrm{C}_{15} \mathrm{H}_{13} \mathrm{NO} 223.0992$ [M] ${ }^{+}$, found 223.0997.

\subsubsection{Synthesis of poly(3-vinyl-N-methylphenoxazine) (PVMPO)}

A solution of azobisisobutyronitrile $(2.4 \mathrm{mg}, 14 \mu \mathrm{mol})$ in dry and degassed THF $(0.2 \mathrm{~mL})$ was added to a stirred solution of 3-vinyl- $N$-methylphenoxazine $(3,320 \mathrm{mg}, 1.43 \mathrm{mmol})$ in dry and degassed THF $(1.2 \mathrm{~mL})$. The flask was immediately immersed in a pre-heated oil bath, and the solution was stirred at $60{ }^{\circ} \mathrm{C}$ for $3 \mathrm{~d}$. The reaction was quenched by adding methanol $(2 \mathrm{~mL})$, and the solvent was removed under reduced pressure. The residue was dissolved in $\mathrm{CH}_{2} \mathrm{Cl}_{2}$, and the polymer was precipitated from cyclohexane and cold acetone to afford PVMPO (245 mg, 77\%) as an off-white solid. ${ }^{1} \mathrm{H}$ NMR (300 MHz, $\left.\mathrm{CDCl}_{3}\right): \delta 6.88-5.84(\mathrm{~m}, 7 \mathrm{H}), 2.96-2.47(\mathrm{~m}, 3 \mathrm{H}), 2.09-1.61(\mathrm{~m}, 1 \mathrm{H}), 1.51-0.97(\mathrm{~m}, 2 \mathrm{H}) ; \mathrm{FT}$-IR (ATR): $\tilde{v}_{\max }=627(\mathrm{w}), 735(\mathrm{vs}), 801(\mathrm{~m}), 848(\mathrm{w}), 1143(\mathrm{w}), 1212(\mathrm{~m}), 1272(\mathrm{vs}), 1360(\mathrm{~m}), 1430(\mathrm{w}), 1489(\mathrm{vs})$, 1598 (w), 2920 (vw) cm ${ }^{-1}$; UV/Vis $\left(\mathrm{CH}_{2} \mathrm{Cl}_{2}\right): \lambda_{\max }(\log \varepsilon)=326 \mathrm{~nm}$ (4.00); elemental analysis: calcd (\%) for $\mathrm{C}_{15} \mathrm{H}_{13} \mathrm{NO}$ : C 80.69, H 5.87, N 6.27; found: C 79.96, H 6.19, N 6.10; GPC (eluent THF, polystyrene standard): $M_{\mathrm{n}} 2.4 \times 10^{4} \mathrm{~g} \mathrm{~mol}^{-1}, M_{\mathrm{w}} / M_{\mathrm{n}} 1.7 ; \operatorname{TGA}\left(10^{\circ} \mathrm{C} \mathrm{min}^{-1}\right.$, air): onset decomposition $390^{\circ} \mathrm{C}, T_{\mathrm{d} 10 \%}$ (temperature for $10 \%$ weight loss) $392^{\circ} \mathrm{C}$; DSC $\left(10^{\circ} \mathrm{C} \mathrm{min}^{-1}\right.$, air): $T_{\mathrm{g}} 178^{\circ} \mathrm{C}$.

\subsubsection{Synthesis of 3,7-dibromo-N-methylphenoxazine (5)}

$\mathrm{N}$-Bromosuccinimide $(270 \mathrm{mg}, 1.52 \mathrm{mmol})$ was added in two portions to a solution of $N$-methylphenoxazine (MPO, $130 \mathrm{mg}, 0.66 \mathrm{mmol}$ ) in dry dichloromethane $(4 \mathrm{~mL})$ at $0{ }^{\circ} \mathrm{C}$. After warming to room temperature, the solution was stirred for $16 \mathrm{~h}$. The reaction was quenched by adding water and a saturated aqueous solution of $\mathrm{Na}_{2} \mathrm{CO}_{3}(10 \mathrm{~mL})$. The aqueous layer was extracted with dichloromethane $(3 \times 15 \mathrm{~mL})$. The combined organic extracts were dried over $\mathrm{MgSO}_{4}$, filtered, and the solvent was removed under reduced pressure. Column chromatography (silica gel, cyclohexane/ethyl acetate: $10 / 1)$ yielded 3,7-dibromo- $N$-methylphenoxazine $(5,210 \mathrm{mg}, 0.59 \mathrm{mmol}, 90 \%)$ as a white solid. $R_{\mathrm{f}} 0.36$ (cyclohexane/ethyl acetate: 10/1); ${ }^{1} \mathrm{H} \mathrm{NMR}\left(500 \mathrm{MHz}, \mathrm{CDCl}_{3}\right): \delta 6.95$ (dd, J = 8.5, $\left.2.2 \mathrm{~Hz}, 2 \mathrm{H}\right), 6.80$ (d, J $=2.3 \mathrm{~Hz}, 2 \mathrm{H}), 6.35(\mathrm{~d}, J=8.5 \mathrm{~Hz}, 2 \mathrm{H}), 2.98(\mathrm{~s}, 3 \mathrm{H}) ;{ }^{13} \mathrm{C} \mathrm{NMR}\left(125 \mathrm{MHz}, \mathrm{CDCl}_{3}\right): \delta$ 145.8, 133.8, 126.8, 118.7, 112.8, 112.7, 31.2; HRMS (ESI+): $m / z$ calcd. for $\mathrm{C}_{13} \mathrm{H}_{9} \mathrm{NBr}^{81} \mathrm{BrO} 354.9025[\mathrm{M}]^{+}$, found 354.9024 . 


\subsubsection{Synthesis of 3,7-divinyl- $\mathrm{N}$-methylphenoxazine (4)}

A solution of 3,7-dibromo- $N$-methylphenoxazine $(5,50 \mathrm{mg}, 0.14 \mathrm{mmol}), 4,4,5,5$-tetramethyl-2-vinyl1,3,2-dioxaborolane $(0.10 \mathrm{~mL}, 0.56 \mathrm{mmol})$ and $\mathrm{Pd}\left(\mathrm{PPh}_{3}\right)_{4}(16 \mathrm{mg}, 14 \mu \mathrm{mol})$ in a degassed mixture of THF $(1.7 \mathrm{~mL})$ and aqueous $\mathrm{NaOH}(2.8 \mathrm{M}, 0.3 \mathrm{~mL})$ was heated to $80^{\circ} \mathrm{C}$ for $24 \mathrm{~h}$. After cooling to room temperature, $\mathrm{H}_{2} \mathrm{O}(5 \mathrm{~mL})$ and brine $(2 \mathrm{~mL})$ were added, and the mixture was extracted with dichloromethane $(3 \times 20 \mathrm{~mL})$. The combined organic extracts were dried over $\mathrm{MgSO}_{4}$, filtered, and the solvent was removed under reduced pressure. Column chromatography (triethylamine-impregnated silica gel, cyclohexane/ethyl acetate: 15/1) yielded 3,7-divinyl- $N$-methylphenoxazine (4, $22 \mathrm{mg}$, $88 \mu \mathrm{mol}, 63 \%$ ) as a white solid. $R_{\mathrm{f}} 0.54$ (cyclohexane/ethyl acetate: $10 / 1$ ); ${ }^{1} \mathrm{H} \mathrm{NMR}\left(500 \mathrm{MHz}, \mathrm{CDCl}_{3}\right.$ ): $\delta$ $6.85(\mathrm{dd}, J=8.2,2.1 \mathrm{~Hz}, 2 \mathrm{H}), 6.82(\mathrm{~d}, J=2.1 \mathrm{~Hz}, 2 \mathrm{H}), 6.53(\mathrm{dd}, J=17.5,10.8 \mathrm{~Hz}, 2 \mathrm{H}), 6.46(\mathrm{~d}, J=8.2 \mathrm{~Hz}$, $2 \mathrm{H}), 5.55$ (dd, $J=17.5,0.8 \mathrm{~Hz}, 2 \mathrm{H}), 5.10$ (dd, $J=10.8,0.9 \mathrm{~Hz}, 2 \mathrm{H}), 3.06(\mathrm{~s}, 3 \mathrm{H}) ;{ }^{13} \mathrm{C} \mathrm{NMR}(125 \mathrm{MHz}$, $\left.\mathrm{CDCl}_{3}\right): \delta 145.4,135.9,134.2,131.2,122.6,112.4,111.6,111.3,31.2 ; \mathrm{HRMS}(\mathrm{APCl}+): \mathrm{m} / \mathrm{z}$ calcd. for $\mathrm{C}_{17} \mathrm{H}_{16} \mathrm{NO} 250.1226[\mathrm{M}+\mathrm{H}]^{+}$, found 250.1228 .

\subsubsection{Synthesis of crosslinked poly(3-vinyl-N-methylphenoxazine) (X-PVMPO)}

A solution of azobisisobutyronitrile $(4.0 \mathrm{mg}, 24 \mu \mathrm{mol})$ in dry and degassed THF $(0.3 \mathrm{~mL})$ was added to a stirred solution of 3-vinyl- $\mathrm{N}$-methylphenoxazine $(3,270 \mathrm{mg}, 1.21 \mathrm{mmol})$ and 3,7-divinyl- $\mathrm{N}$-methylphenoxazine $(4,30 \mathrm{mg}, 0.12 \mathrm{mmol})$ in dry and degassed THF (1.5 mL). The flask was immediately immersed in a pre-heated oil bath, and the solution was stirred at $60^{\circ} \mathrm{C}$ for $5 \mathrm{~d}$. The reaction was quenched by adding methanol $(2 \mathrm{~mL})$, and the mixture was evaporated to dryness under reduced pressure. The crude product was pestled into a powder, suspended with dichloromethane, allowed to swell until the phase looked homogenious, and precipitated from cyclohexane. The purified crosslinked poly(3-vinyl-N-methylphenoxazine) (X-PVMPO, $201 \mathrm{mg}, 67 \%$ ) was obtained as an off-white powder. FT-IR (ATR): $\tilde{v}_{\max }=627(\mathrm{w}), 735(\mathrm{vs}), 801(\mathrm{~m}), 848(\mathrm{w}), 1143(\mathrm{w}), 1212(\mathrm{~m}), 1272(\mathrm{vs}), 1360(\mathrm{~m})$, 1430 (w), 1489 (vs), 1598 (w), 2920 (vw) cm ${ }^{-1}$; elemental analysis: calcd (\%) for $\mathrm{C}_{15} \mathrm{H}_{13} \mathrm{NO}$ : C 80.69, H 5.87, N 6.27; found: $\mathrm{C} 80.33, \mathrm{H} 6.09, \mathrm{~N} 6.10$; TGA $\left(10^{\circ} \mathrm{C} \mathrm{min}^{-1}\right.$, air): onset $423^{\circ} \mathrm{C}, T_{\mathrm{d} 10 \%}$ (temperature for $10 \%$ weight loss) $420^{\circ} \mathrm{C}$.

Investigation by GC/MS analysis of the monomer ratio in the cyclohexane filtrate after precipitation allowed to estimate the ratio of monomers incorporated in the polymer. The calculated ratio of $\mathbf{3}$ to $\mathbf{4}$ in the crosslinked polymer was 7.7 to 1 , leading to a higher crosslinkage than the estimated ratio of 10 to 1 . So crosslinkage occured statistically at every $8.7^{\text {th }}$ monomeric unit. 


\subsection{Characterization data}

\subsubsection{NMR spectra}

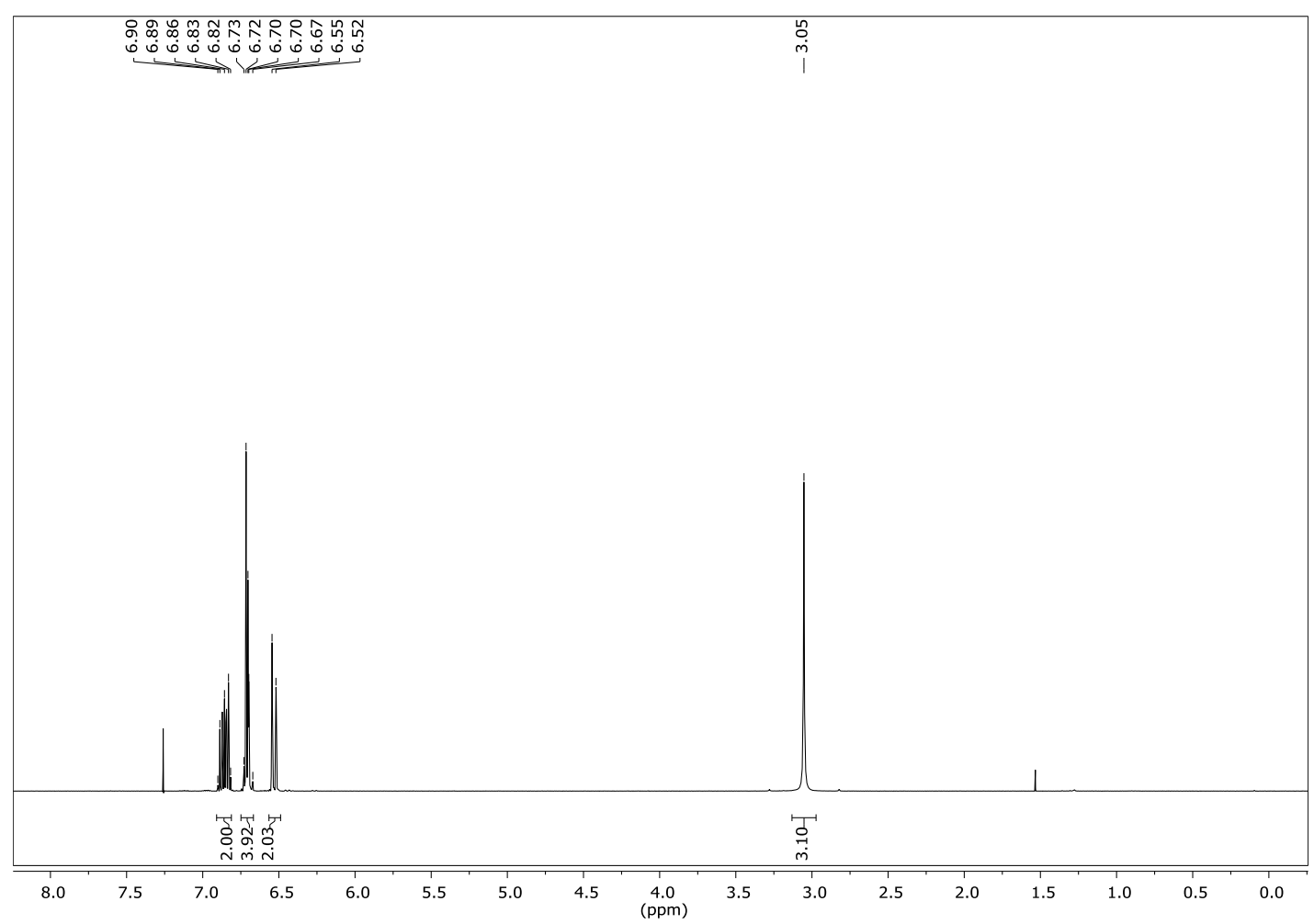

Figure S1. $300 \mathrm{MHz}^{1} \mathrm{H}$ NMR spectrum of $\mathrm{N}$-methylphenoxazine (MPO) in $\mathrm{CDCl}_{3}$.

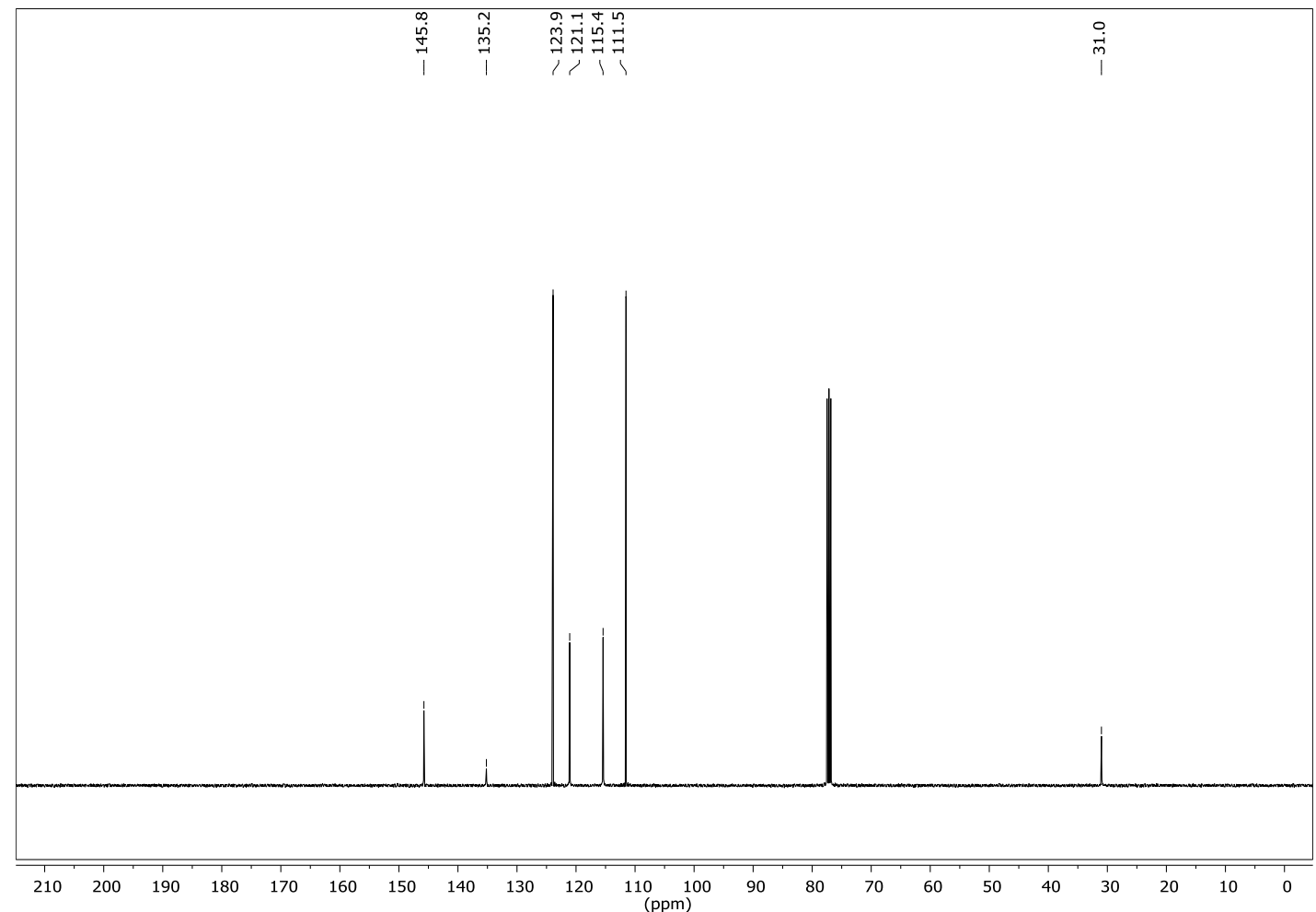

Figure S2. $100 \mathrm{MHz}{ }^{13} \mathrm{C}$ NMR spectrum of $\mathrm{N}$-methylphenoxazine (MPO) in $\mathrm{CDCl}_{3}$. 


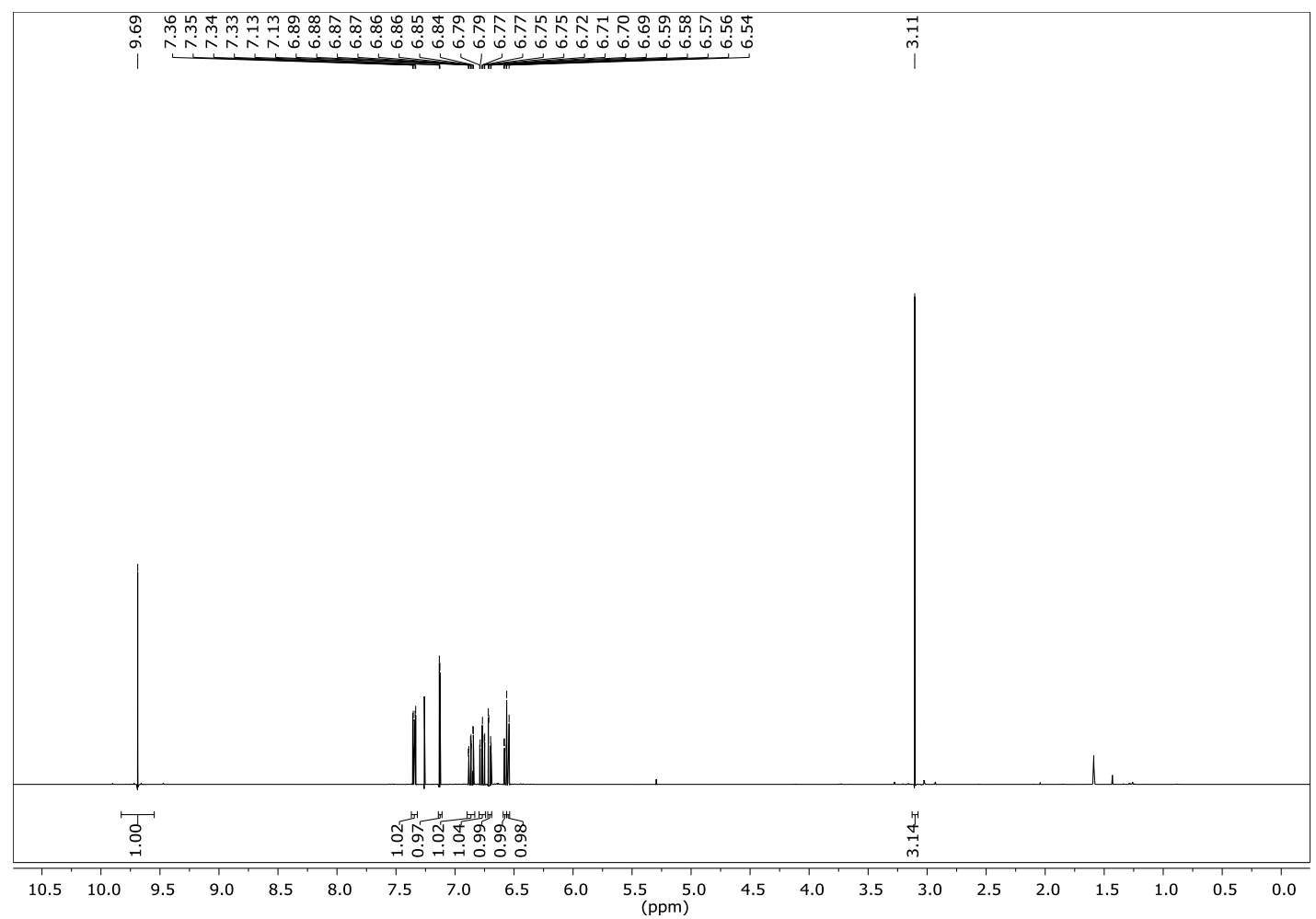

Figure S3. $400 \mathrm{MHz}^{1} \mathrm{H}$ NMR spectrum of $\mathrm{N}$-methylphenoxazinyl-3-carbaldehyde (2) in $\mathrm{CDCl}_{3}$.

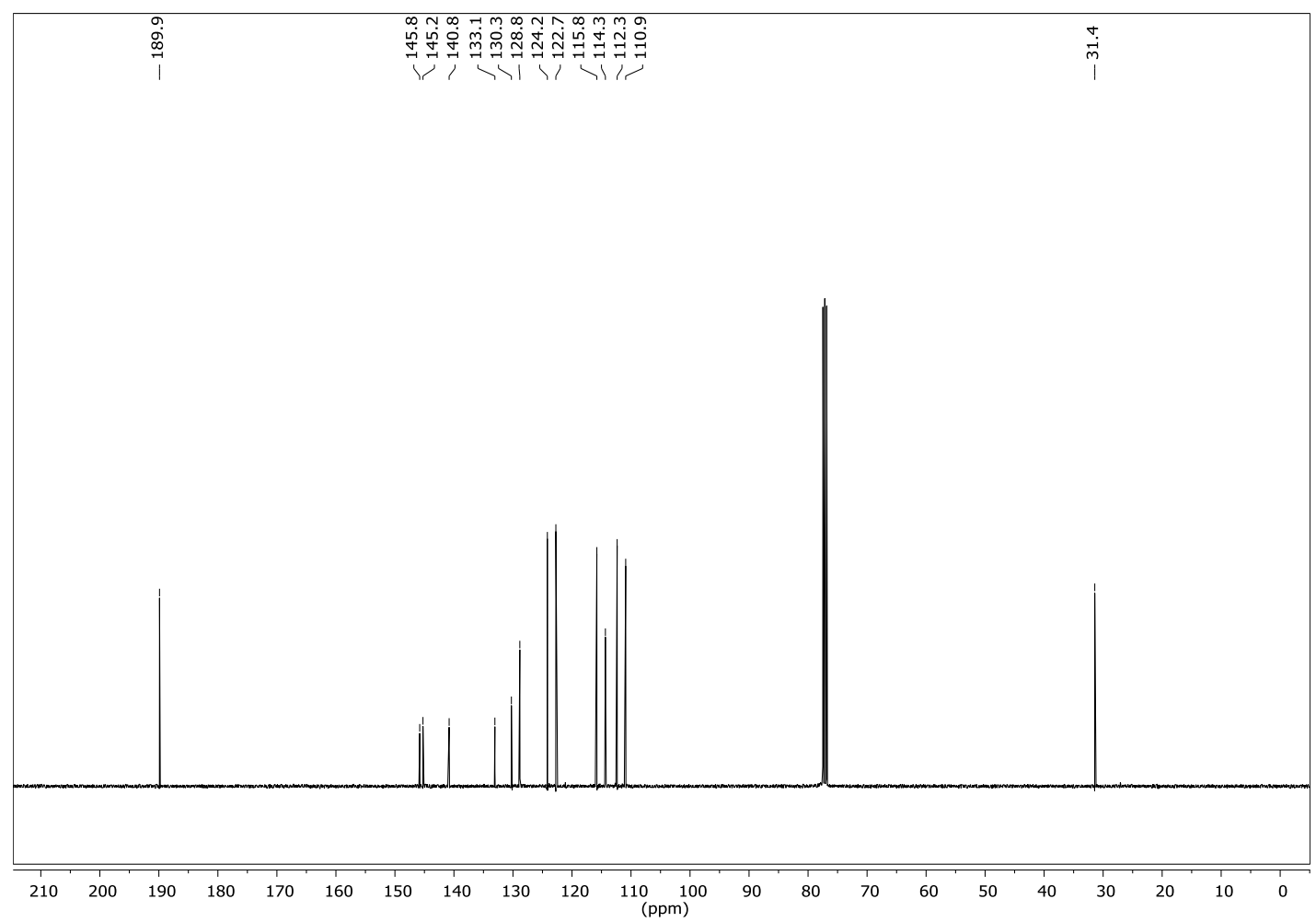

Figure S4. $100 \mathrm{MHz}{ }^{13} \mathrm{C}$ NMR spectrum of $\mathrm{N}$-methylphenoxazinyl-3-carbaldehyde (2) in $\mathrm{CDCl}_{3}$. 


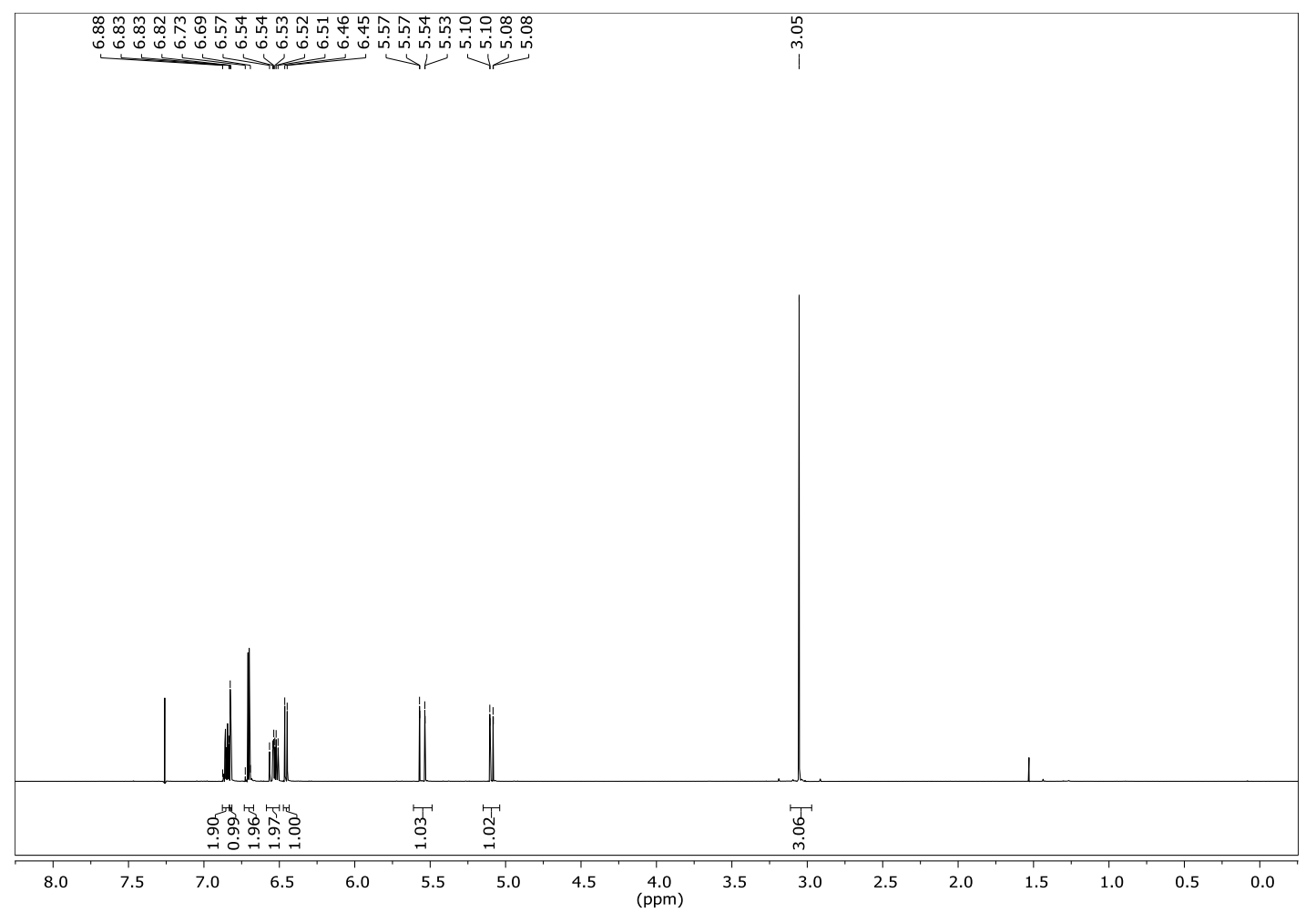

Figure S5. $500 \mathrm{MHz}{ }^{1} \mathrm{H}$ NMR spectrum of 3-vinyl- $N$-methylphenoxazine (3) in $\mathrm{CDCl}_{3}$.

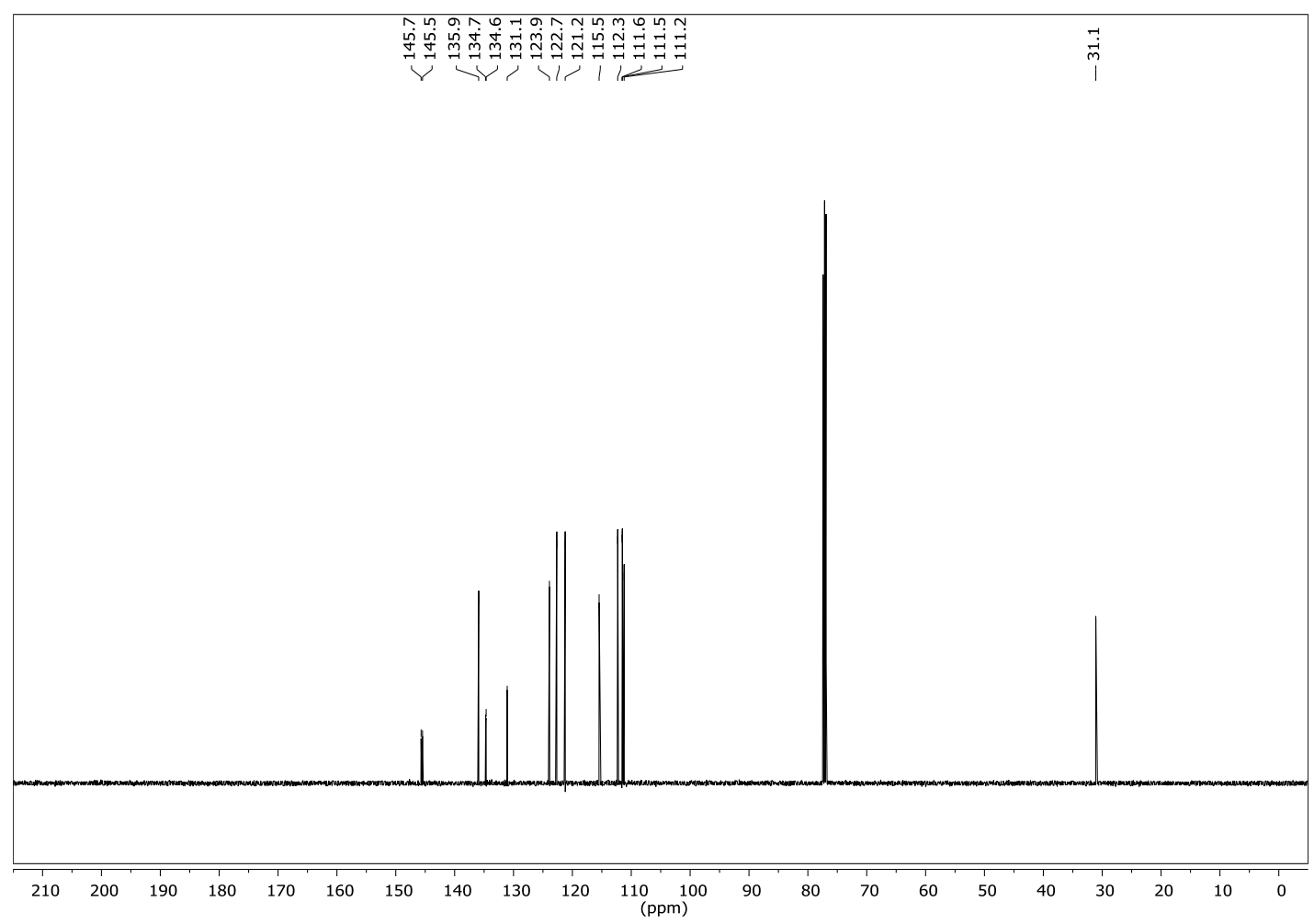

Figure S6. $125 \mathrm{MHz}{ }^{13} \mathrm{C}$ NMR spectrum of 3-vinyl- $N$-methylphenoxazine (3) in $\mathrm{CDCl}_{3}$. 


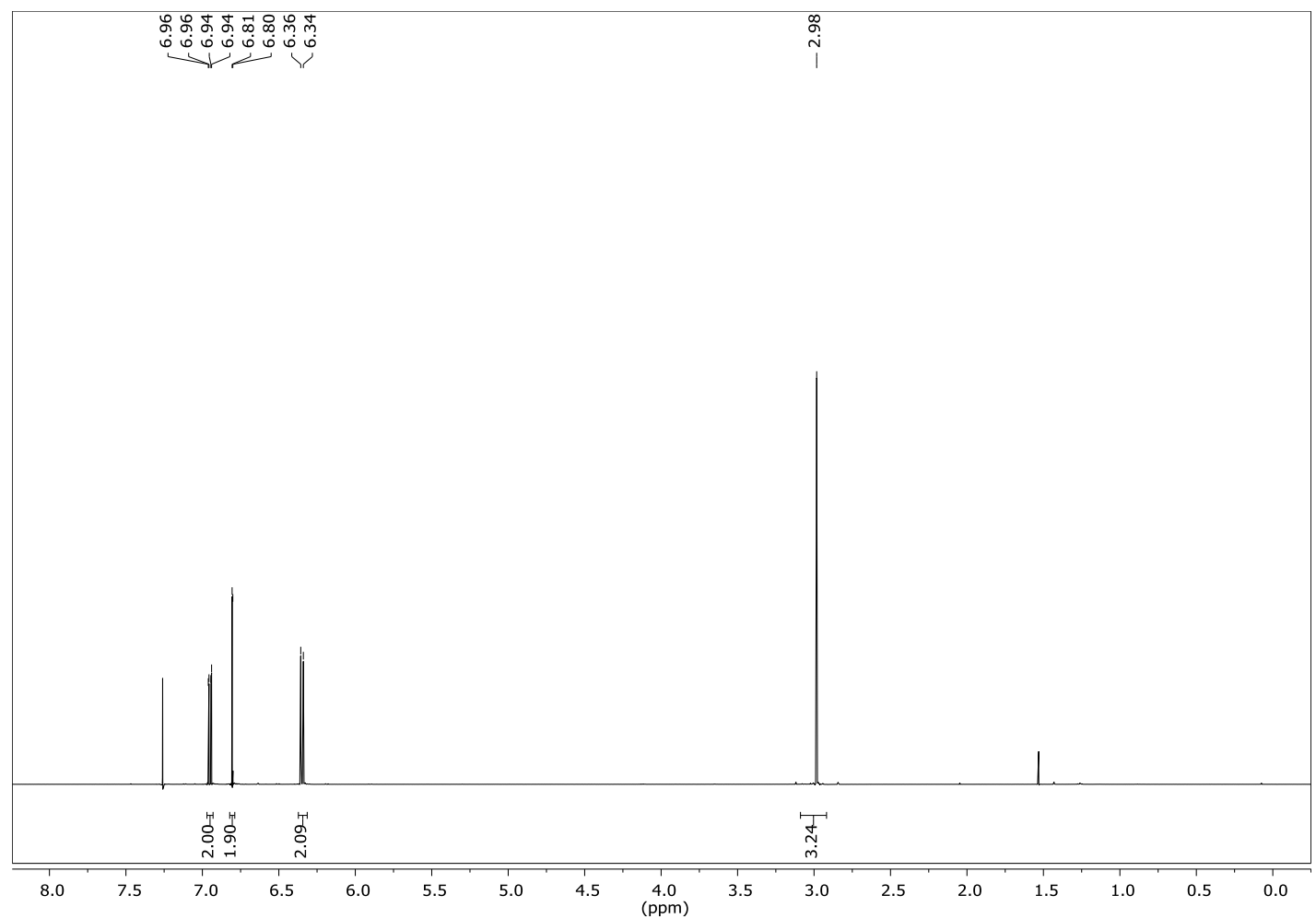

Figure S7. $500 \mathrm{MHz}{ }^{1} \mathrm{H}$ NMR spectrum of 3,7-dibromo- $N$-methylphenoxazine (5) in $\mathrm{CDCl}_{3}$.

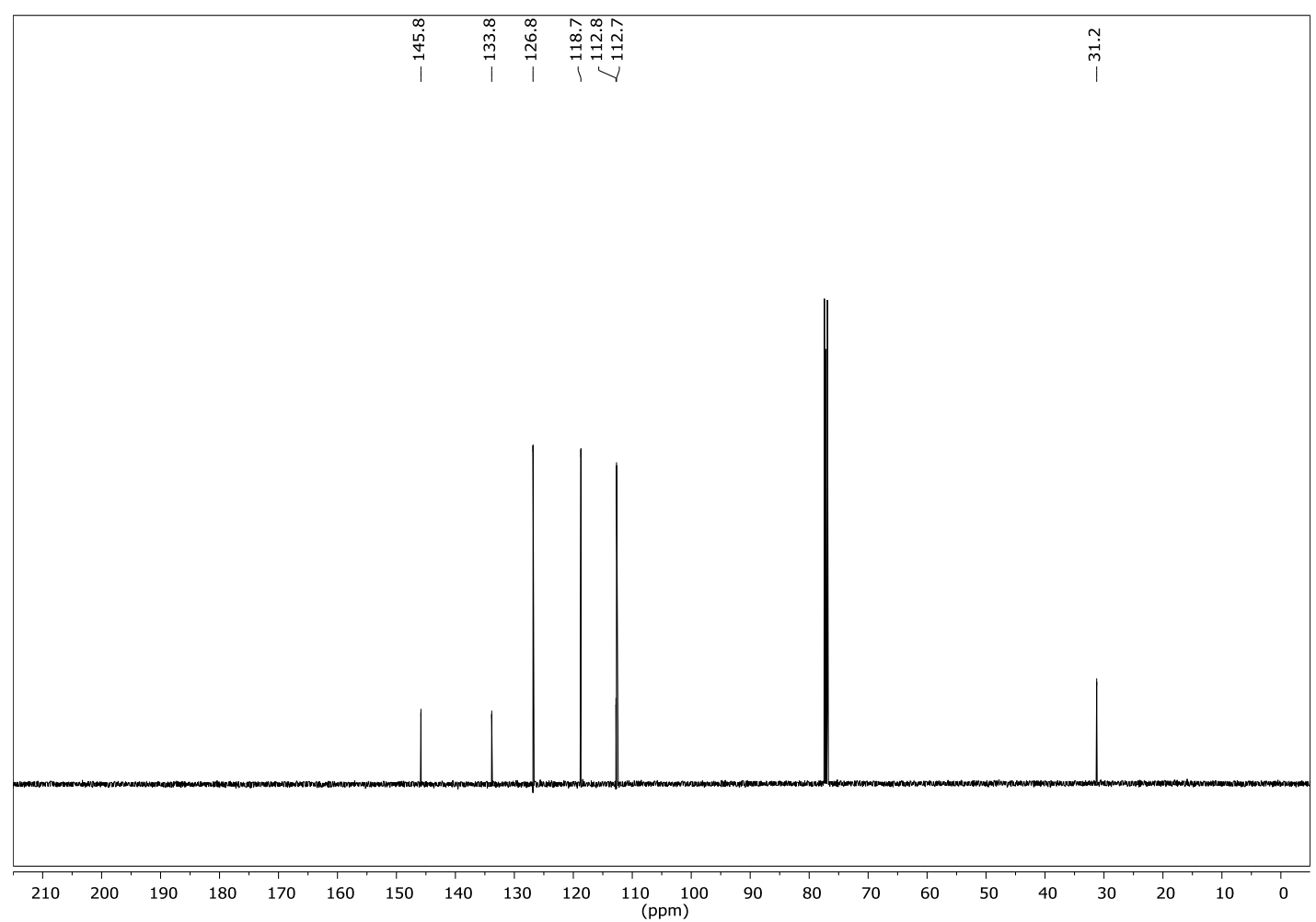

Figure S8. $125 \mathrm{MHz}{ }^{13} \mathrm{C}$ NMR spectrum of 3,7-dibromo- $N$-methylphenoxazine (5) in $\mathrm{CDCl}_{3}$. 


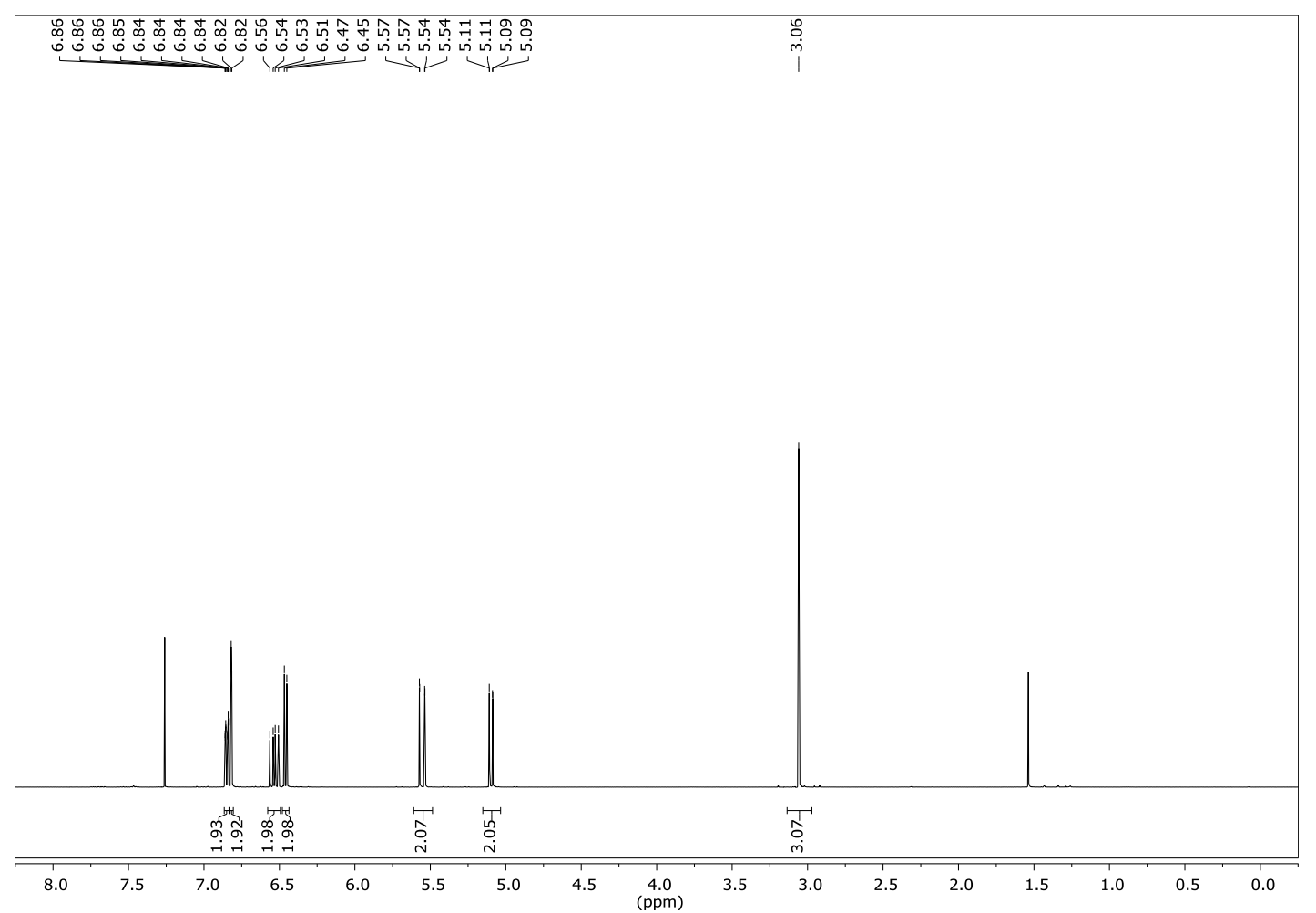

Figure S9. $500 \mathrm{MHz}{ }^{1} \mathrm{H}$ NMR spectrum of 3,7-divinyl- $N$-methylphenoxazine (4) in $\mathrm{CDCl}_{3}$.

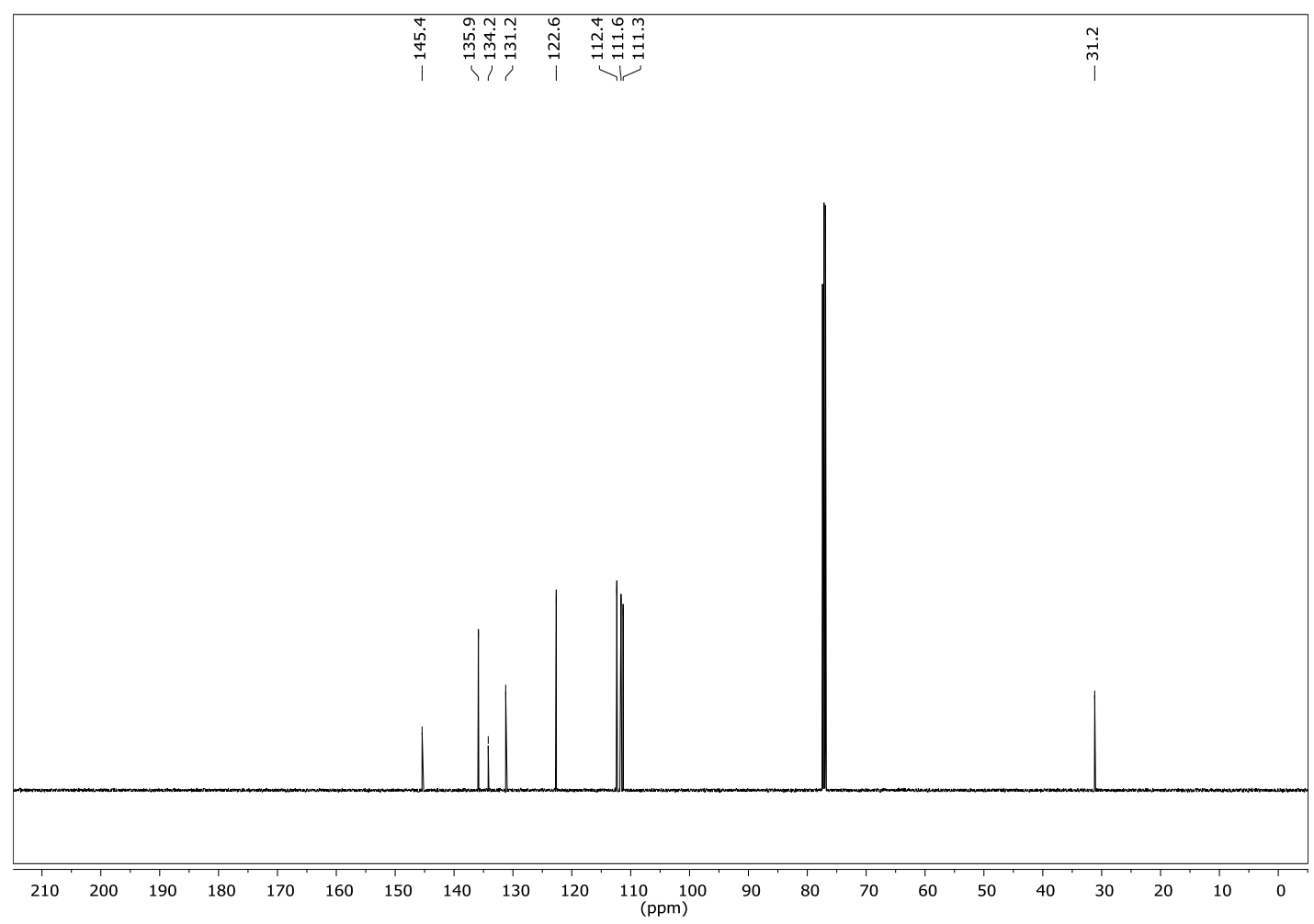

Figure S10. $125 \mathrm{MHz}{ }^{13} \mathrm{C}$ NMR spectrum of 3,7-divinyl- $N$-methylphenoxazine (4) in $\mathrm{CDCl}_{3}$. 


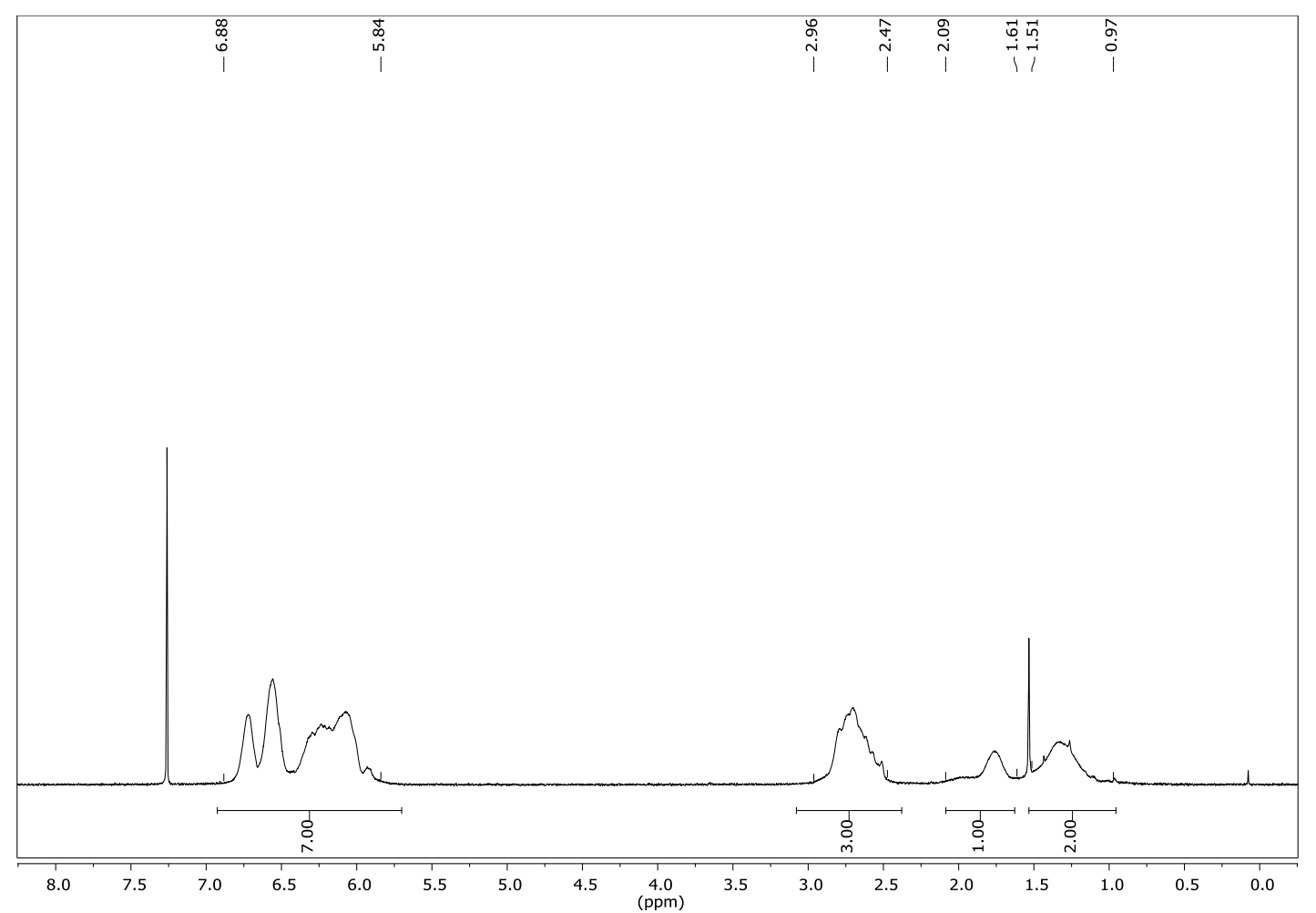

Figure S11. $300 \mathrm{MHz}^{1} \mathrm{H}$ NMR spectrum of poly(3-vinyl- $N$-methylphenoxazine) (PVMPO) in $\mathrm{CDCl}_{3}$.

\subsubsection{FTIR spectra of PVMPO and X-PVMPO}

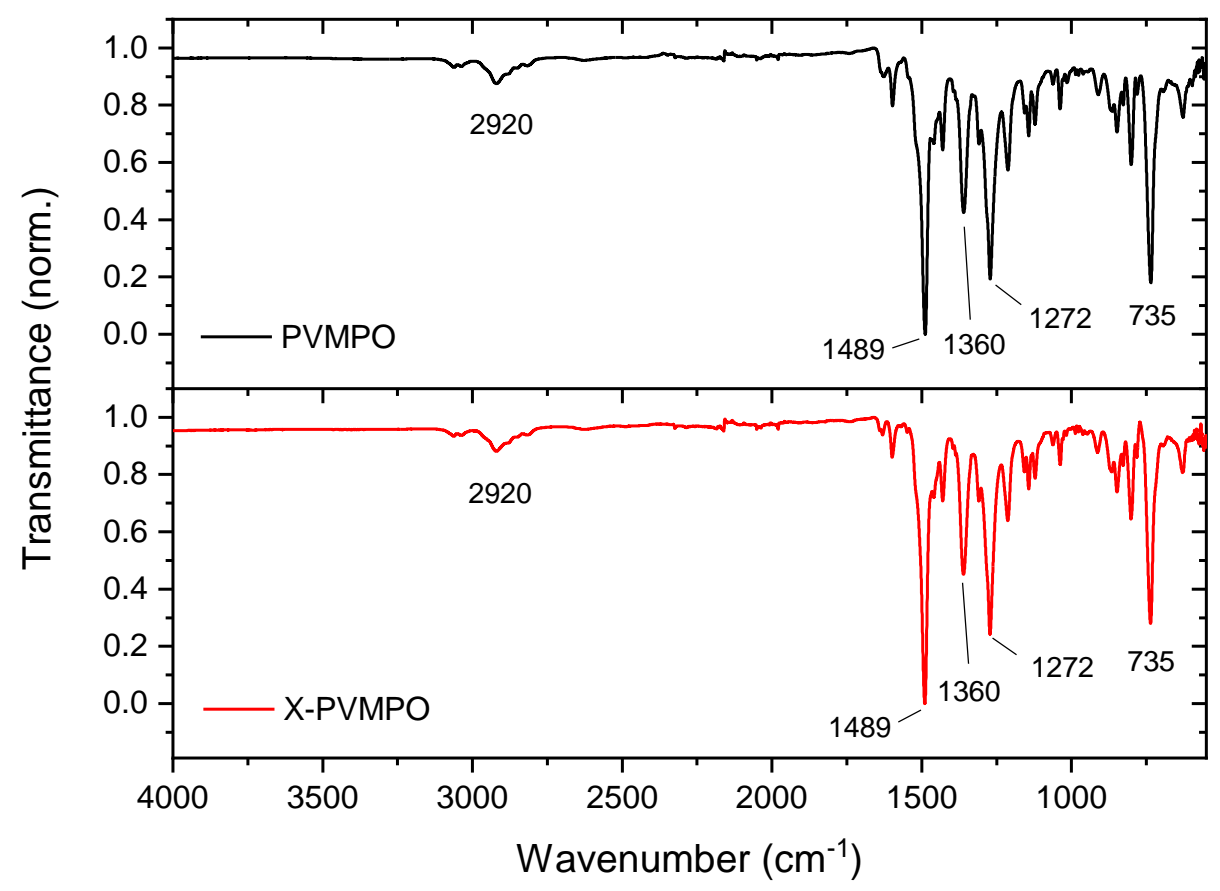

Figure S12. ATR FT-IR spectrum (diamond, 64 scans, res. $2 \mathrm{~cm}^{-1}$ ) of PVMPO (top, black curve) and X-PVMPO (bottom, red curve). 


\subsubsection{Thermal gravimetric analyses (TGA) of PVMPO and X-PVMPO}

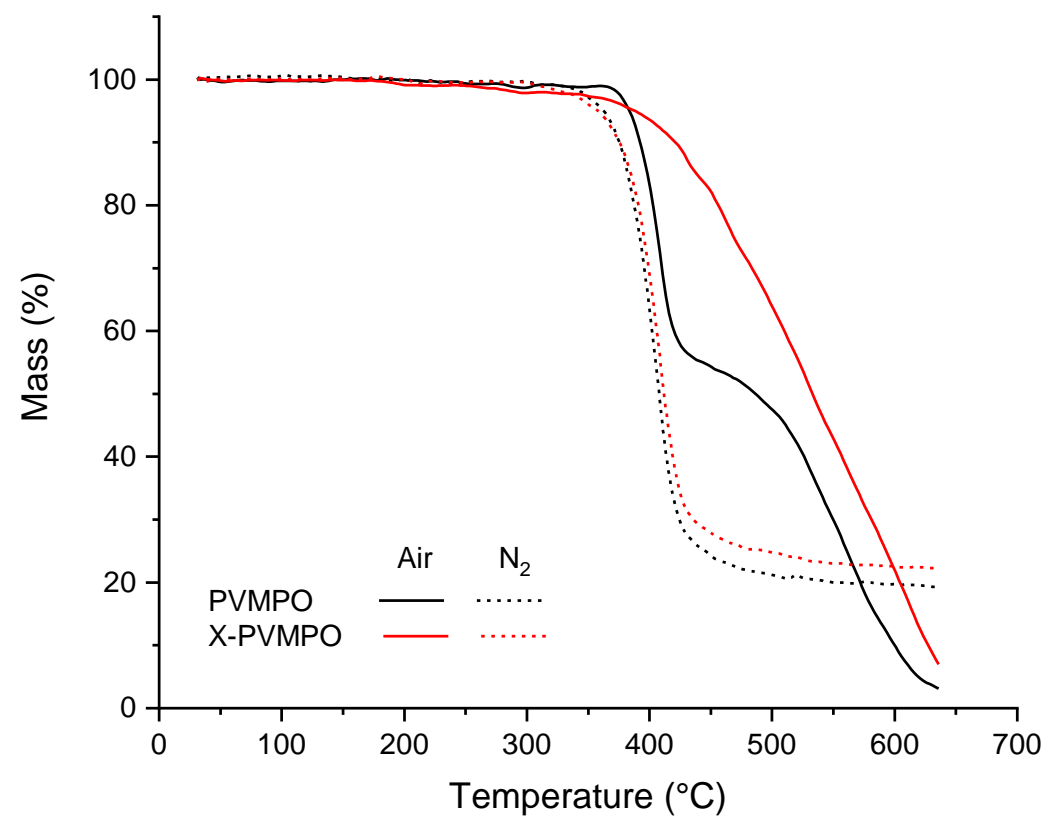

Figure S13. TGA curves of PVMPO and X-PVMPO in ambient air atmosphere and $\mathrm{N}_{2}$ at a heating rate of $10{ }^{\circ} \mathrm{C} \min ^{-1}$.

\subsubsection{Differential scanning calorimetry (DSC) measurements of PVMPO and X-PVMPO}

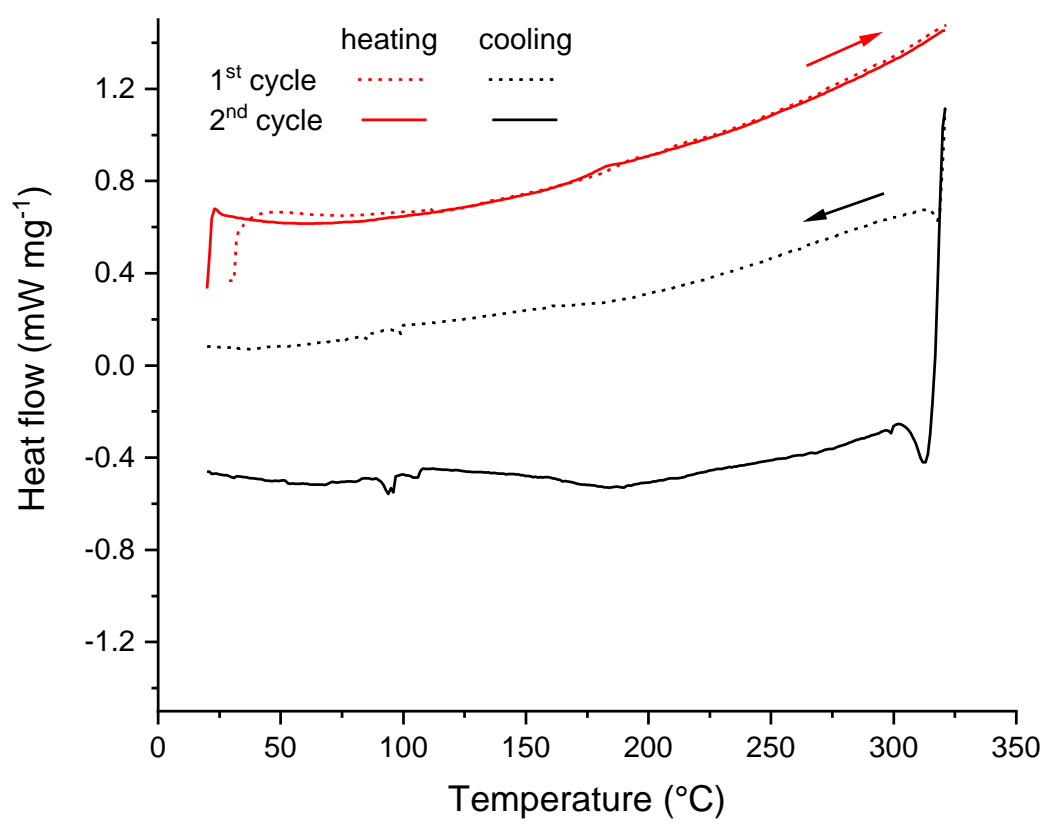

Figure S14. DSC measurement of PVMPO in ambient air atmosphere at a heating rate of $10^{\circ} \mathrm{C} \mathrm{min}^{-1}$. 


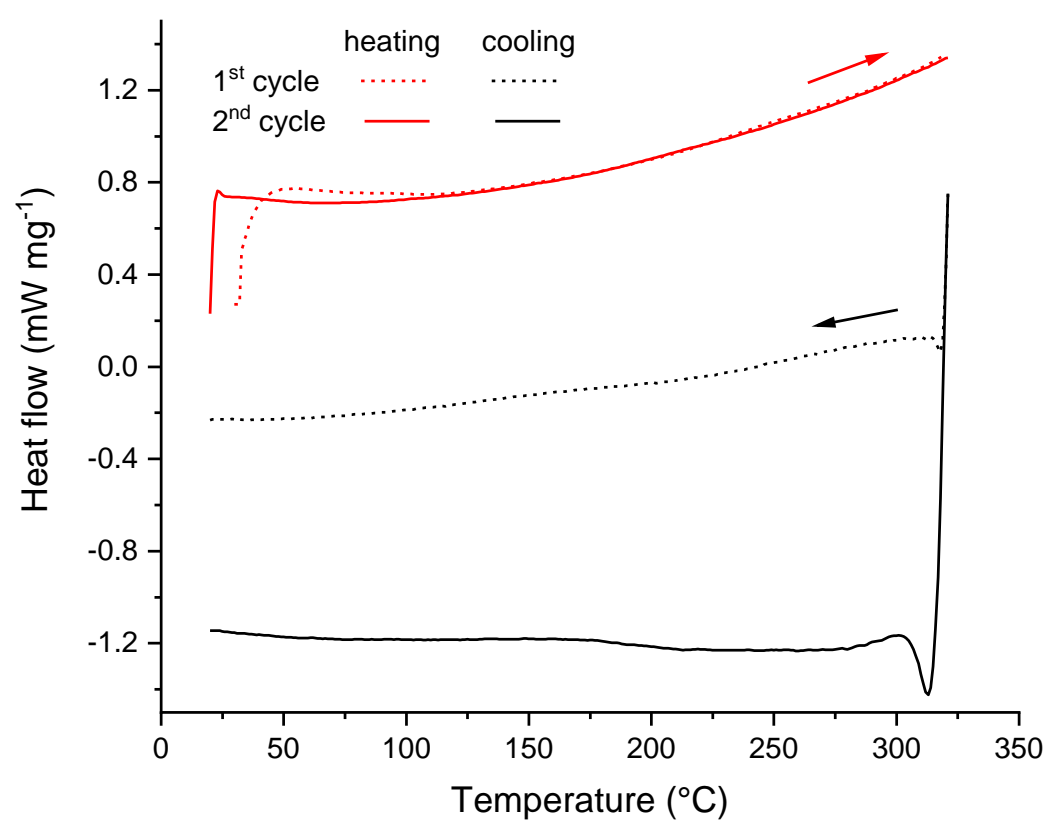

Figure S15. DSC measurement of X-PVMPO in ambient air atmosphere at a heating rate of $10{ }^{\circ} \mathrm{C} \mathrm{min}^{-1}$.

\section{Electrochemical investigations in solution}

a)

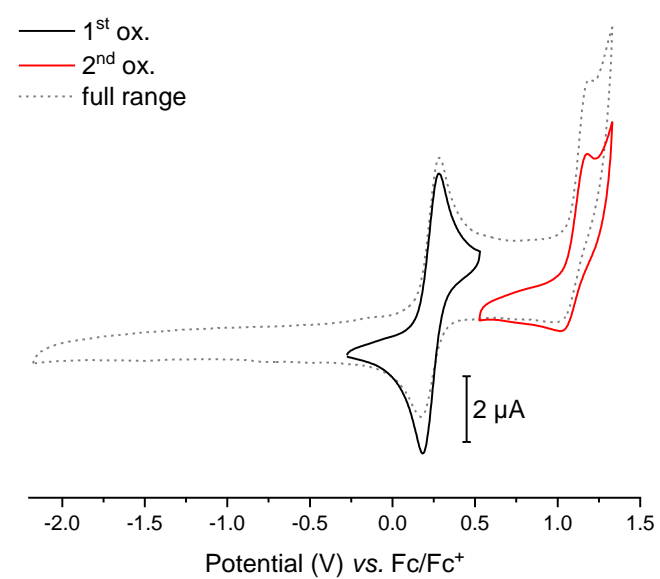

b)

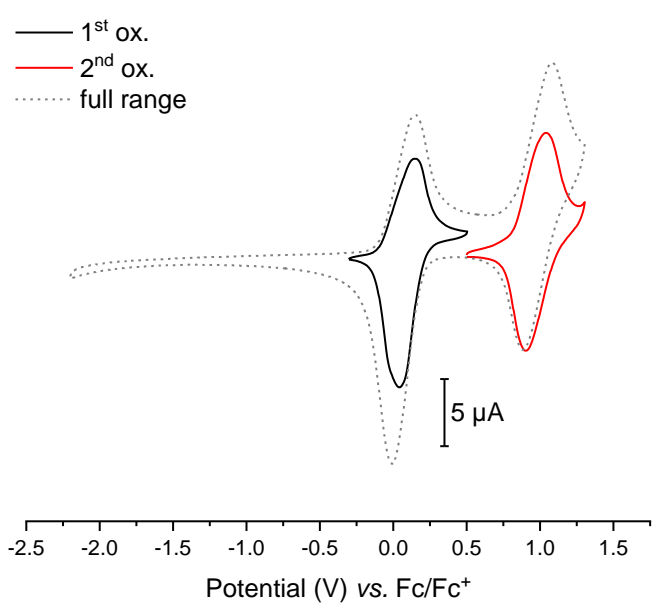

Figure S16. Cyclic voltammograms of a) MPO and b) PVMPO. Measurements performed in $\mathrm{CH}_{2} \mathrm{Cl}_{2}, 1 \mathrm{mM}$ (referred to the redox active group) with $0.1 \mathrm{M} n-\mathrm{Bu}_{4} \mathrm{NPF}_{6}$, at a scan rate of $100 \mathrm{mV} \mathrm{s}^{-1}$; WE: GC, CE: Pt, RE: $\mathrm{Ag} / \mathrm{AgNO}_{3}$ (referenced to internal standard $\mathrm{Fc} / \mathrm{Fc}^{+}$). 


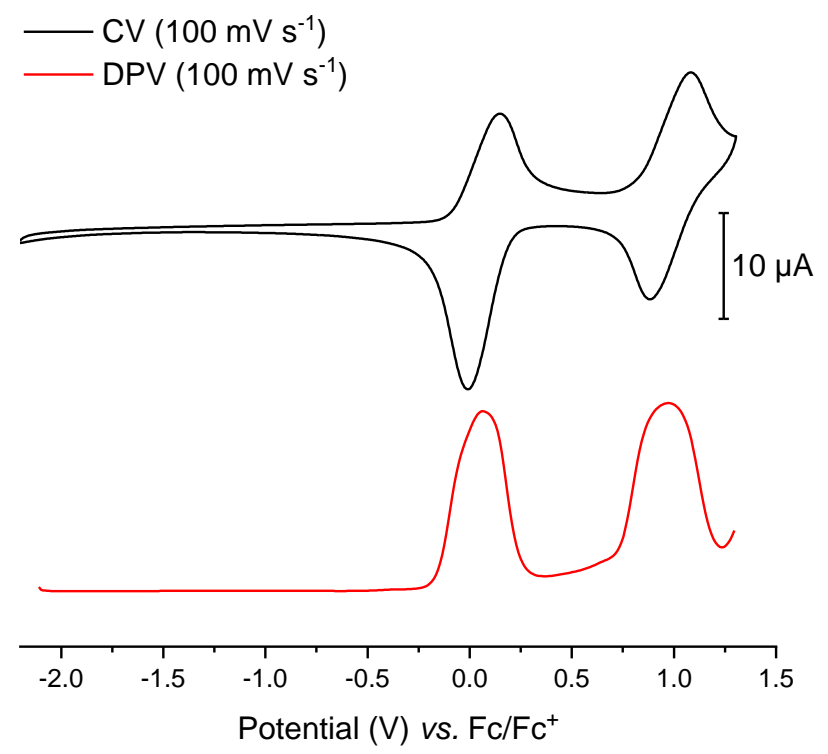

Figure S17. Cyclic voltammogram (CV, top, black curve) and differential pulse voltammogram (DPV, bottom, red curve) of PVMPO. Measurements performed in $\mathrm{CH}_{2} \mathrm{Cl}_{2}, 1 \mathrm{mM}$ (referred to the redox active group) with $0.1 \mathrm{M} n-\mathrm{Bu}_{4} \mathrm{NPF}_{6}$, at a scan rate of $100 \mathrm{mV} \mathrm{s}^{-1}$; WE: GC, CE: Pt, RE: $\mathrm{Ag} / \mathrm{AgNO}_{3}$ (referenced to internal standard $\left.\mathrm{Fc} / \mathrm{Fc}^{+}\right)$.

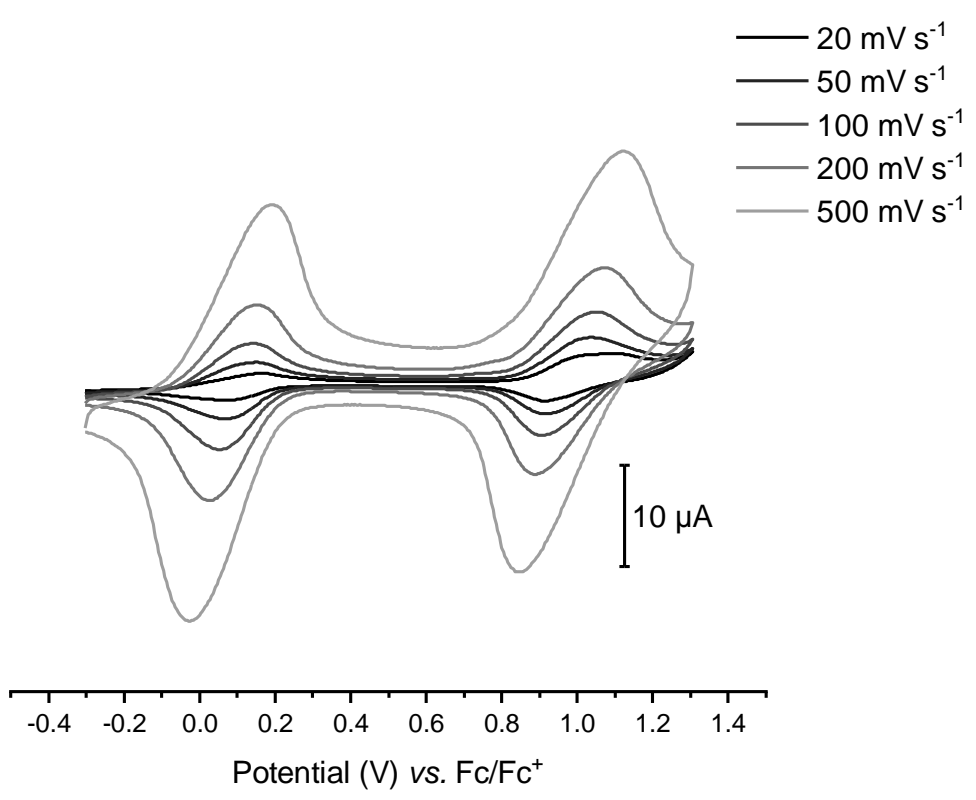

Figure S18. Cyclic voltammograms of PVMPO at different scan rates. Measurements performed in $\mathrm{CH}_{2} \mathrm{Cl}_{2}, 1 \mathrm{mM}$ (referred to the redox active group) with $0.1 \mathrm{M} n-\mathrm{Bu}_{4} \mathrm{NPF}_{6}$; WE: GC, $\mathrm{CE}$ : Pt, $\mathrm{RE}: \mathrm{Ag} / \mathrm{AgNO}_{3}$ (referenced to internal standard $\left.\mathrm{Fc} / \mathrm{Fc}^{+}\right)$. 
a)

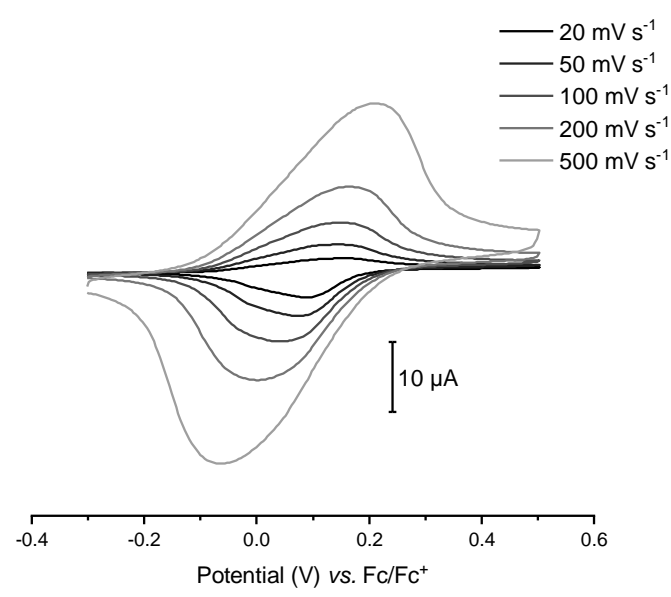

b)

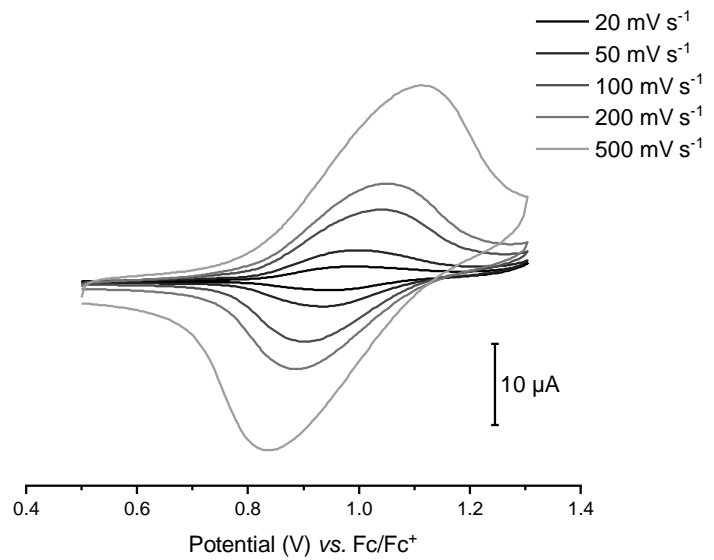

Figure S19. Cyclic voltammograms of PVMPO at different scan rates: a) $1^{\text {st }}$ redox reaction and b) $2^{\text {nd }}$ redox reaction. Measurements performed in $\mathrm{CH}_{2} \mathrm{Cl}_{2}, 1 \mathrm{mM}$ (referred to the redox active group) with $0.1 \mathrm{M} n-\mathrm{Bu}_{4} \mathrm{NPF}_{6}$; WE: GC, CE: Pt, $\mathrm{RE}: \mathrm{Ag} / \mathrm{AgNO}_{3}$ (referenced to internal standard $\mathrm{Fc} / \mathrm{Fc}^{+}$). 


\section{Investigations on (X-)PVMPO-based composite electrodes}

All composite electrodes were fabricated as described in the Experimental Procedures section of the manuscript.

\subsection{SEM/EDS measurements}
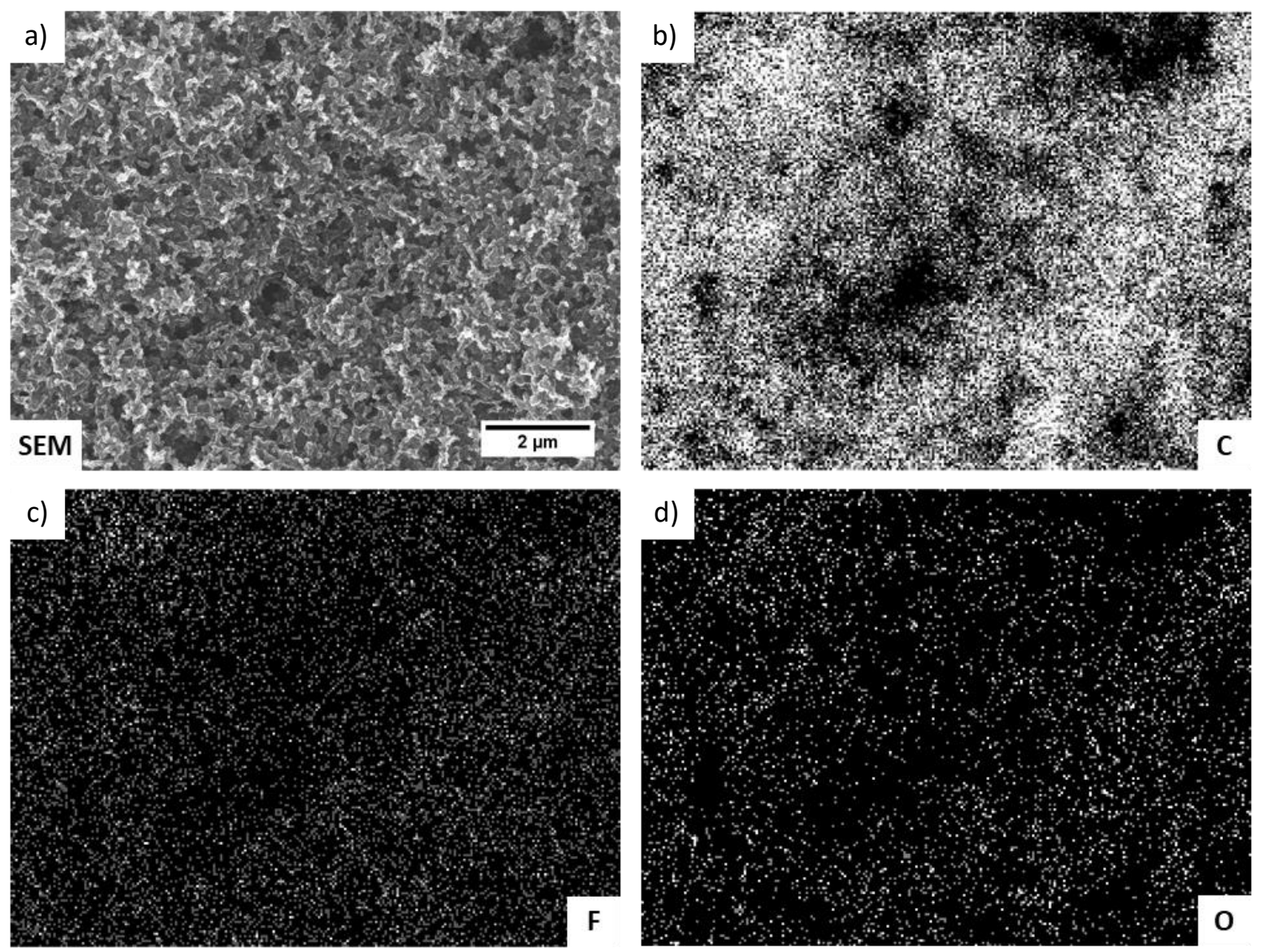

Figure S20. a) SEM micrograph (10,000x magnification) and EDS mappings of b) carbon, c) fluorine, and d) oxygen of a pristine PVMPO-based electrode. 

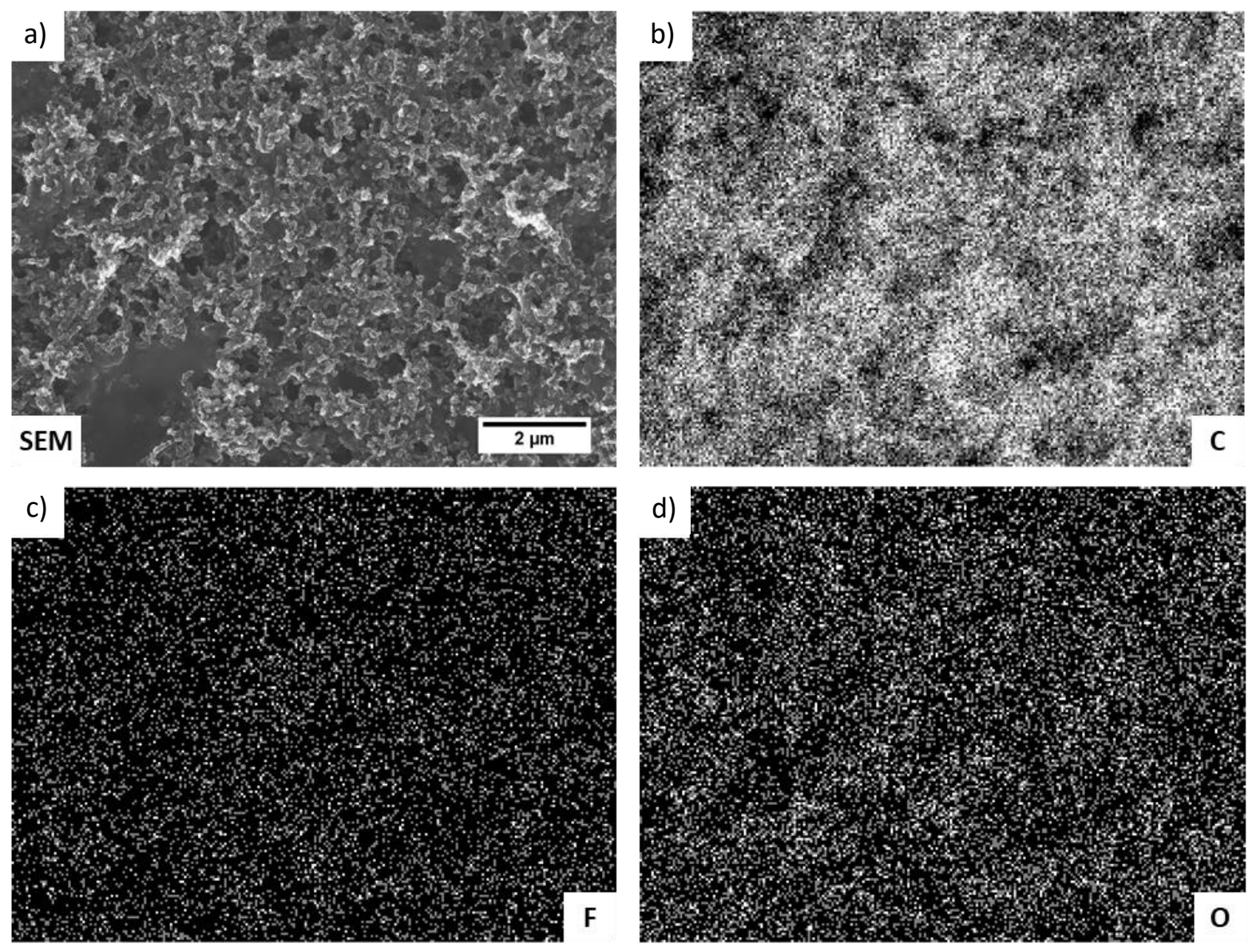

Figure S21. a) SEM micrograph (10,000x magnification) and EDS mappings of b) carbon, c) fluorine, and d) oxygen of a pristine X-PVMPO-based electrode. 
PVMPO
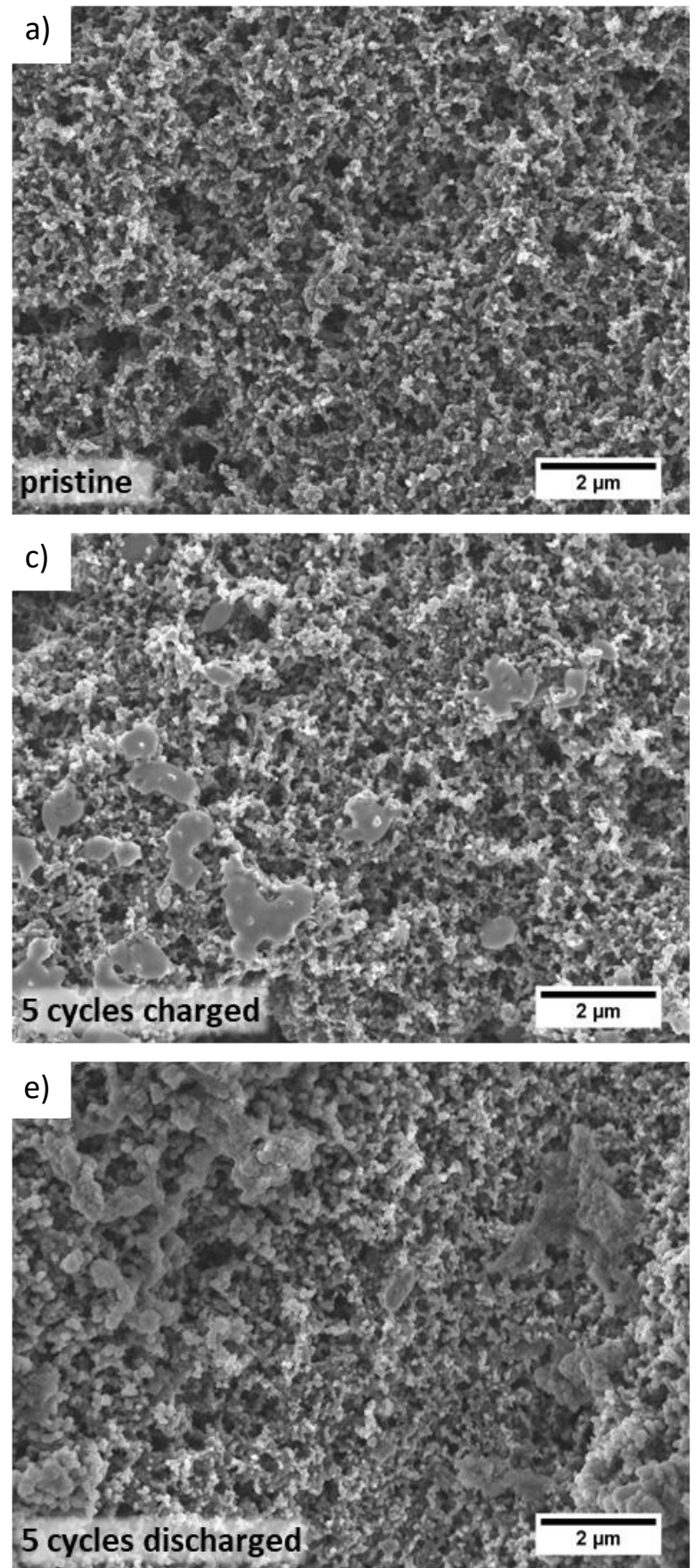

X-PVMPO
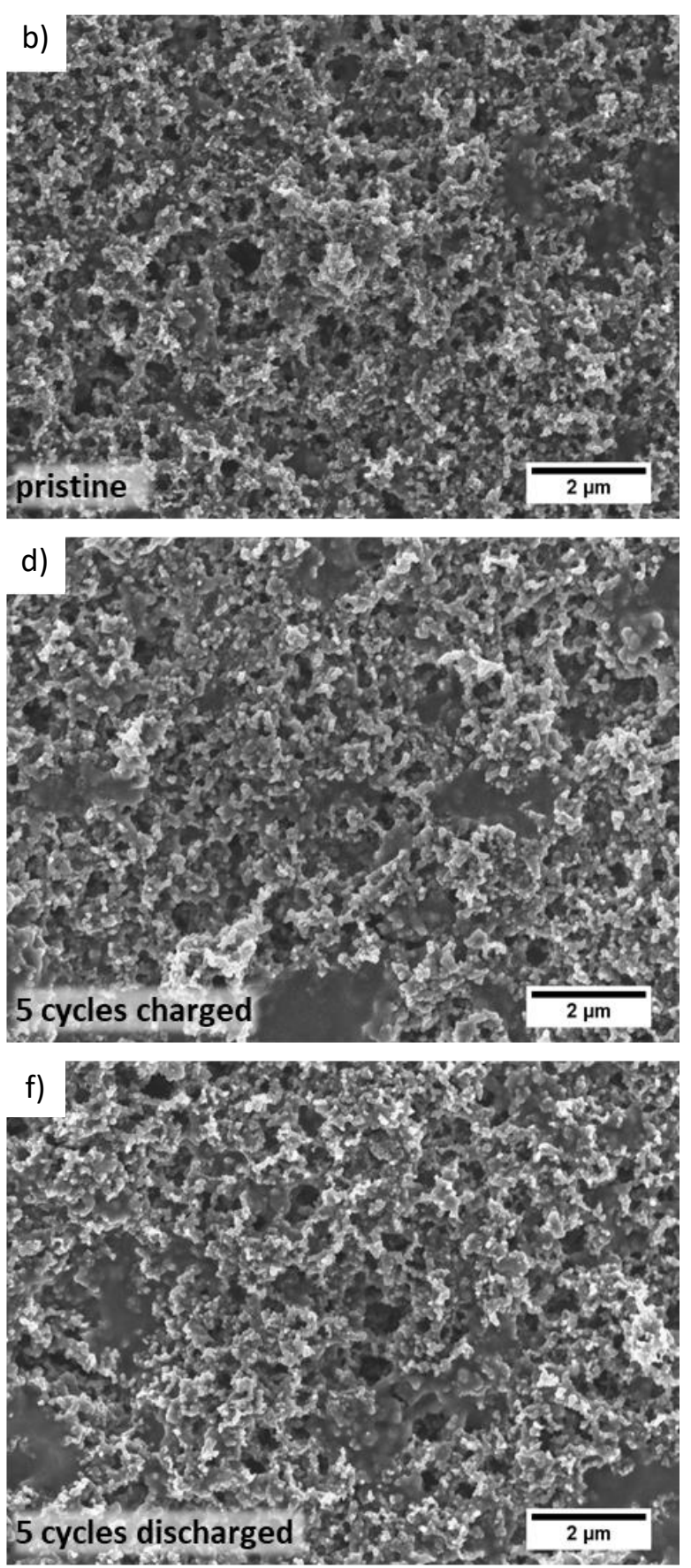

Figure S22. SEM micrographs (10,000x magnification) in cross-section view of PVMPO- $(a, c, e)$ and X-PVMPObased (b, d, f) electrodes: pristine (a, b), after 5 cycles in the charged (c, d), and in the discharged (e, f) state. 

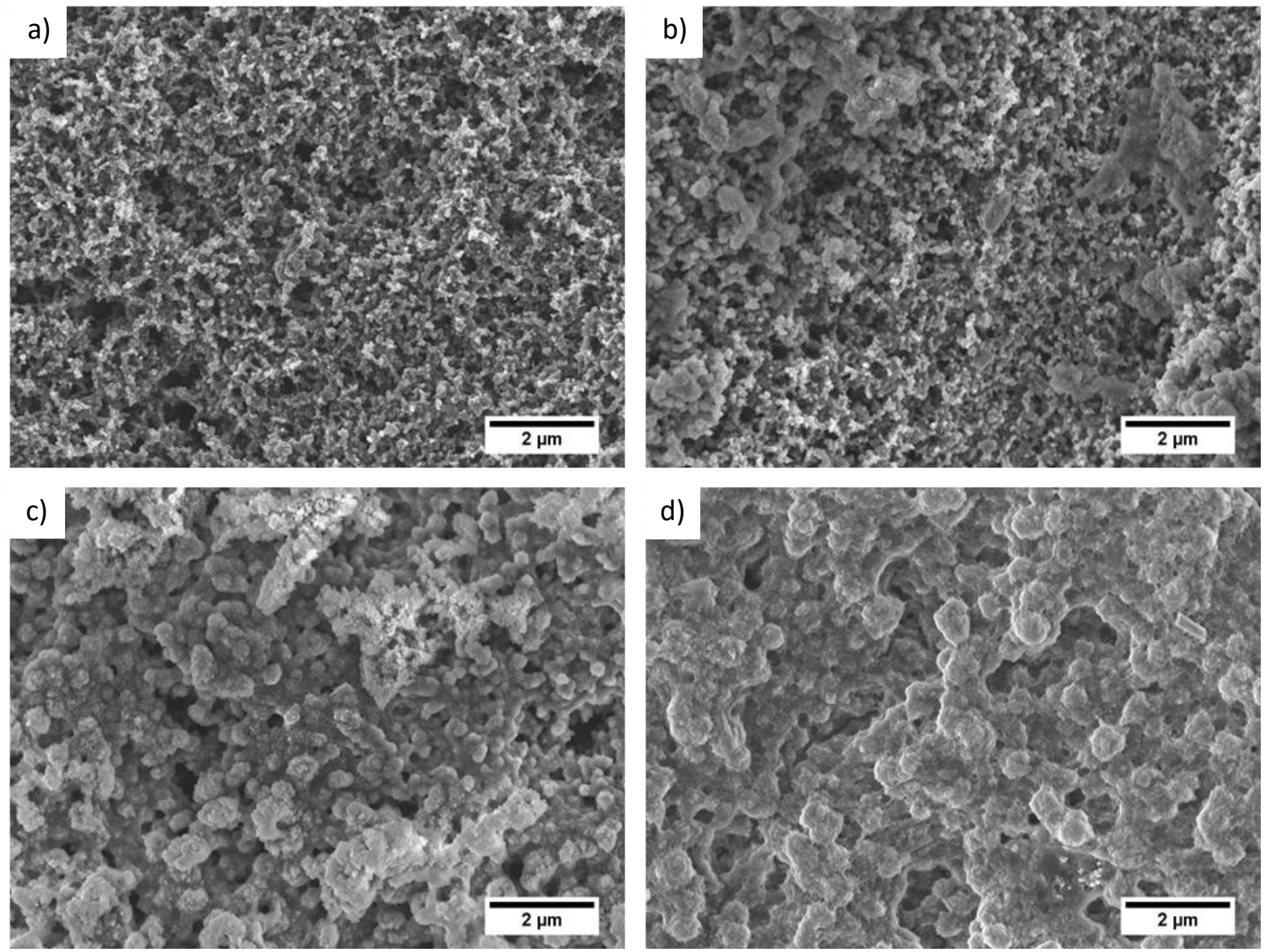

Figure S23. SEM micrographs (10,000x magnification) in cross-section view of PVMPO-based electrodes: a) pristine, b) after 5 cycles, c) after 50 cycles, and d) after 1000 cycles in discharged state.

\subsection{Cyclic voltammetry investigations}

a)

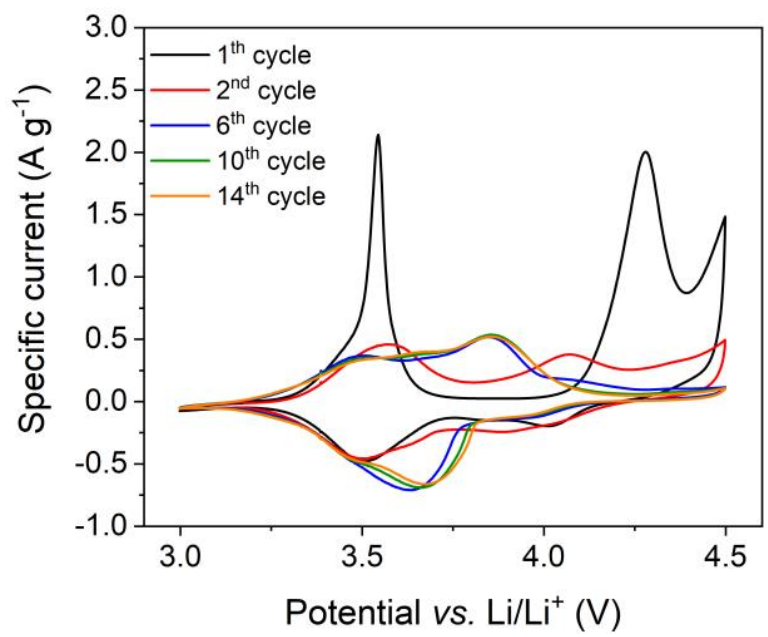

b)

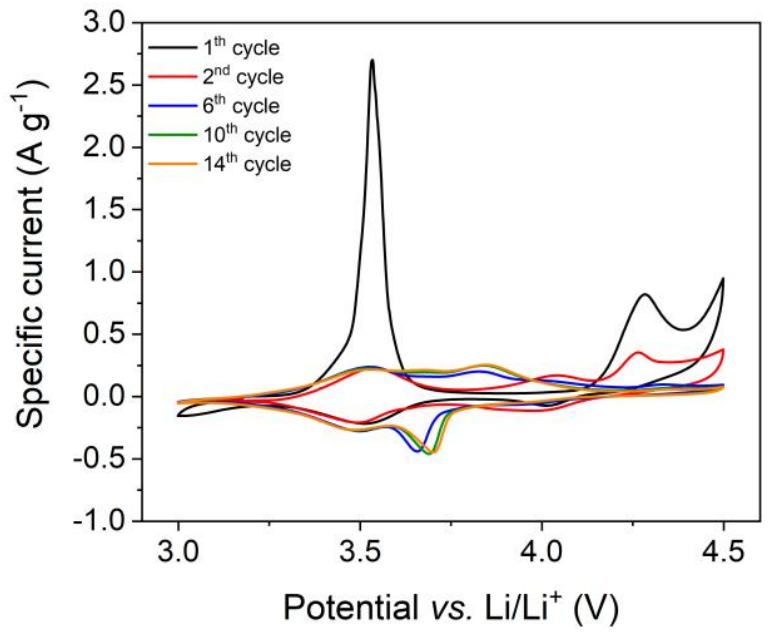

Figure S24. Cyclic voltammograms of a) a PVMPO and b) a X-PVMPO-based composite electrode $\left(0.16 \mathrm{mg} \mathrm{cm}^{-2}\right)$ between 3 and $4.5 \mathrm{~V} v$ s. $\mathrm{Li} / \mathrm{Li}^{+}$measured at a scan rate of $0.5 \mathrm{mV} \mathrm{s}^{-1}$. 


\section{Spectroscopic investigations}

\subsection{UV/Vis/NIR spectroscopy}

a)

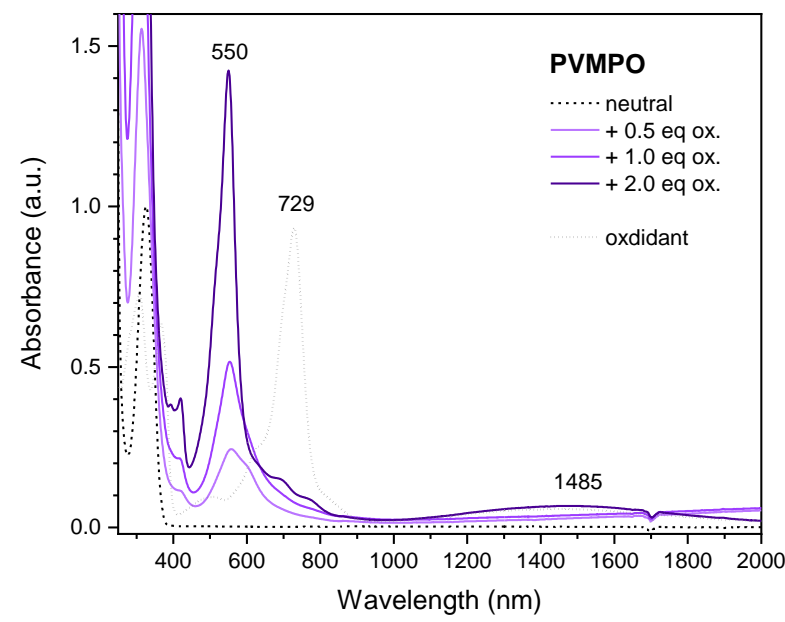

b)

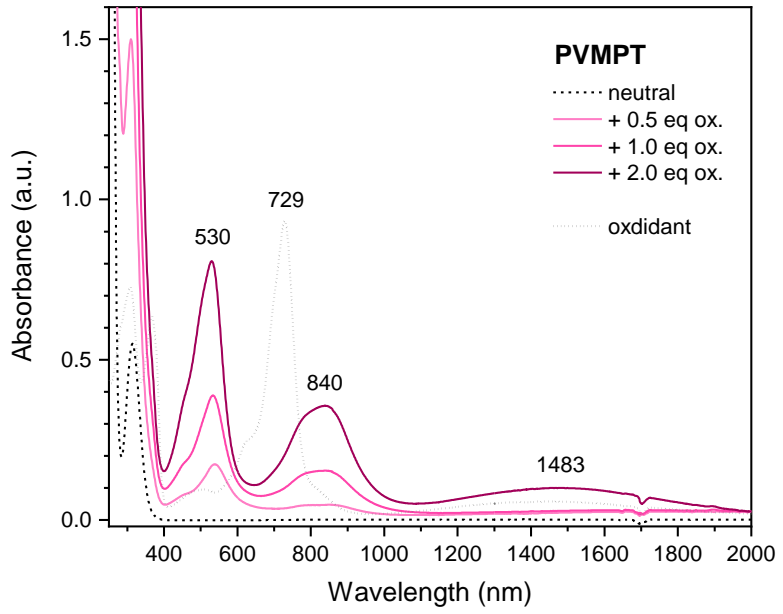

Figure S25. UV/Vis/NIR spectra of a) PVMPO and b) PVMPT in its neutral states and after the addition of 0.5, 1.0 and 2.0 equivalents of the oxidant tris-(4-bromophenyl)-ammoniumyl hexachloroantimonate in $\mathrm{CH}_{2} \mathrm{Cl}_{2}$ (0.1 $\mathrm{mm}$ referred to the redox active group).

\subsection{Spectroelectrochemical measurements}

a)

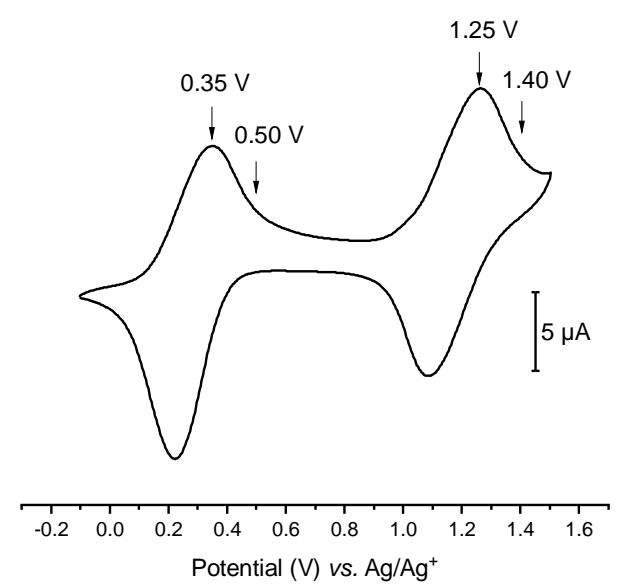

b)

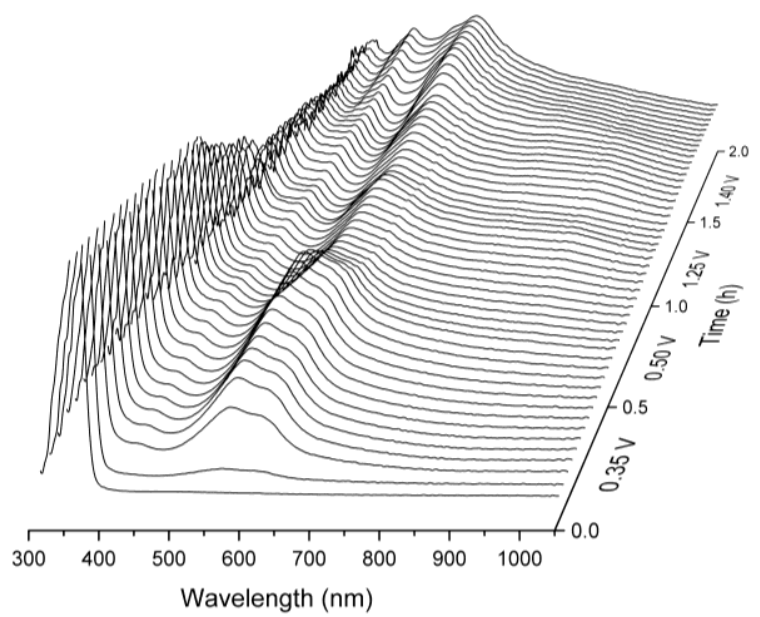

Figure S26. a) Cyclic voltammogram of PVMPO in $\mathrm{CH}_{2} \mathrm{Cl}_{2}, 1 \mathrm{mM}$ (referred to the redox active group) with $0.1 \mathrm{M}$ $n$-Bu4 $\mathrm{NPF}_{6}$ at a scan rate of $100 \mathrm{mV} \mathrm{s}{ }^{-1}$ (WE: GC, CE: Pt, RE: $\mathrm{Ag} / \mathrm{AgNO}_{3}$ ), and b) spectroelectrochemical measurements of PVMPO: UV/Vis spectra recorded during chronoamperometric experiment in $\mathrm{CH}_{2} \mathrm{Cl}_{2}, 10 \mathrm{mM}$ (referred to the redox active group) with $0.2 \mathrm{M} n-\mathrm{Bu}_{4} \mathrm{NPF}_{6}$, applied for various potentials vs. $\mathrm{Ag} / \mathrm{Ag}^{+}$(WE: Pt net, $\left.\mathrm{CE}: \mathrm{Pt}, \mathrm{RE}: \mathrm{Ag} / \mathrm{AgNO}_{3}\right)$. 
a)

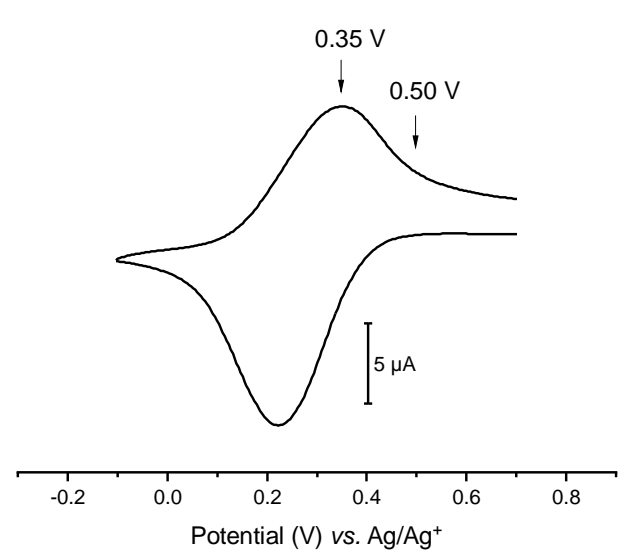

b)

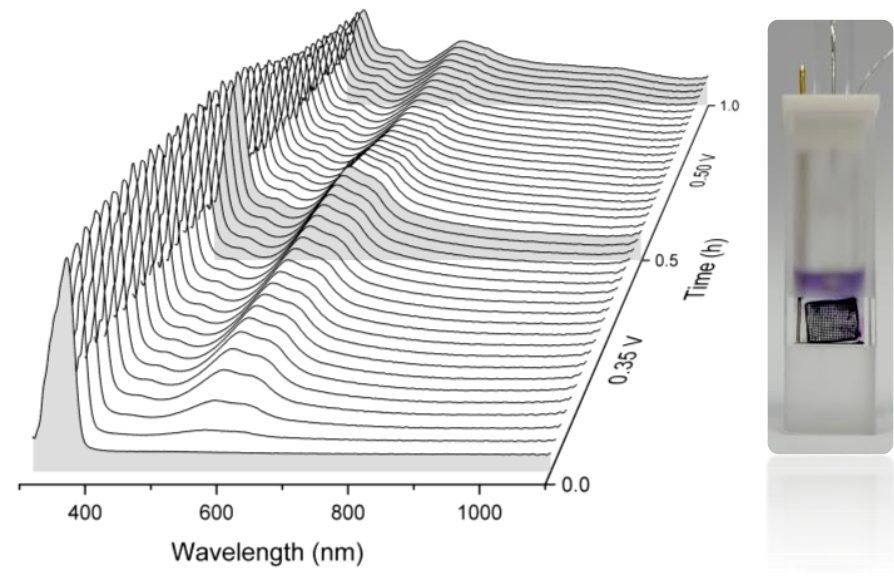

Figure S27. a) Cyclic voltammogram of PVMPO in $\mathrm{CH}_{2} \mathrm{Cl}_{2}, 1 \mathrm{mM}$ (referred to the redox active group) with $0.1 \mathrm{M}$ $n$-Bu4NPF 6 at a scan rate of $100 \mathrm{mV} \mathrm{s}^{-1}$ (WE: GC, CE: Pt, RE: Ag/AgNO ${ }_{3}$ ), and b) spectroelectrochemical measurements of PVMPO: UV/Vis spectra recorded during chronoamperometric experiment in $\mathrm{CH}_{2} \mathrm{Cl}_{2}, 10 \mathrm{mM}$ (referred to the redox active group) with $0.2 \mathrm{M} n-\mathrm{Bu}_{4} \mathrm{NPF}_{6}$, applied for various potentials versus $\mathrm{Ag} / \mathrm{Ag}^{+}$(WE: $\mathrm{Pt}$ net, $\left.\mathrm{CE}: \mathrm{Pt}, \mathrm{RE}: \mathrm{Ag} / \mathrm{AgNO}_{3}\right)$.

a)

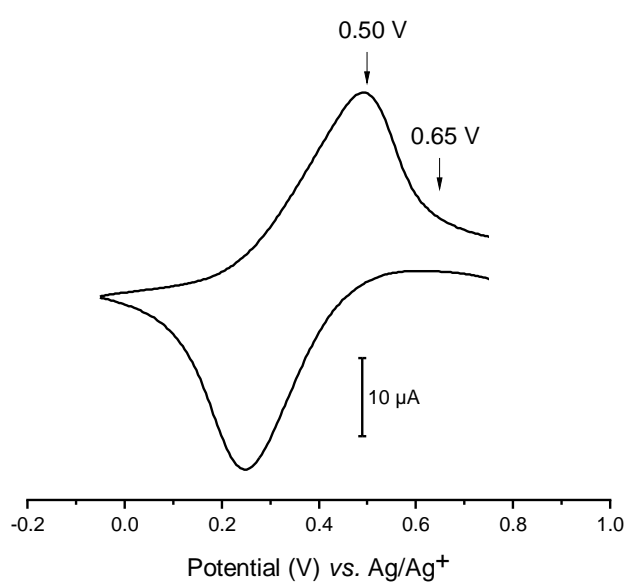

b)

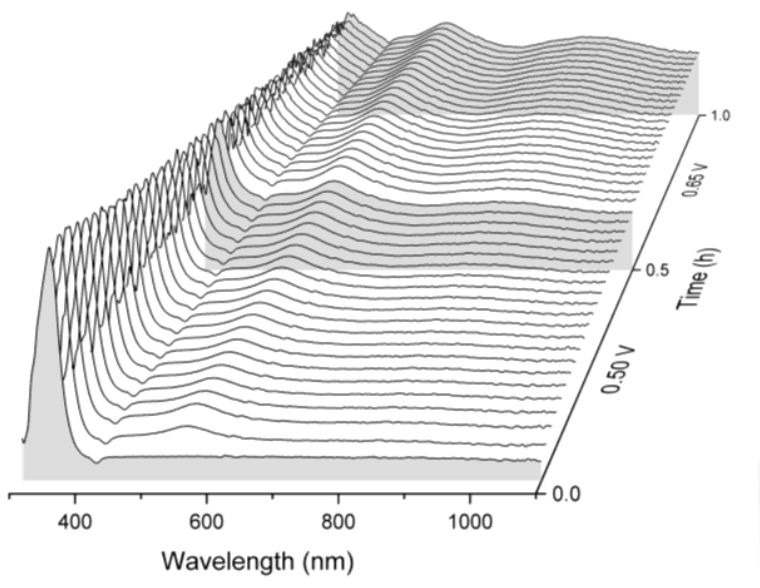

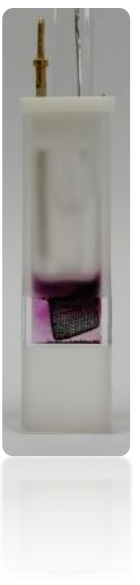

Figure S28. a) Cyclic voltammogram of PVMPT in $\mathrm{CH}_{2} \mathrm{Cl}_{2}, 1 \mathrm{mM}$ (referred to the redox active group) with $0.1 \mathrm{M}$ $n$-Bu4NPF 6 at a scan rate of $100 \mathrm{mV} \mathrm{s}^{-1}$ (WE: GC, CE: Pt, RE: Ag/AgNO ${ }_{3}$ ), and b) spectroelectrochemical measurements of PVMPT: UV/Vis spectra recorded during chronoamperometric experiment in $\mathrm{CH}_{2} \mathrm{Cl}_{2}, 10 \mathrm{mM}$ (referred to the redox active group) with $0.2 \mathrm{M} n-\mathrm{Bu}_{4} \mathrm{NPF}_{6}$, applied for various potentials versus $\mathrm{Ag} / \mathrm{Ag}^{+}$(WE: $\mathrm{Pt}$ net, $\left.\mathrm{CE}: \mathrm{Pt}, \mathrm{RE}: \mathrm{Ag} / \mathrm{AgNO}_{3}\right)$. 
a)

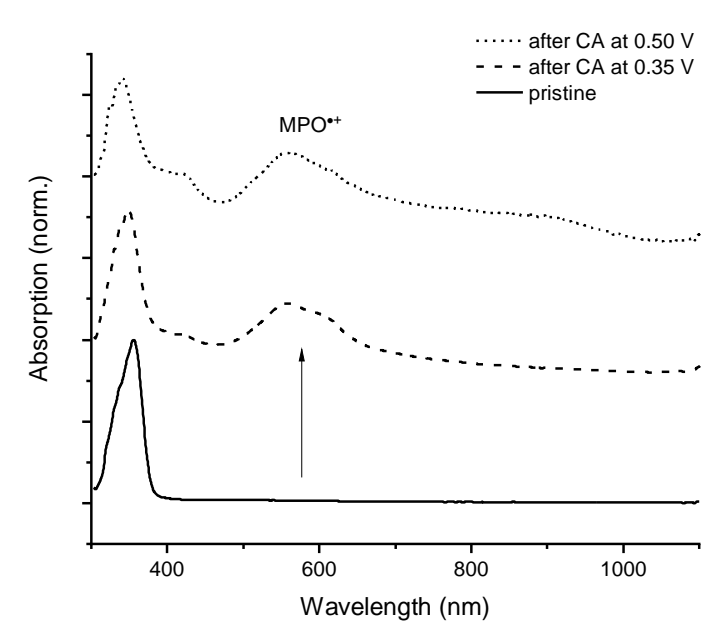

b)

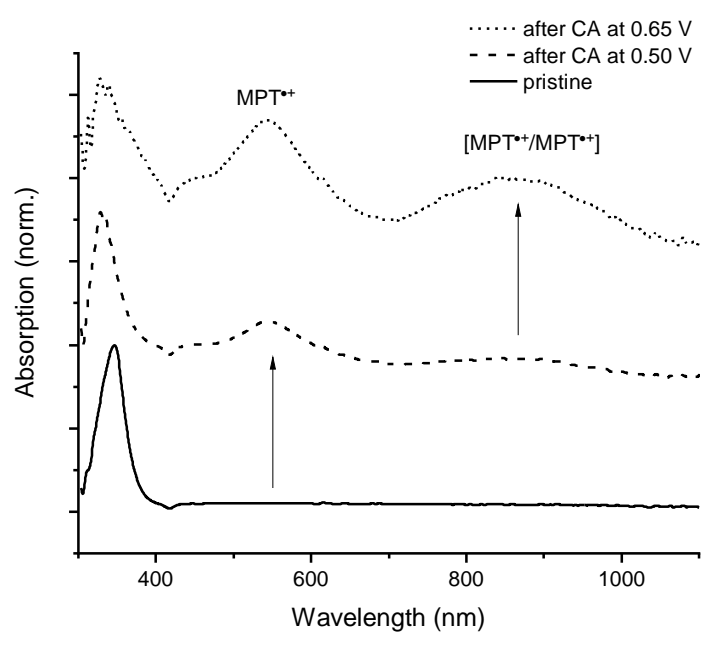

Figure S29. UV/Vis spectra of a) PVMPO and b) PVMPT recorded during chronoamperometric experiments in

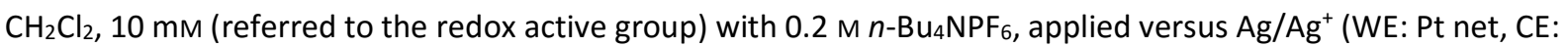
$\mathrm{Pt}, \mathrm{RE}: \mathrm{Ag} / \mathrm{AgNO}_{3}$ ). The spectra shown were recorded before applying the chronoamperometric experiment (pristine, solid curve) and after the indicated potential steps (dashed curves). Each step was held for $0.5 \mathrm{~h}$.

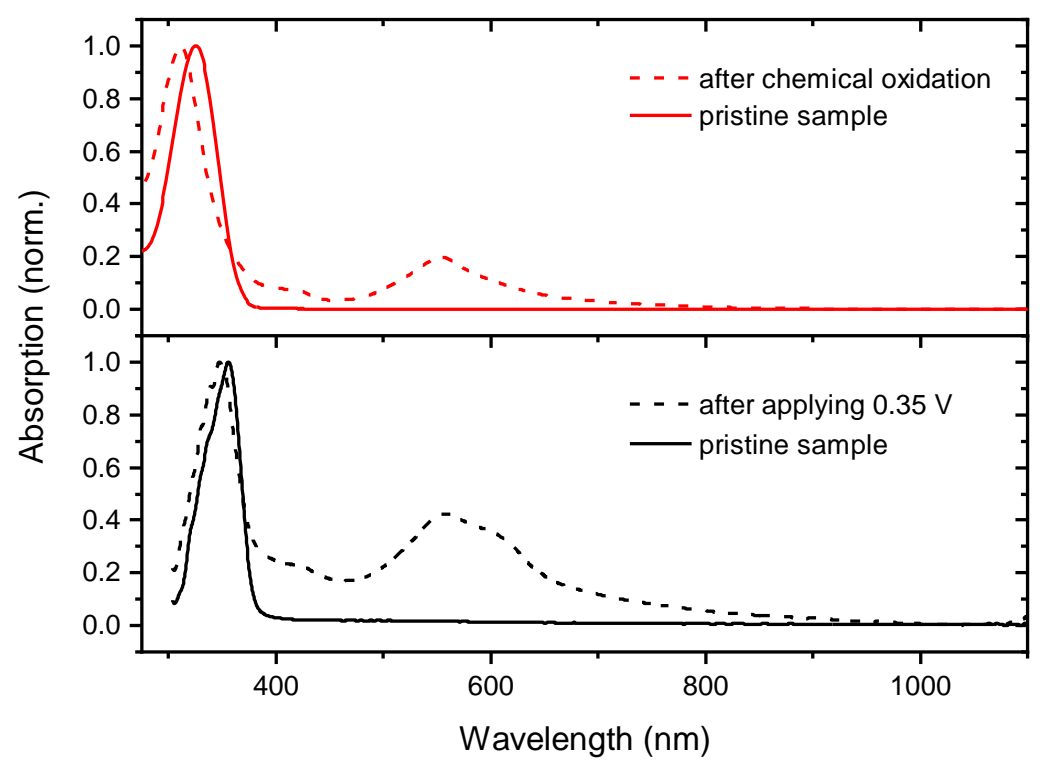

Figure S30. Comparison of UV/Vis spectra of PVMPO in its neutral state (pristine, solid curves) and oxidized state (dashed curves) after chemical oxidation (red curves, top) and after chronoamperometric experiment at a potential of $0.35 \mathrm{~V}$ versus $\mathrm{Ag} / \mathrm{Ag}^{+}$(black curves, bottom). Chemical oxidation was performed by the addition of 1.0 equivalent of the oxidant tris-(4-bromophenyl)-ammoniumyl hexachloroantimonate in $\mathrm{CH}_{2} \mathrm{Cl}_{2}, 0.1 \mathrm{mM}$ (referred to the redox active group). The chronoamperometric experiment was performed in $\mathrm{CH}_{2} \mathrm{Cl}_{2}, 10 \mathrm{mM}$ (referred to the redox active group) with $0.2 \mathrm{M} n-\mathrm{Bu}_{4} \mathrm{NPF}_{6}$, the indicated potential was applied for a duration of $0.5 \mathrm{~h}$ (WE: Pt net, $\mathrm{CE}: \mathrm{Pt}, \mathrm{RE}: \mathrm{Ag} / \mathrm{AgNO}_{3}$ ). 


\section{DFT calculations on model compound 6}

DFT calculations were performed with the TURBOMOLE v7.3 program package. ${ }^{1}$ The resolution-ofidentity ${ }^{2}$ (RI, RIJDX for SP) approximation for the Coulomb integrals was used in all DFT calculations employing matching auxiliary basis set def2-XVP/J. ${ }^{3}$ Further, the D3 dispersion correction scheme ${ }^{4,5}$ with the Becke-Johnson damping function was applied. ${ }^{6,7}$ The geometries of all molecules were first optimized without symmetry restrictions (in oxidation state $\boldsymbol{A}$ ) with the PBEh- $3 c^{8}$ composite scheme followed by harmonic vibrational frequency analysis to confirm minima as stationary points. This geometry was used as an input for further geometry optimizations in oxidations states $\boldsymbol{A}$ to $\boldsymbol{C}$. They were each optimized on the B3LYP9,10-D3/def2-TZVP level of theory. Structures were optimized with unrestricted orbitals for the oxidation state $\boldsymbol{B}$ and with restricted orbitals for the oxidation states $\boldsymbol{A}$ and $\boldsymbol{C}$. For vibrational contributions and the free energy calculations the rigid-rotor-harmonicoscillator approximation was made.

6 was chosen as model compound for PVMPO, containing two subunits (see Figure 5C, Manuscript). It can exist in the three oxidation states $\boldsymbol{A}$ (neutral), the $\boldsymbol{B}$ (half-oxidized), and $\boldsymbol{C}$ (fully oxidized).
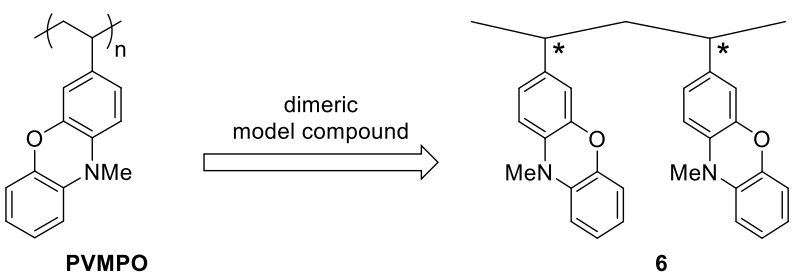

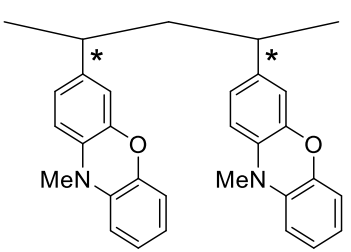

A

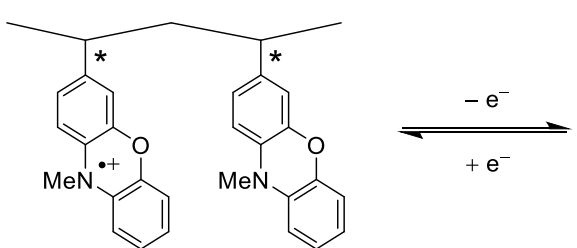

B

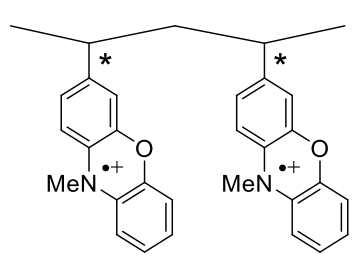

c

There are four constitutional and confirmational isomers of model compound $\mathbf{6 :} \mathbf{6 a - 6 d}$. Calculations were performed for all four isomers.

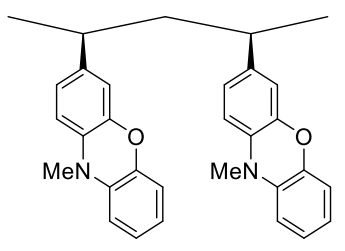

$6 a$

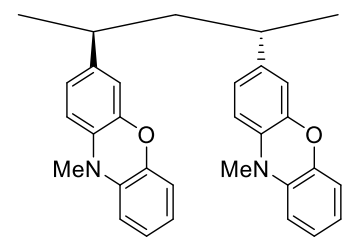

$6 b$

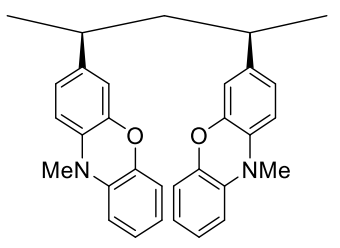

$6 c$

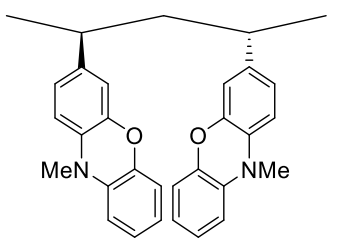

6d 
A

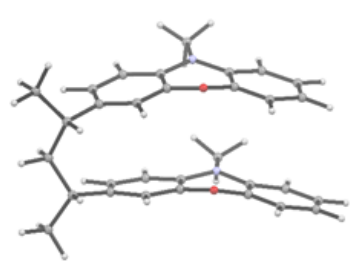

B

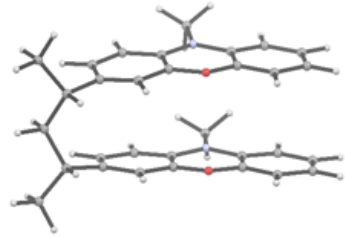

c

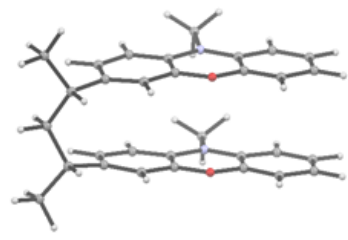

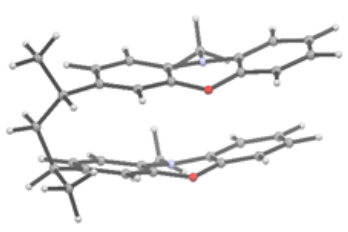
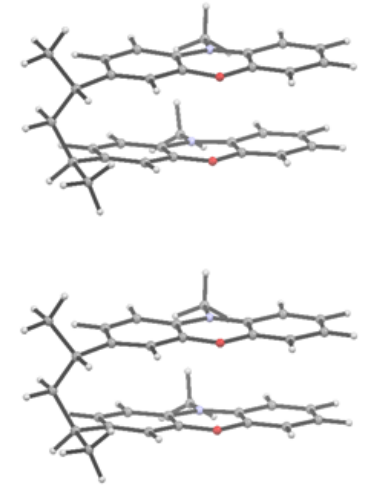
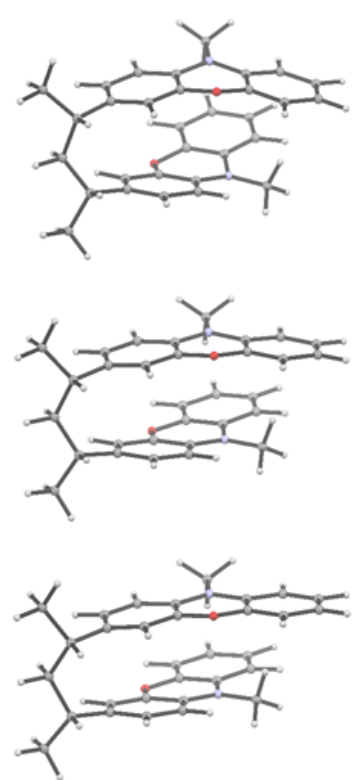
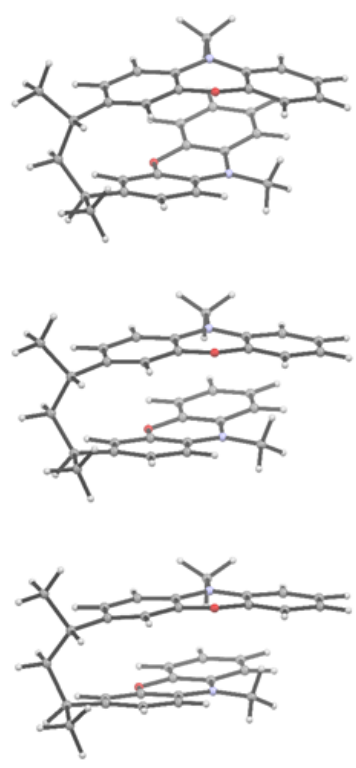

Figure S31. Optimized structures of isomers 6a-d in oxidation state $\boldsymbol{A}, \boldsymbol{B}$, and $\boldsymbol{C}$ (B3LYP-D3/def2-TZVP+COSMO).

Table S1. Calculated geometrical parameters (B3LYP-D3/def2-TZVP+COSMO) for model compounds 6a-d, $\mathrm{N}$-methylphenoxazine (MPO), and $\mathrm{N}$-methylphenothiazine (MPT).

\begin{tabular}{|c|c|c|c|}
\hline & & $\mathrm{d}_{\text {NO-Centroid }}(\AA)$ & $\theta\left({ }^{\circ}\right)^{[a]}$ \\
\hline \multirow{3}{*}{$6 a$} & $A$ & 3.745 & 158.8 \\
\hline & $B$ & 3.468 & 174.1 \\
\hline & $C$ & 3.330 & 177.8 \\
\hline \multirow{3}{*}{$6 b$} & $A$ & 3.830 & 159.9 \\
\hline & $B$ & 3.466 & 175.0 \\
\hline & $C$ & 3.323 & 178.0 \\
\hline \multirow{3}{*}{$6 c$} & $A$ & 4.142 & 161.5 \\
\hline & $B$ & 3.981 & 170.4 \\
\hline & $C$ & 4.141 & 173.8 \\
\hline \multirow{3}{*}{$6 d$} & $A$ & 4.160 & 161.6 \\
\hline & $B$ & 4.010 & 170.2 \\
\hline & $C$ & 4.206 & 173.5 \\
\hline \multirow{3}{*}{ MPO } & $A$ & - & 155.5 \\
\hline & $B$ & - & 175.1 \\
\hline & $C$ & - & 178.3 \\
\hline \multirow{3}{*}{ MPT } & $A$ & - & 139.2 \\
\hline & $B$ & - & 165.4 \\
\hline & $C$ & - & 174.0 \\
\hline
\end{tabular}

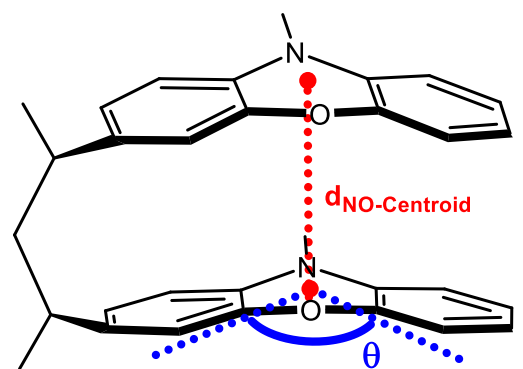

[a] For 6a-d average of both MPO units. 
Table S2. Energies obtained for all structures after geometry optimization and calculation of the harmonic vibrational frequencies (PBEh3c/def2-mSVP) and electronic energies after the optimization on the B3LYPD3/def2-TZVP level of theory.

\begin{tabular}{|c|c|c|c|c|c|}
\hline & \multicolumn{3}{|c|}{$A$} & \multirow{2}{*}{$\frac{\boldsymbol{B}}{E\left(\mathrm{E}_{\mathrm{h}}\right)^{[\mathrm{b}]}}$} & \multirow{2}{*}{$\frac{\boldsymbol{C}}{E\left(\mathrm{E}_{\mathrm{h}}\right)^{[\mathrm{b}]}}$} \\
\hline & $E\left(E_{h}\right)^{[a]}$ & $\mathrm{ZPE}\left(\mathrm{E}_{\mathrm{h}}\right)^{[\mathrm{a}]}$ & $E\left(E_{h}\right)^{[b]}$ & & \\
\hline $6 a$ & -1456.1659854 & 0.5573309 & -1459.1324673 & -1458.9686602 & -1458.7813096 \\
\hline $6 b$ & -1456.1649007 & 0.5575544 & -1459.1310541 & -1458.9671235 & -1458.7800112 \\
\hline $6 c$ & -1456.1687895 & 0.5572427 & -1459.1353189 & -1458.9671734 & -1458.7734675 \\
\hline $6 d$ & -1456.1663279 & 0.5576664 & -1459.1326187 & -1458.9648105 & -1458.7717174 \\
\hline MPO & -630.5980451 & 0.2156941 & -631.896336 & -631.720851 & -631.5005811 \\
\hline MPT & -953.2981099 & 0.2132727 & -954.845195 & -954.665759 & -954.4501925 \\
\hline
\end{tabular}

[a] PBEh3c/def2-mSVP.

[b] B3LYP-D3/def2-TZVP.
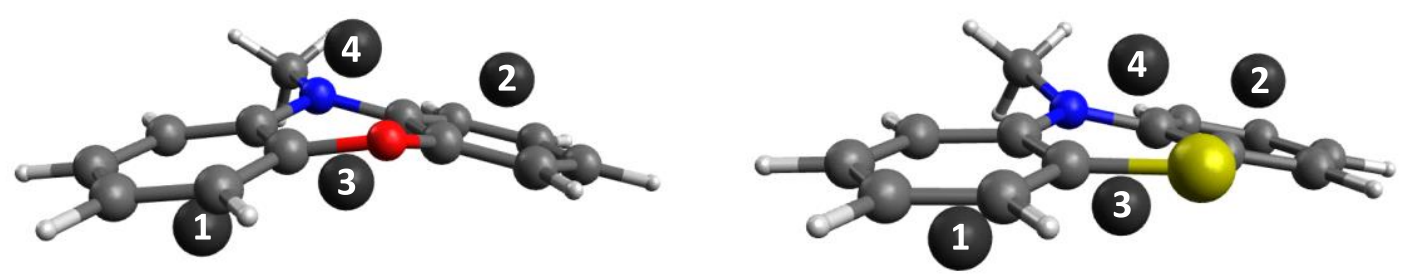

Figure S32. Representative positions of the dummy atoms for the $\mathrm{NICS}_{1}$ (iso) calculations (left: MPO, right:

MPT). Each dummy atom is positioned $1 \AA$ above the respective ring plane. Dummy atoms 1 and 3 are on the convex side, 2 and 4 are on the concave side of the molecule.

Nucleus independent chemical shift (NICS) ${ }^{11,12}$ values were calculated using the Gaussian 16 program package ${ }^{13}$ applying the standard Gauge-Including Atomic Orbitals $(G I A O)$ method on the B3LYP/6-31G* level of theory. Negative NICS values indicate a diatropic ring current (associated with an aromatic character), while positive NICS values indicate a paratropic ring current (associated with an antiaromatic character). In the neutral state for both (MPO and MPT) the NICS values of the peripheric benzene rings indicate high aromaticity and the NICS value of the heteroaromatic rings indicate a slightly antiaromatic character (except for the concave position of MPT with a slightly aromatic character). When oxidizing the compounds all NICS values indicate an increased aromaticity. 
Table S3. Results from above mentioned NICS calculation.

\begin{tabular}{|l|c|c|c|c|}
\hline & $\mathbf{1}$ & $\mathbf{2}$ & $\mathbf{3}$ & $\mathbf{4}$ \\
\hline MPO (A) & -8.91 & -9.48 & 2.90 & 3.79 \\
MPO (B) & -9.95 & -9.87 & -2.57 & -2.20 \\
MPO (C) & -10.77 & -10.61 & -10.15 & -10.07 \\
\hline MPT (A) & -9.86 & -10.23 & -1.41 & 0.56 \\
MPT (B) & -10.19 & -9.96 & -3.34 & -2.75 \\
MPT (C) & -12.02 & -11.42 & -10.46 & -10.31 \\
\hline
\end{tabular}

\subsection{Detailed calculations on model compound 6a}

Only in isomers $\mathbf{6 a}$ and $\mathbf{6 b}$ the phenoxazine units were aligned such that significant $\pi$-stacking interactions were possible. For both isomers the angle of the heteroaromatic ring as well as the intramolecular distance between the two phenoxazines was decreased with increasing oxidation of the molecule. 6a was chosen for a more detailed theoretical investigation.

Table S4. Energies obtained for oxidation states $\boldsymbol{A}-\boldsymbol{C}$ of isomer $\mathbf{6 a}$ after geometry optimization and calculation of the harmonic vibrational frequencies (B3LYP-D3/def2-TZVP+COSMO). (Preoptimized groundstate $\boldsymbol{A}$ on the PBEh3c/def2-mSVP level of theory). In all calculations the COSMO solvation model ( $\varepsilon=37.5$, acetonitrile) was used. Single point energies were calculated on the PW6B95 ${ }^{14}-\mathrm{D} 3 /$ def2-TZVP+COSMO level of theory.

\begin{tabular}{|l|c|c|c|}
\hline \multirow{2}{*}{} & \multicolumn{3}{|c|}{ Oxidation state } \\
\cline { 2 - 4 } & $\boldsymbol{A}$ & $\boldsymbol{B}$ & $\boldsymbol{C}$ \\
\hline$E(\mathrm{PW6B95}-\mathrm{D} 3)\left(\mathrm{E}_{\mathrm{h}}\right)^{[\mathrm{aa}]}$ & -1461.8149236 & -1461.645198134 & -1461.450504813 \\
\hline$Z \mathrm{ZPE}\left(\mathrm{E}_{\mathrm{h}}\right)^{[\mathrm{b}]}$ & 0.538759 & 0.5408906 & 0.5425405 \\
\hline$G(298)\left(\mathrm{kcal} \mathrm{mol}^{-1}\right)^{[\mathrm{b}]}$ & 297.70 & 300.05 & 300.59 \\
\hline Distance $\mathrm{d}_{\text {No-Centroid }}(\AA)$ & 3.745 & 3.468 & 3.330 \\
\hline Angle $\theta\left(^{\circ}\right)^{[\mathrm{c}]}$ & 158.8 & 174.1 & 177.8 \\
\hline
\end{tabular}
[a] PW6B95-D3/def2-TZVP.
[b] B3LYP-D3/def2-TZVP.
[c] Average of both MPO units. 
Table S5. Free energies of oxidation $\Delta G_{\text {ox }}(298)$ and oxidation potentials calculated from the energies listed in Table S2 (PW6B95-D3/def2-TZVP//B3LYP-D3/def2-TZVP+COSMO(CH $\left.{ }_{3} \mathrm{CN}\right)$ ).

\begin{tabular}{|c|c|c|}
\hline Oxidation process of $\mathbf{6 a}$ & $\Delta G_{\text {ox }}\left(\mathrm{kcal} \mathrm{mol}^{-1}\right)$ & $E^{[\mathrm{a]}}(\mathrm{V})$ \\
\hline $\boldsymbol{A} \rightarrow \boldsymbol{B}+\mathrm{e}^{-}$ & 110.2 & -4.78 \\
\hline $\boldsymbol{B} \rightarrow \boldsymbol{C}+\mathrm{e}^{-}$ & 123.8 & -5.37 \\
\hline
\end{tabular}

[a] $E=-\Delta G_{\mathrm{ox}}(298) / \mathrm{nF}$

Table S6. Frontier molecular orbital energies (B3LYP-D3/def2-TZVP+COSMO) of 6a in oxidation state $\boldsymbol{A}$ (uncharged), B (radical cation), and $\boldsymbol{C}$ (dication).

\begin{tabular}{|l|c|c|c|}
\hline \multirow{2}{*}{ Molecular orbital } & \multicolumn{3}{|c|}{ Energy of oxidation state $(\mathrm{eV})$} \\
\cline { 2 - 4 } & $\boldsymbol{A}$ & $\boldsymbol{B}_{\boldsymbol{\alpha}} / \boldsymbol{B}_{\boldsymbol{\beta}}$ & $\boldsymbol{C}$ \\
\hline LUMO+1 & -0.487 & $-1.174 /-1.090$ & -2.254 \\
\hline LUMO & -0.614 & $-1.483 /-1.372$ & -4.825 \\
\hline HOMO & -4.796 & $-5.367 /-4.150$ (unoccupied) & -6.196 \\
\hline HOMO-1 & -4.973 & $-5.846 /-5.292$ & -7.066 \\
\hline gарономо/Lимо & +4.181 & +1.143 (spin flip) & +1.371 \\
\hline
\end{tabular}

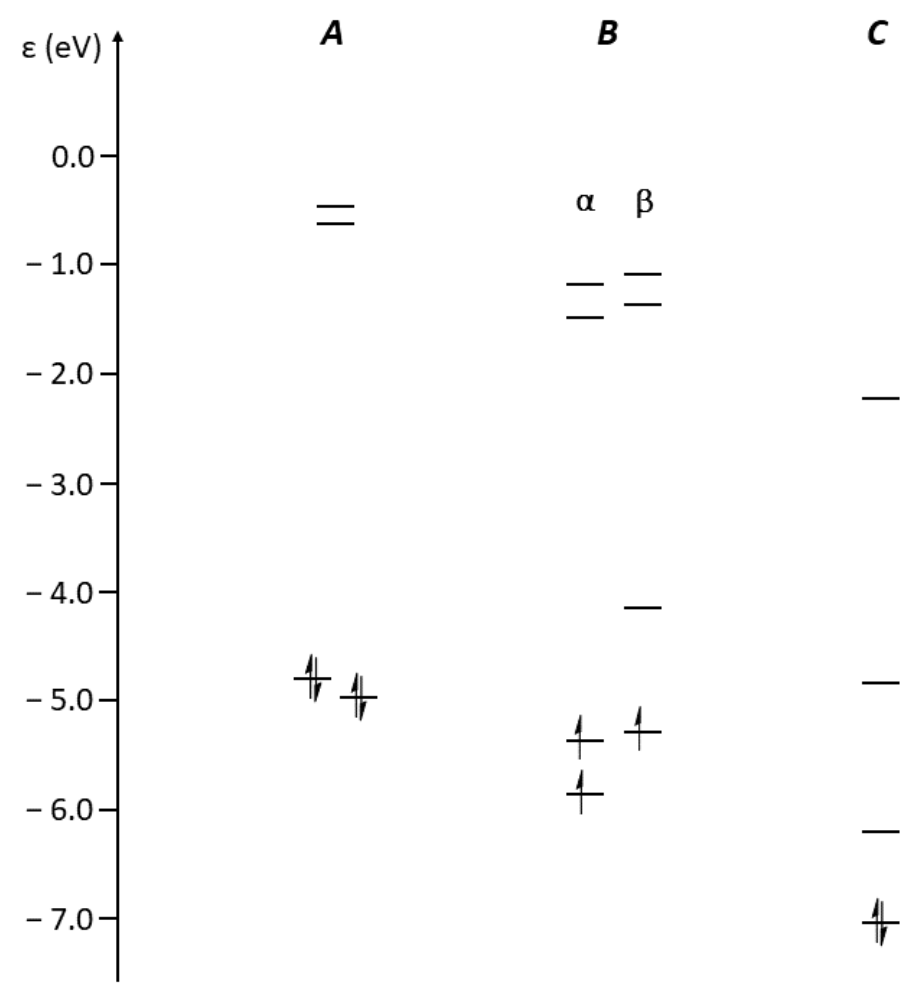

Figure S33. Frontier molecular orbital energies (B3LYP-D3/def2-TZVP+COSMO) of 6a in oxidation state $\boldsymbol{A}$ (uncharged), $\boldsymbol{B}$ (radical cation), and $\boldsymbol{C}$ (dication). 


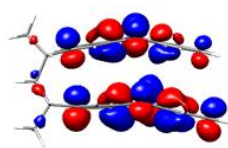

HOMO

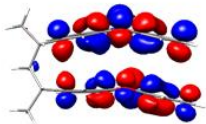

HOMO-1
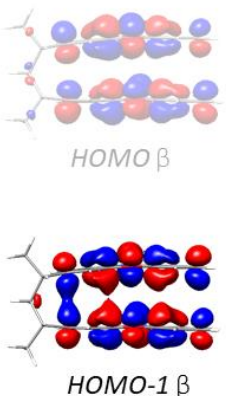

HOMO-1 $\beta$

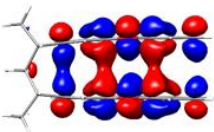

HOMO

Figure S34. Highest occupied molecular orbitals (B3LYP-D3/def2-TZVP+COSMO) of 6a in oxidation state $\boldsymbol{A}$ (uncharged), $\boldsymbol{B}$ (radical cation), and $\mathbf{C}$ (dication). In oxidation state $\boldsymbol{B}$ a large stabilisation of HOMO $\alpha$ and destabilisation of HOMO $\beta$ is observed resulting in a shuffling of the frontier orbitals.

Table S7. Electrochemical data of PVMPO in comparison to values calculated for 6 a.

\begin{tabular}{|c|c|c|c|c|c|c|}
\hline $\begin{array}{c}E_{1 / 2, \text { ox }}(\mathrm{V}) \text { vs. } \\
\mathrm{Fc} / \mathrm{Fc}^{+}\end{array}$ & $\begin{array}{c}E_{\text {Homo, cv }} \\
(\mathrm{eV})^{[\mathrm{ad}]}\end{array}$ & $\begin{array}{c}E_{\mathrm{g}, \text { opt }} \\
(\mathrm{eV})^{[\mathrm{b}]}\end{array}$ & $\begin{array}{c}E_{\text {LUMO }} \\
(\mathrm{eV})^{[\mathrm{c}]}\end{array}$ & $\begin{array}{c}E_{\text {HOMo, calc }} \\
(\mathrm{eV})^{[\mathrm{d}]}\end{array}$ & $\begin{array}{c}E_{\text {LUMo, calc }} \\
(\mathrm{eV})^{[\mathrm{d}]}\end{array}$ & $\begin{array}{c}E_{\mathrm{g}, \text { calc }} \\
(\mathrm{eV})^{[\mathrm{d}]}\end{array}$ \\
\hline 0.09 & -4.74 & +3.41 & -1.33 & -4.80 & -0.61 & +4.18 \\
\hline
\end{tabular}

[a] Calculated from the onset of the oxidation peak $\left[E_{\text {Hомо }}=-\left(E_{\text {onset, ox }}+4.8\right) \mathrm{eV}\right] .{ }^{15}$

[b] Optical band gap calculated from the onset of the longest wavelength absorption band ( $364 \mathrm{~nm}$ ).

[c] $E_{\mathrm{LuMO}}=E_{\mathrm{HOMO}} \mathrm{cv}+E_{\mathrm{g}, \mathrm{opt}}$

[d] B3LYP-D3/def2-TZVP+COSMO. 


\subsection{Cartesian coordinates}

\subsubsection{Cartesian coordinates of $6 a$ in oxidation State $A$}

$\begin{array}{lrrr}\text { C } & -1.3485683 & 5.2907429 & -0.7650400 \\ \text { C } & -0.3416939 & 4.1431397 & -0.6031554 \\ \text { C } & 0.6548153 & 4.4683079 & 0.5268478 \\ \text { C } & -1.0561982 & 2.8178700 & -0.4218444 \\ \text { C } & -1.8918055 & 2.5697151 & 0.6610808 \\ \text { C } & -2.5009152 & 1.3301094 & 0.8421854 \\ \text { C } & -2.3072303 & 0.2983234 & -0.0755967 \\ \text { C } & -1.4804943 & 0.5625055 & -1.1723685 \\ \text { C } & -0.8718901 & 1.7871970 & -1.3438485 \\ \text { C } & -2.2742631 & -2.0254889 & -0.6561791 \\ \text { C } & -1.4421589 & -1.7187020 & -1.7434411 \\ \text { O } & -1.2566947 & -0.4063262 & -2.1335048 \\ \text { C } & -2.4493272 & -3.3713590 & -0.3322320 \\ \text { C } & -1.8313361 & -4.3707314 & -1.0838887 \\ \text { C } & -1.0147782 & -4.0456048 & -2.1540445 \\ \text { C } & -0.8141702 & -2.7042400 & -2.4762378 \\ \text { C } & 1.9751607 & 3.6746983 & 0.5211043 \\ \text { C } & 2.9336163 & 4.2428905 & 1.5764262 \\ \text { C } & 1.7740278 & 2.1848887 & 0.7002613 \\ \text { C } & 1.1603969 & 1.6673019 & 1.8336302 \\ \text { C } & 0.8797699 & 0.3105066 & 1.9517842 \\ \text { C } & 1.1890275 & -0.5736117 & 0.9195443 \\ \text { C } & 1.8529395 & -0.0552459 & -0.1974091 \\ \text { C } & 2.1510578 & 1.2883419 & -0.3016434 \\ \text { C } & 1.5404719 & -2.7830262 & 0.0741004 \\ \text { C } & 2.2000978 & -2.2293722 & -1.0340820 \\ \text { O } & 2.1580797 & -0.8699062 & -1.2716433 \\ \text { C } & 1.6008733 & -4.1654720 & 0.2444344 \\ \text { C } & 2.2584599 & -4.9694965 & -0.6847528 \\ \text { C } & 2.8874571 & -4.4061487 & -1.7834868 \\ \text { C } & 2.8663339 & -3.0206340 & -1.9473211 \\ \text { N } & -2.8850153 & -0.9750576 & 0.0369875 \\ \text { C } & -3.8073925 & -1.2577802 & 1.1163917 \\ \text { N } & 0.8426210 & -1.9289702 & 0.9289430 \\ \text { C } & 0.0435384 & -2.4649798 & 2.0086681 \\ \text { H } & -1.9150980 & 5.4470662 & 0.1558870 \\ \text { H } & -0.8352393 & 6.2242514 & -1.0058786 \\ \text { H } & -2.0606948 & 5.0738701 & -1.5633980 \\ \text { H } & 0.2317365 & 4.0741910 & -1.5331178 \\ \text { H } & 0.9145293 & 5.5283572 & 0.4476409\end{array}$

$\begin{array}{rrrr}H & 0.1589683 & 4.3476331 & 1.4946835 \\ H & -2.0547779 & 3.3362680 & 1.4082296 \\ H & -3.1128239 & 1.1684965 & 1.7172835 \\ H & -0.2210728 & 1.9202237 & -2.1985018 \\ H & -3.0623373 & -3.6483389 & 0.5124500 \\ H & -1.9832368 & -5.4061460 & -0.8077802 \\ H & -0.5124873 & -4.8165131 & -2.7216530 \\ H & -0.1668529 & -2.4114225 & -3.2919760 \\ H & 2.4357209 & 3.8233383 & -0.4608296 \\ H & 3.1175983 & 5.3055218 & 1.4021797 \\ H & 2.5160782 & 4.1347801 & 2.5800307 \\ H & 3.8917363 & 3.7203946 & 1.5540418 \\ H & 0.8529047 & 2.3281625 & 2.6336167 \\ H & 0.3849323 & -0.0493738 & 2.8413969 \\ H & 2.6267601 & 1.6411209 & -1.2087365 \\ H & 1.1159479 & -4.6250562 & 1.0925768 \\ H & 2.2705306 & -6.0419386 & -0.5386523 \\ H & 3.3965967 & -5.0269856 & -2.5086660 \\ H & 3.3476439 & -2.5455874 & -2.7926557 \\ H & -4.4434554 & -2.0959399 & 0.8404752 \\ H & -4.4467734 & -0.3936791 & 1.2810587 \\ H & -3.2983232 & -1.4997059 & 2.0573876 \\ H & -0.7205992 & -1.7410422 & 2.2822990 \\ H & 0.6372688 & -2.7005068 & 2.9002459 \\ H & -0.4599936 & -3.3658249 & 1.6696920\end{array}$




\subsubsection{Cartesian coordinates of $6 a$ in oxidation State $B$}

\begin{tabular}{|c|c|c|c|}
\hline & 42 & 01 & 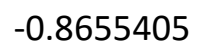 \\
\hline$r$ & -0.3232040 & 4.0989518 & -0.6662566 \\
\hline & 0.6260287 & 4.5234961 & 0.4715625 \\
\hline & -0.9362896 & 2.7307790 & -0.4578284 \\
\hline & 7467 & 088 & 7791 \\
\hline$\tau$ & 1240 & 776 & 290 \\
\hline & -2.0146013 & 0.1442472 & -0.0346411 \\
\hline & -1.1954685 & 0.4346410 & -1.1431905 \\
\hline & -0.6871201 & 1.7009233 & -1.3572772 \\
\hline & -2.0393609 & -2.15 & -0.7055694 \\
\hline C & -1.22 & -1.82 & -1.8060324 \\
\hline o & -0.8657390 & -0.52 & -2.0533565 \\
\hline & -2.3515690 & -3.5106763 & -0.5079233 \\
\hline & -1.8983258 & -4.47 & -1.3968670 \\
\hline & -1.1 & -4.12 & 0850 \\
\hline & -0.7759583 & -2.78 & 9113 \\
\hline & 1.97 & 3.77 & 897 \\
\hline & 2.87 & 4.41 & 196 \\
\hline & 1.79 & 2.29 & 171 \\
\hline & 1.1551868 & 1.81 & 028 \\
\hline & 0.87 & 0.47 & 5107 \\
\hline & 1.22 & -0.45 & 5347 \\
\hline & 1.93 & 0.02 & 2118 \\
\hline & 2.224 & 1.36 & 0356 \\
\hline & 1.3882922 & -2.67 & 9631 \\
\hline & 2.10 & -2.1 & 7925 \\
\hline & 2.3? & -0.8 & 7404 \\
\hline$C$ & 1.21 & -4.0 & 096 \\
\hline$c$ & 1.7112040 & -4.88 & -0.7274992 \\
\hline C & 2.4078217 & -4.3481676 & -1.8084789 \\
\hline 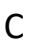 & 2.6101637 & -2.9777234 & -1.8854756 \\
\hline $\mathrm{N}$ & -2.49 & $-1.1<$ & 0.1335957 \\
\hline C & -3.44 & -1.44 & 7732 \\
\hline $\mathrm{N}$ & 0.8852668 & -1.7994137 & 1.1583772 \\
\hline C & 0.0417697 & -2.3106714 & 2.2296511 \\
\hline $\mathrm{H}$ & -2.0105550 & 5.2861085 & 0.0421537 \\
\hline$H$ & -0.9700381 & 6.123 & -1.1131052 \\
\hline ז & -2.0922275 & 4.8754108 & -1.6740675 \\
\hline п & 0.2668051 & 4.0517392 & -1.5861462 \\
\hline $\mathrm{H}$ & 0.8496528 & 5.5854772 & 0.3396870 \\
\hline $\mathrm{H}$ & 0.1090350 & 4.4371765 & 1.4316459 \\
\hline $\mathrm{H}$ & -1.9830884 & 3.2309455 & 1.3578796 \\
\hline
\end{tabular}

$\begin{array}{rrrr}H & -2.9000471 & 1.0207559 & 1.7249752 \\ H & -0.0524350 & 1.8565147 & -2.2196861 \\ H & -2.9439943 & -3.8112548 & 0.3417674 \\ H & -2.1499019 & -5.5112811 & -1.2213579 \\ H & -0.7589027 & -4.8750885 & -3.1781986 \\ H & -0.1557484 & -2.4794950 & -3.5195959 \\ H & 2.4603410 & 3.8947654 & -0.4324203 \\ H & 3.0444207 & 5.4665277 & 1.3815631 \\ H & 2.4269650 & 4.3417659 & 2.5950853 \\ H & 3.8474740 & 3.9104157 & 1.6371872 \\ H & 0.8331792 & 2.5042362 & 2.6887083 \\ H & 0.3705789 & 0.1471284 & 2.9829500 \\ H & 2.7305596 & 1.6842817 & -1.0722973 \\ H & 0.6864458 & -4.4981140 & 1.1028724 \\ H & 1.5522482 & -5.9500105 & -0.6584350 \\ H & 2.7915333 & -4.9937435 & -2.5866408 \\ H & 3.1454525 & -2.5267314 & -2.7103798 \\ H & -4.0956365 & -2.2522025 & 0.8774618 \\ H & -4.0527119 & -0.5717496 & 1.3937596 \\ H & -2.9291971 & -1.7411623 & 2.1145767 \\ H & -0.5963269 & -1.5167535 & 2.6005712 \\ H & 0.6391551 & -2.7048449 & 3.0543489 \\ H & -0.5920207 & -3.1020051 & 1.8388358\end{array}$




\subsubsection{Cartesian coordinates of $6 a$ in oxidation State $C$}

\begin{tabular}{|c|c|c|c|}
\hline & -1.4870692 & 5.1 & 27 \\
\hline & -0.3450851 & 4.1087979 & -0.6899894 \\
\hline & 0.6091607 & 4.5401656 & 0.4405449 \\
\hline - & -0.8960581 & 2.7179616 & -0.4928910 \\
\hline C & -1.6826650 & 2.3967229 & 0.6344792 \\
\hline & -2.1639324 & 1.1279956 & 0.8492729 \\
\hline & -1.8704768 & 0.0962087 & -0.0611812 \\
\hline & -1.0966883 & 0.4331894 & -1.2035860 \\
\hline & -0.6505713 & 1.7210276 & -1.4254799 \\
\hline C & 3396 & 053 & -0.7974668 \\
\hline C & -1.1306253 & -1.8032890 & -1.9228050 \\
\hline D & -0.7806278 & -0.5047236 & -2.1273302 \\
\hline C & -2.2323619 & -3.5 & -0.6468472 \\
\hline & 5078 & -4.4 & -1.5960021 \\
\hline C & 6779 & -4.0 & -2.7111487 \\
\hline$C$ & -0.7363766 & -2.7 & -2.8744982 \\
\hline & 1.9465988 & 3.7757674 & 0.4982053 \\
\hline 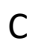 & 2.8760825 & 531 & 1.5459007 \\
\hline$\zeta$ & 1.7511520 & 064 & 0.7617529 \\
\hline C & 1.1267754 & 1.8 & 1.9454897 \\
\hline C & 0.8488054 & 374 & 2.1640823 \\
\hline C & 1.1688065 & -0.4 & 1.1871833 \\
\hline & 1.8615617 & 151 & 0.0323013 \\
\hline C & 2.1641920 & 666 & -0.1614980 \\
\hline C & 1.2586928 & -2.6525859 & 0.3191234 \\
\hline$c$ & 1.9613175 & -2.1 & -0.8073310 \\
\hline 0 & 2.2246572 & -0.8 & -0.9402487 \\
\hline$c$ & 1.0255523 & -4.03 & 0.3968075 \\
\hline C & 1.4581791 & -4.8662754 & -0.6142546 \\
\hline C & 2.1522790 & -4.35 & -1.7198462 \\
\hline C & 2.4121018 & -3.0 & -1.8121399 \\
\hline $\mathrm{N}$ & -2.2931877 & -1.1 & 0.0976266 \\
\hline c & -3.2004472 & -1.5459387 & 1.1988373 \\
\hline N & 0.8533260 & -1.7605419 & 1.2966155 \\
\hline$C$ & 0.0977284 & -2.25 & 2.4515160 \\
\hline $\mathrm{H}$ & -2.0629078 & 5.2115614 & 0.0854153 \\
\hline $\mathrm{H}$ & -1.0798771 & 6.1116896 & -1.0737766 \\
\hline $\mathrm{H}$ & -2.1677594 & 4.8360412 & -1.6391937 \\
\hline $\mathrm{H}$ & 0.2250367 & 4.1032783 & -1.6222629 \\
\hline $\boldsymbol{H}$ & 0.8417293 & 5.5973979 & 0.2944859 \\
\hline . & 0.0986956 & 4.4675292 & 1.4045898 \\
\hline & -1.9003 & 3.16068 & \\
\hline
\end{tabular}

$\begin{array}{rrrr}H & -2.7339985 & 0.9224556 & 1.7398979 \\ H & -0.0581956 & 1.9133243 & -2.3095933 \\ H & -2.7918989 & -3.8653702 & 0.2121559 \\ H & -2.0903826 & -5.4927955 & -1.4640569 \\ H & -0.7797989 & -4.7857191 & -3.4478245 \\ H & -0.1552312 & -2.3862676 & -3.7198595 \\ H & 2.4239227 & 3.8703558 & -0.4801277 \\ H & 3.0574653 & 5.4552043 & 1.2993252 \\ H & 2.4333039 & 4.3672806 & 2.5428496 \\ H & 3.8360691 & 3.8911117 & 1.5771501 \\ H & 0.8362528 & 2.5753264 & 2.6996456 \\ H & 0.3659530 & 0.2376974 & 3.0813112 \\ H & 2.6591571 & 1.6447802 & -1.0793729 \\ H & 0.5114368 & -4.4538954 & 1.2449766 \\ H & 1.2625304 & -5.9270056 & -0.5439725 \\ H & 2.4874628 & -5.0246185 & -2.5021599 \\ H & 2.9425439 & -2.5751378 & -2.6508367 \\ H & -3.8568574 & -2.3456315 & 0.8789979 \\ H & -3.8012729 & -0.6822163 & 1.4523587 \\ H & -2.6302605 & -1.8655921 & 2.0711954 \\ H & -0.5194316 & -1.4559206 & 2.8458831 \\ H & 0.7793177 & -2.6066437 & 3.2232185 \\ H & -0.5468858 & -3.0653995 & 2.1349554\end{array}$




\subsubsection{Cartesian coordinates of $6 \mathrm{~b}$ in oxidation State $A$}

$\begin{array}{lrrr}\text { C } & -3.7065388 & 3.4772041 & -1.6407245 \\ \text { C } & -2.2730420 & 3.3201792 & -1.1134936 \\ \text { C } & -2.1369087 & 4.0431180 & 0.2399061 \\ \text { C } & -1.8695995 & 1.8614265 & -1.0554139 \\ \text { C } & -2.4783525 & 0.9753101 & -0.1758908 \\ \text { C } & -2.0668724 & -0.3492481 & -0.0777033 \\ \text { C } & -1.0099003 & -0.8275374 & -0.8505699 \\ \text { C } & -0.4214664 & 0.0602343 & -1.7576669 \\ \text { C } & -0.8484938 & 1.3681493 & -1.8702942 \\ \text { C } & 0.2643962 & -2.6115393 & -1.8081276 \\ \text { C } & 0.8436146 & -1.6916188 & -2.6958864 \\ \text { O } & 0.6589703 & -0.3341277 & -2.5246305 \\ \text { C } & 0.5135517 & -3.9670211 & -2.0212592 \\ \text { C } & 1.3462988 & -4.3846567 & -3.0578968 \\ \text { C } & 1.9241633 & -3.4598575 & -3.9132846 \\ \text { C } & 1.6555757 & -2.1022461 & -3.7334993 \\ \text { C } & -0.7227275 & 4.1664333 & 0.8568062 \\ \text { C } & 0.2442534 & 4.8835150 & -0.0856666 \\ \text { C } & -0.1934958 & 2.8486956 & 1.3975907 \\ \text { C } & -0.7651636 & 2.2766596 & 2.5294609 \\ \text { C } & -0.3540702 & 1.0370584 & 3.0127301 \\ \text { C } & 0.6724402 & 0.3325106 & 2.3842623 \\ \text { C } & 1.2505558 & 0.9192745 & 1.2544803 \\ \text { C } & 0.8357437 & 2.1425618 & 0.7739068 \\ \text { C } & 1.8576146 & -1.6934338 & 1.8975265 \\ \text { C } & 2.4097269 & -1.0712515 & 0.7667866 \\ \text { O } & 2.2861048 & 0.2918008 & 0.5860391 \\ \text { C } & 2.0452224 & -3.0688928 & 2.0374002 \\ \text { C } & 2.7758484 & -3.7885755 & 1.0913911 \\ \text { C } & 3.3109655 & -3.1545271 & -0.0173436 \\ \text { C } & 3.1162723 & -1.7835545 & -0.1795614 \\ \text { N } & -0.5005638 & -2.1260668 & -0.7482996 \\ \text { C } & -1.0035247 & -3.0275109 & 0.2651834 \\ \text { N } & 1.1573709 & -0.9091977 & 2.8198794 \\ \text { C } & 0.6405728 & -1.5040172 & 4.0344483 \\ \text { H } & -3.9694905 & 4.5327187 & -1.7414343 \\ \text { H } & -3.8149585 & 3.0017883 & -2.6173247 \\ \text { H } & -4.4250600 & 3.0145328 & -0.9601938 \\ \text { H } & -1.6091792 & 3.8120255 & -1.8289604 \\ \text { H } & -2.5227488 & 5.0590462 & 0.1085715 \\ \text { H } & -2.7946837 & 3.5595465 & 0.9668840 \\ \text { H } & -3.2729056 & 1.3164162 & 0.4746972\end{array}$

$\begin{array}{rrrr}H & -2.5622196 & -1.0026438 & 0.6248070 \\ H & -0.3345715 & 2.0180623 & -2.5683841 \\ H & 0.0747272 & -4.7044730 & -1.3661102 \\ H & 1.5374327 & -5.4422839 & -3.1868087 \\ H & 2.5729523 & -3.7792407 & -4.7180724 \\ H & 2.0878281 & -1.3515157 & -4.3828370 \\ H & -0.8559450 & 4.8175583 & 1.7277524 \\ H & 1.2044774 & 5.0644618 & 0.4007654 \\ H & 0.4359239 & 4.3126900 & -0.9949286 \\ H & -0.1713120 & 5.8476106 & -0.3853790 \\ H & -1.5683548 & 2.7923138 & 3.0427008 \\ H & -0.8442698 & 0.6221937 & 3.8810986 \\ H & 1.3213107 & 2.5189054 & -0.1143663 \\ H & 1.6154011 & -3.5895395 & 2.8800983 \\ H & 2.9037973 & -4.8549073 & 1.2260605 \\ H & 3.8551190 & -3.7128373 & -0.7664492 \\ H & 3.5036035 & -1.2578665 & -1.0418799 \\ H & -0.2473471 & -3.7741542 & 0.4896080 \\ H & -1.9283958 & -3.5325076 & -0.0387090 \\ H & -1.1955393 & -2.4697555 & 1.1784834 \\ H & -0.3046746 & -2.0376641 & 3.8761123 \\ H & 0.4797168 & -0.7265875 & 4.7775539 \\ H & 1.3708238 & -2.2031439 & 4.4360590\end{array}$

$\begin{array}{llll}\text { H } & -2.5622196 & -1.0026438 & 0.6248070\end{array}$

H $\quad-0.3345715 \quad 2.0180623 \quad-2.5683841$

H $\quad 0.0747272-4.7044730-1.3661102$

H $\quad 1.5374327-5.4422839-3.1868087$

H $\quad 2.5729523 \quad-3.7792407 \quad-4.7180724$

H $\quad 2.0878281-1.3515157-4.3828370$

H $\quad-0.8559450 \quad 4.8175583 \quad 1.7277524$

H $\quad 1.2044774 \quad 5.0644618 \quad 0.4007654$

H $\quad 0.4359239 \quad 4.3126900-0.9949286$

H $\quad-0.1713120 \quad 5.8476106-0.3853790$

H $\quad-1.5683548 \quad 2.7923138 \quad 3.0427008$

H $\quad-0.8442698 \quad 0.6221937 \quad 3.8810986$

H $\quad 1.3213107 \quad 2.5189054-0.1143663$

H $\quad 1.6154011-3.5895395 \quad 2.8800983$

H $\quad 2.9037973 \quad-4.8549073 \quad 1.2260605$

H $3.8551190 \quad-3.7128373 \quad-0.7664492$

H $3.5036035-1.2578665-1.0418799$

H $\quad-0.2473471 \quad-3.77415420 .4896080$

H $-1.9283958-3.5325076 \quad-0.0387090$

H $-1.1955393 \quad-2.4697555 \quad 1.1784834$

$\begin{array}{llll}H & -0.3046746 & -2.0376641 & 3.8761123\end{array}$

H $\quad 1.3708238-2.2031439 \quad 4.4360590$ 


\subsubsection{Cartesian coordinates of $6 c$ in oxidation State $A$}

\begin{tabular}{|c|c|c|c|}
\hline & -2.38 & 820 & 37 \\
\hline & -1.4899539 & 3.2968098 & 2.2039224 \\
\hline & -0.0308217 & 3.6511366 & 2.5532541 \\
\hline & -1.6348424 & 1.9137357 & 1.6028797 \\
\hline & -1.4552161 & 0.7545542 & 2.3480889 \\
\hline & -1.4952374 & -0.5056712 & 1.7543489 \\
\hline & -1.7373298 & -0.6450689 & 0.3884542 \\
\hline & -1.9274398 & 0.5275226 & -0.3515664 \\
\hline & -1.8833101 & 1.7717156 & 5966 \\
\hline & -1.6762323 & -1.8895991 & 5931 \\
\hline & -1.8591947 & -0.6905103 & -2.3690567 \\
\hline & -2.1844724 & 0.4760276 & -1.7087470 \\
\hline & -1.3880340 & -3.0388293 & -2.3982858 \\
\hline & -1.3158221 & -2.9971751 & -3.7 \\
\hline & -1.50 & -1.8048190 & -4.4 \\
\hline & -1.7679384 & -0.6412369 & 255 \\
\hline & 0.9403550 & 3.8331039 & 1.37 \\
\hline & 2.2537451 & 4.4554203 & 7236 \\
\hline & 1.2215846 & 2.5667240 & 245 \\
\hline & 1.1269113 & 2.5319313 & -0.7 \\
\hline & 1.34 & 1.3575251 & 892 \\
\hline & 1.6944636 & 0.1781162 & 5227 \\
\hline & 1.8006271 & 0.2263008 & 0.5 \\
\hline & 1.5786121 & 1.3849784 & 652 \\
\hline & 1.8786216 & -2.2097254 & 1153 \\
\hline & 1.97 & -2.1218106 & 121 \\
\hline & 2.1514382 & -0.9009902 & 7202 \\
\hline & 1.7393179 & -3.4804267 & -1.3183863 \\
\hline & 1.7259567 & -4.6194290 & -0.5144139 \\
\hline & 1.8266430 & -4.5111686 & 0.8634777 \\
\hline & 1.9412665 & -3.2455869 & 1086 \\
\hline & -1.8064567 & -1.8780452 & -0.2722660 \\
\hline & -1.7451856 & -3.1147162 & 0.4813225 \\
\hline & 1.9414572 & -1.0369041 & -1.5102388 \\
\hline & 1.9597087 & -1.0927218 & -2.9586012 \\
\hline & -2.3402918 & 4.5121206 & 3.7926161 \\
\hline & -2.0626457 & 2.8330438 & 4.2565788 \\
\hline & -3.4219188 & 3.2392099 & 3.2060303 \\
\hline & -1.8221412 & 4.0124737 & 1.4448108 \\
\hline & -0.0464913 & 4.5949947 & 3.1065131 \\
\hline & 0.3641025 & 2.9024222 & 3.2468695 \\
\hline & רחי & & 3.407 \\
\hline
\end{tabular}

$\begin{array}{rrrr}H & -1.3124494 & -1.3791991 & 2.3620973 \\ H & -2.0138014 & 2.6417890 & -0.3929700 \\ H & -1.2078218 & -3.9721652 & -1.8886467 \\ H & -1.0959140 & -3.9074584 & -4.3328775 \\ H & -1.4411125 & -1.7655906 & -5.5494421 \\ H & -1.9162811 & 0.3098109 & -4.2405973 \\ H & 0.4800168 & 4.5428072 & 0.6773134 \\ H & 2.9427141 & 4.6256421 & 1.0425425 \\ H & 2.7469787 & 3.7925382 & 2.5870371 \\ H & 2.0687600 & 5.4109078 & 2.3679131 \\ H & 0.8343711 & 3.4254634 & -1.3314152 \\ H & 1.2236027 & 1.3651623 & -2.5854701 \\ H & 1.6585881 & 1.3413657 & 2.3226953 \\ H & 1.6296439 & -3.5871666 & -2.3861855 \\ H & 1.6218817 & -5.5908445 & -0.9803045 \\ H & 1.8084684 & -5.3914773 & 1.4919755 \\ H & 2.0167169 & -3.1202861 & 2.5136700 \\ H & -2.2746060 & -2.9874972 & 1.4230720 \\ H & -0.7186963 & -3.4268783 & 0.6910744 \\ H & -2.2460330 & -3.9030827 & -0.0766499 \\ H & 2.4284447 & -0.1903425 & -3.3455758 \\ H & 0.9578964 & -1.1835910 & -3.3867370 \\ H & 2.5588699 & -1.9419403 & -3.2799549\end{array}$




\subsubsection{Cartesian coordinates of $6 \mathrm{~d}$ in oxidation State $\boldsymbol{A}$}

\begin{tabular}{|c|c|c|c|}
\hline & 0395 & 812 & 99 \\
\hline & -1.0443164 & 3.7545960 & 4312 \\
\hline & -0.3196756 & 4.4179905 & 0.4683243 \\
\hline & -1.2359050 & 2.2548052 & 1.5006655 \\
\hline & -0.8167620 & 1.3173952 & 2.4338833 \\
\hline & -0.9633996 & -0.0542002 & 2.2129890 \\
\hline & -1.5528209 & -0.5308667 & 1.0472908 \\
\hline & -1.9836040 & 0.4220210 & 0.1132861 \\
\hline & -1.8403824 & 1.7704021 & 2510 \\
\hline & -1.9715528 & -2.2552162 & -0.56 \\
\hline & -2.3850986 & -1.2711518 & -1.4767462 \\
\hline & -2.5903944 & 0.0293485 & -1.0653477 \\
\hline & -1.8241636 & -3.5588796 & -1.0400065 \\
\hline & -2.1058402 & -3.87 & -2.36 \\
\hline & -2.5155294 & -2.8 & -3.2 \\
\hline & -2.6450659 & -1.5728684 & -2.7984143 \\
\hline & 1.1490380 & 4.0253200 & 0.20 \\
\hline & 1.7941749 & 5.0364621 & -0.7471002 \\
\hline & 1.2919880 & 2.604 & 048 \\
\hline & 0.8448113 & 2.2 & 404 \\
\hline & 0.9034481 & $0.8 \varepsilon$ & 280 \\
\hline & 1.4344742 & -0.0990797 & -1.13 \\
\hline & 1.8917133 & 0.30 & 0.1230095 \\
\hline & 1.8278007 & 1.6183407 & 0.5313234 \\
\hline & 1.7183706 & -2.38 & -0.4724505 \\
\hline 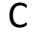 & 2.1646300 & $-1.9<$ & 0.78 \\
\hline & 2.4420617 & $-0.6 c$ & 1.00 \\
\hline & 1.4941775 & -3.7537144 & -0.6328273 \\
\hline & 1.7346014 & -4.6461758 & 0.4111945 \\
\hline & 2.1794907 & -4.1887002 & 1.6411476 \\
\hline & 2.3849894 & -2.82 & 1.82 \\
\hline & -1.7448985 & -1.8877901 & 0.7621535 \\
\hline C & -1.4368288 & -2.8901797 & 1.7629089 \\
\hline & 1.5380182 & -1.4502478 & -1.4910938 \\
\hline & 1.1894952 & -1.8809667 & -2.8306297 \\
\hline 7 & -0.3087812 & 5.2365973 & 3.0533442 \\
\hline$H$ & -0.9966971 & 3.8153379 & 3.8406545 \\
\hline & 0.6017516 & 3.7278539 & 3.1047633 \\
\hline & -2.0482321 & 4.1969481 & 1.6606088 \\
\hline & -0.8900352 & 4.2417079 & -0.4468001 \\
\hline & -0.3519755 & 5.4982386 & 0.639907 \\
\hline & & 1.6324831 & \\
\hline
\end{tabular}

$\begin{array}{rrrr}H & -0.5879406 & -0.7466419 & 2.9515998 \\ H & -2.1850367 & 2.4461719 & -0.4371983 \\ H & -1.4775415 & -4.3361087 & -0.3773079 \\ H & -1.9862357 & -4.8929843 & -2.7061054 \\ H & -2.7268716 & -3.1220523 & -4.2878480 \\ H & -2.9587839 & -0.7754387 & -3.4599016 \\ H & 1.6892670 & 4.0845207 & 1.1576964 \\ H & 2.8336075 & 4.7723606 & -0.9501531 \\ H & 1.2640289 & 5.0711343 & -1.7014770 \\ H & 1.7720738 & 6.0402284 & -0.3173434 \\ H & 0.4042022 & 2.9420787 & -2.2243069 \\ H & 0.5098652 & 0.6192680 & -2.9377691 \\ H & 2.1761664 & 1.8620812 & 1.5267470 \\ H & 1.1202091 & -4.1296155 & -1.5721112 \\ H & 1.5555211 & -5.7017697 & 0.2525180 \\ H & 2.3596515 & -4.8760548 & 2.4568494 \\ H & 2.7270037 & -2.4241730 & 2.7729743 \\ H & -1.7290216 & -2.5183915 & 2.7429540 \\ H & -0.3750496 & -3.1485950 & 1.7839281 \\ H & -2.0146448 & -3.7897998 & 1.5630467 \\ H & 1.7224907 & -2.8000427 & -3.0649182 \\ H & 0.1165485 & -2.0541109 & -2.9491232 \\ H & 1.5057413 & -1.1234931 & -3.5444427\end{array}$




$\begin{array}{lrrr}\text { H } & 1.4008823 & 4.5932617 & -0.0673158 \\ \text { C } & 0.9309403 & 3.6289614 & 0.0729574 \\ \text { C } & 0.1241031 & 3.3874579 & 1.1740376 \\ \text { C } & -0.4784494 & 2.1421084 & 1.3539645 \\ \text { C } & -0.2998514 & 1.1251228 & 0.4154764 \\ \text { C } & 0.5272084 & 1.3873821 & -0.6872805 \\ \text { C } & 1.1410838 & 2.6113171 & -0.8589612 \\ \text { C } & -0.2844104 & -1.1912696 & -0.1683103 \\ \text { C } & 0.5421420 & -0.8892043 & -1.2612172 \\ \text { O } & 0.7103737 & 0.4234371 & -1.6612841 \\ \text { C } & -0.4469725 & -2.5336741 & 0.1758373 \\ \text { C } & 0.1702096 & -3.5373949 & -0.5711455 \\ \text { C } & 0.9760047 & -3.2181050 & -1.6530308 \\ \text { C } & 1.1702222 & -1.8778360 & -1.9909097 \\ \text { N } & -0.9039662 & -0.1339405 & 0.5076251 \\ \text { C } & -1.8388206 & -0.4105657 & 1.5803530 \\ H & -0.0413582 & 4.1633067 & 1.9103657 \\ \text { H } & -1.0907371 & 1.9717442 & 2.2269533 \\ H & 1.7675508 & 2.7633350 & -1.7285868 \\ \text { H } & -1.0582339 & -2.8049299 & 1.0236700 \\ \text { H } & 0.0170347 & -4.5715545 & -0.2908921 \\ \text { H } & 1.4571821 & -3.9948180 & -2.2323279 \\ \text { H } & 1.7951729 & -1.5917517 & -2.8272214 \\ \text { H } & -2.4692286 & -1.2512185 & 1.3002117 \\ \text { H } & -2.4806315 & 0.4544591 & 1.7302923 \\ \text { H } & -1.3374507 & -0.6456308 & 2.5267390\end{array}$




$\begin{array}{lrrr}\text { H } & 1.1958608 & 4.6671929 & -0.1933933 \\ \text { C } & 0.8129666 & 3.6728957 & -0.0089556 \\ \text { C } & -0.0513531 & 3.4425880 & 1.0714217 \\ \text { C } & -0.5546932 & 2.1842076 & 1.3203708 \\ \text { C } & -0.2009694 & 1.1077533 & 0.4870677 \\ \text { C } & 0.6871356 & 1.3589942 & -0.5821681 \\ \text { C } & 1.1841831 & 2.6298965 & -0.8349856 \\ \text { C } & -0.1850938 & -1.2082535 & -0.0963678 \\ \text { C } & 0.7020919 & -0.9117670 & -1.1546086 \\ \text { O } & 1.0836946 & 0.3627678 & -1.4102658 \\ \text { C } & -0.5218944 & -2.5553766 & 0.1274136 \\ \text { C } & -0.0045337 & -3.5392148 & -0.6870207 \\ \text { C } & 0.8576363 & -3.2192249 & -1.7460926 \\ \text { C } & 1.2131084 & -1.9048208 & -1.9785389 \\ \text { N } & -0.6824281 & -0.1732056 & 0.6699833 \\ \text { C } & -1.6972385 & -0.4393651 & 1.6948227 \\ H & -0.3273389 & 4.2604662 & 1.7225471 \\ \text { H } & -1.2076068 & 2.0276340 & 2.1634012 \\ H & 1.8544237 & 2.7701753 & -1.6719272 \\ \text { H } & -1.1723747 & -2.8249386 & 0.9434313 \\ \text { H } & -0.2670156 & -4.5714749 & -0.5010134 \\ \text { H } & 1.2510899 & -4.0024855 & -2.3793255 \\ \text { H } & 1.8819666 & -1.6235534 & -2.7803452 \\ \text { H } & -2.3170937 & -1.2671925 & 1.3727394 \\ \text { H } & -2.3219190 & 0.4375621 & 1.8116614 \\ \text { H } & -1.2126044 & -0.6812605 & 2.6401479\end{array}$




$\begin{array}{lrrr}\text { H } & 1.1650337 & 4.6504591 & -0.2170091 \\ \text { C } & 0.7994026 & 3.6497731 & -0.0347772 \\ \text { C } & -0.0960271 & 3.4240799 & 1.0454442 \\ \text { C } & -0.5969863 & 2.1816751 & 1.3122448 \\ \text { C } & -0.2050489 & 1.0937584 & 0.4981648 \\ \text { C } & 0.7184083 & 1.3467178 & -0.5712373 \\ \text { C } & 1.2088922 & 2.6181599 & -0.8420844 \\ \text { C } & -0.1908829 & -1.2027038 & -0.0811184 \\ \text { C } & 0.7338331 & -0.9067767 & -1.1387815 \\ \text { O } & 1.1250576 & 0.3450141 & -1.3406385 \\ \text { C } & -0.5680473 & -2.5514244 & 0.1163620 \\ \text { C } & -0.0514628 & -3.5121650 & -0.7056662 \\ \text { C } & 0.8456612 & -3.1874891 & -1.7588944 \\ \text { C } & 1.2405523 & -1.8914430 & -1.9778744 \\ \text { N } & -0.6515761 & -0.1751069 & 0.6754225 \\ \text { C } & -1.6522914 & -0.4457870 & 1.7336310 \\ \text { H } & -0.3857075 & 4.2566432 & 1.6701429 \\ \text { H } & -1.2654912 & 2.0344673 & 2.1428604 \\ \text { H } & 1.8940357 & 2.7527983 & -1.6665538 \\ \text { H } & -1.2385901 & -2.8245642 & 0.9127246 \\ \text { H } & -0.3297896 & -4.5448308 & -0.5525413 \\ \text { H } & 1.2234683 & -3.9772550 & -2.3927852 \\ \text { H } & 1.9258309 & -1.6102712 & -2.7644090 \\ \text { H } & -2.2551259 & -1.2915163 & 1.4366781 \\ \text { H } & -2.2819253 & 0.4249922 & 1.8472760 \\ \text { H } & -1.1112235 & -0.6572051 & 2.6534195\end{array}$




$\begin{array}{lrrr}\text { H } & 1.4414870 & 4.6469046 & 0.2433456 \\ \text { C } & 0.9528923 & 3.6815770 & 0.2577474 \\ \text { C } & 0.1794035 & 3.2941915 & 1.3438744 \\ \text { C } & -0.4391365 & 2.0475850 & 1.3648901 \\ \text { C } & -0.3222239 & 1.1739224 & 0.2793907 \\ \text { C } & 0.4564292 & 1.5795258 & -0.8170287 \\ \text { C } & 1.1015173 & 2.8100879 & -0.8168282 \\ \text { C } & -0.2788957 & -1.1851111 & -0.2776628 \\ \text { C } & 0.5041177 & -1.0303682 & -1.4335302 \\ \text { S } & 0.5379138 & 0.5406439 & -2.2470985 \\ \text { C } & -0.3564558 & -2.4554111 & 0.3016759 \\ \text { C } & 0.3040773 & -3.5389334 & -0.2699605 \\ \text { C } & 1.0808623 & -3.3728500 & -1.4088331 \\ \text { C } & 1.1907090 & -2.1081911 & -1.9788410 \\ \text { N } & -0.9639266 & -0.0789358 & 0.2600178 \\ \text { C } & -1.9945735 & -0.3327803 & 1.2549773 \\ \text { H } & 0.0610914 & 3.9556086 & 2.1926838 \\ \text { H } & -1.0141093 & 1.7608431 & 2.2327367 \\ \text { H } & 1.7055715 & 3.0909912 & -1.6705453 \\ \text { H } & -0.9339718 & -2.6069506 & 1.2013311 \\ \text { H } & 0.2159699 & -4.5136918 & 0.1926716 \\ \text { H } & 1.6013340 & -4.2125512 & -1.8502047 \\ \text { H } & 1.7969513 & -1.9567551 & -2.8632475 \\ \text { H } & -2.6025778 & -1.1732840 & 0.9277605 \\ \text { H } & -2.6344637 & 0.5434377 & 1.3324932 \\ \text { H } & -1.5899929 & -0.5595050 & 2.2481846\end{array}$




$\begin{array}{lrrr}\text { H } & 1.1009421 & 4.8352266 & 0.0676832 \\ \text { C } & 0.7520157 & 3.8151944 & 0.1520944 \\ \text { C } & -0.0585708 & 3.4300414 & 1.2285833 \\ \text { C } & -0.5136773 & 2.1356963 & 1.3420627 \\ \text { C } & -0.1709242 & 1.1624034 & 0.3815994 \\ \text { C } & 0.6752784 & 1.5567618 & -0.6830615 \\ \text { C } & 1.1178182 & 2.8816786 & -0.7914184 \\ \text { C } & -0.1270170 & -1.2152950 & -0.1797453 \\ \text { C } & 0.7220628 & -1.0623417 & -1.3025795 \\ \text { S } & 1.1884673 & 0.4772775 & -1.9284309 \\ \text { C } & -0.4260015 & -2.5265256 & 0.2427419 \\ \text { C } & 0.0718443 & -3.6169054 & -0.4344153 \\ \text { C } & 0.8826444 & -3.4517156 & -1.5655854 \\ \text { C } & 1.2068525 & -2.1827873 & -1.9900958 \\ \text { N } & -0.6624254 & -0.1282649 & 0.4921633 \\ \text { C } & -1.7848442 & -0.3670607 & 1.4153235 \\ \text { H } & -0.3274526 & 4.1520537 & 1.9876021 \\ \text { H } & -1.1160005 & 1.8641800 & 2.1928250 \\ \text { H } & 1.7568893 & 3.1537513 & -1.6211841 \\ \text { H } & -1.0284111 & -2.6848824 & 1.1215589 \\ \text { H } & -0.1630746 & -4.6109292 & -0.0788270 \\ \text { H } & 1.2640163 & -4.3136454 & -2.0956842 \\ \text { H } & 1.8450619 & -2.0329122 & -2.8510429 \\ \text { H } & -2.3764455 & -1.1925913 & 1.0384094 \\ \text { H } & -2.4077675 & 0.5187245 & 1.4429749 \\ \text { H } & -1.4212809 & -0.5971329 & 2.4164484\end{array}$




$\begin{array}{lrrr}\text { H } & 1.0156802 & 4.8434167 & -0.0205834 \\ \text { C } & 0.7060939 & 3.8134331 & 0.0868419 \\ \text { C } & -0.1463415 & 3.4420088 & 1.1548610 \\ \text { C } & -0.5767067 & 2.1540254 & 1.3138052 \\ \text { C } & -0.1580266 & 1.1449704 & 0.4140820 \\ \text { C } & 0.7470709 & 1.5294516 & -0.6374216 \\ \text { C } & 1.1503046 & 2.8691422 & -0.7954796 \\ \text { C } & -0.1157602 & -1.2142948 & -0.1435994 \\ \text { C } & 0.7940453 & -1.0562849 & -1.2482356 \\ \text { S } & 1.3722770 & 0.4388758 & -1.7528047 \\ \text { C } & -0.4922836 & -2.5330900 & 0.2058174 \\ \text { C } & -0.0187972 & -3.5981134 & -0.5089601 \\ \text { C } & 0.8379794 & -3.4228343 & -1.6227257 \\ \text { C } & 1.2424154 & -2.1688887 & -1.9854367 \\ \text { N } & -0.6003415 & -0.1397294 & 0.5445795 \\ \text { C } & -1.6979929 & -0.3888460 & 1.5186123 \\ \text { H } & -0.4617819 & 4.1923129 & 1.8658495 \\ \text { H } & -1.2070443 & 1.9118993 & 2.1506101 \\ \text { H } & 1.8170843 & 3.1224288 & -1.6079359 \\ \text { H } & -1.1240645 & -2.7128264 & 1.0571018 \\ \text { H } & -0.3020258 & -4.5976765 & -0.2112337 \\ \text { H } & 1.1823393 & -4.2845688 & -2.1768729 \\ \text { H } & 1.9120268 & -2.0087304 & -2.8190935 \\ \text { H } & -2.2895298 & -1.2200203 & 1.1648617 \\ \text { H } & -2.3238570 & 0.4901139 & 1.5621837 \\ \text { H } & -1.2627638 & -0.6061750 & 2.4911769\end{array}$




\section{Rate capability test and differential capacity plot of (X-)PVMPO- based composite electrodes}

a)

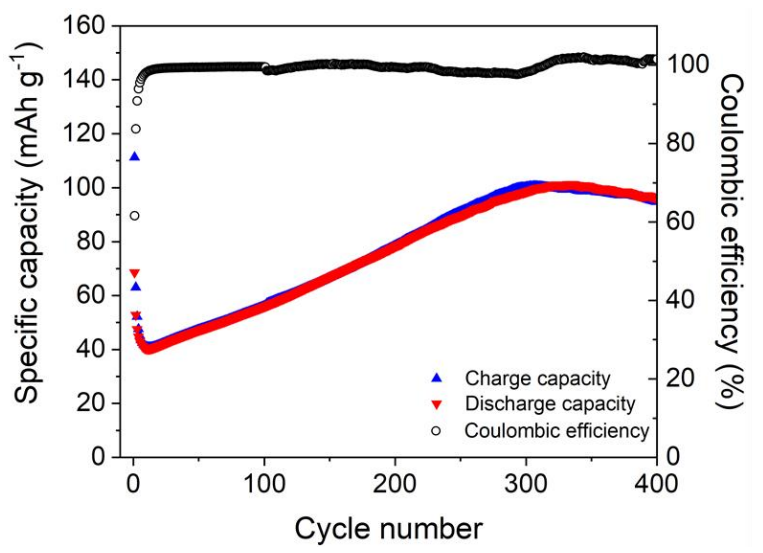

b)

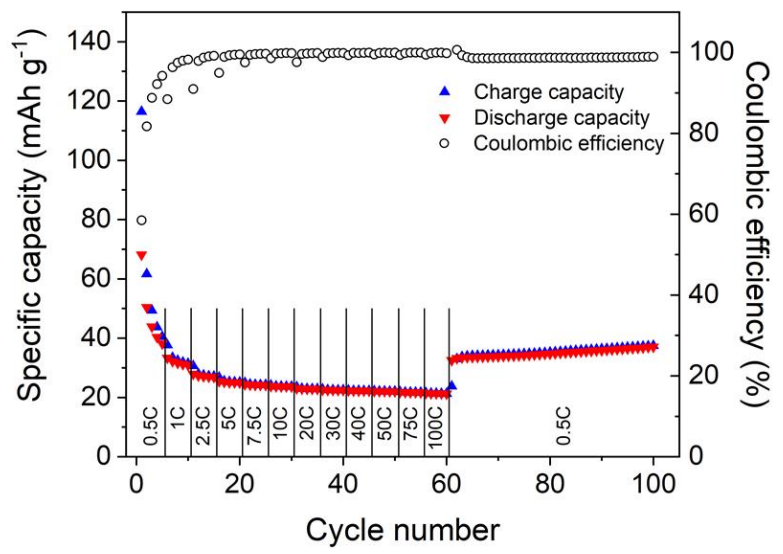

Figure S35. a) Constant current cycling at a $1 \mathrm{C}$ rate prior to a C-rate test (Figure 6A, Manuscript), and b) a C-rate test without previous constant current cycling of a PVMPO-based composite electrode $\left(0.16 \mathrm{mg} \mathrm{cm}^{-2}\right)$.

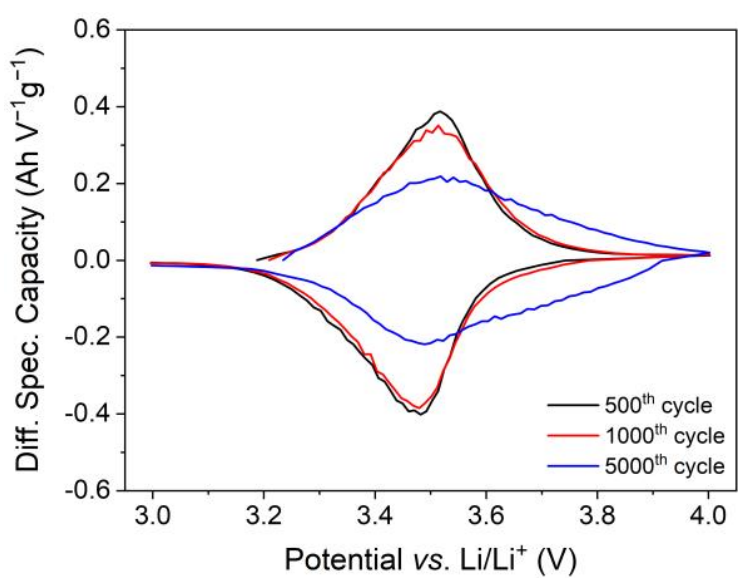

Figure S36. Differential capacity plot for selected cycles of the constant current cycling measurement (Figure 6C, Manuscript) of an X-PVMPO-based electrode at $100 \mathrm{C}$ rate. 


\section{Comparison of PVMPT, X-PVMPT, PVMPO and X-PVMPO}

Table S8. Comparison of PVMPT and X-PVMPT from previous works ${ }^{16,17}$ with the polymers PVMPO and X-

PVMPO investigated in this work. Superior properties are highlighted in green.

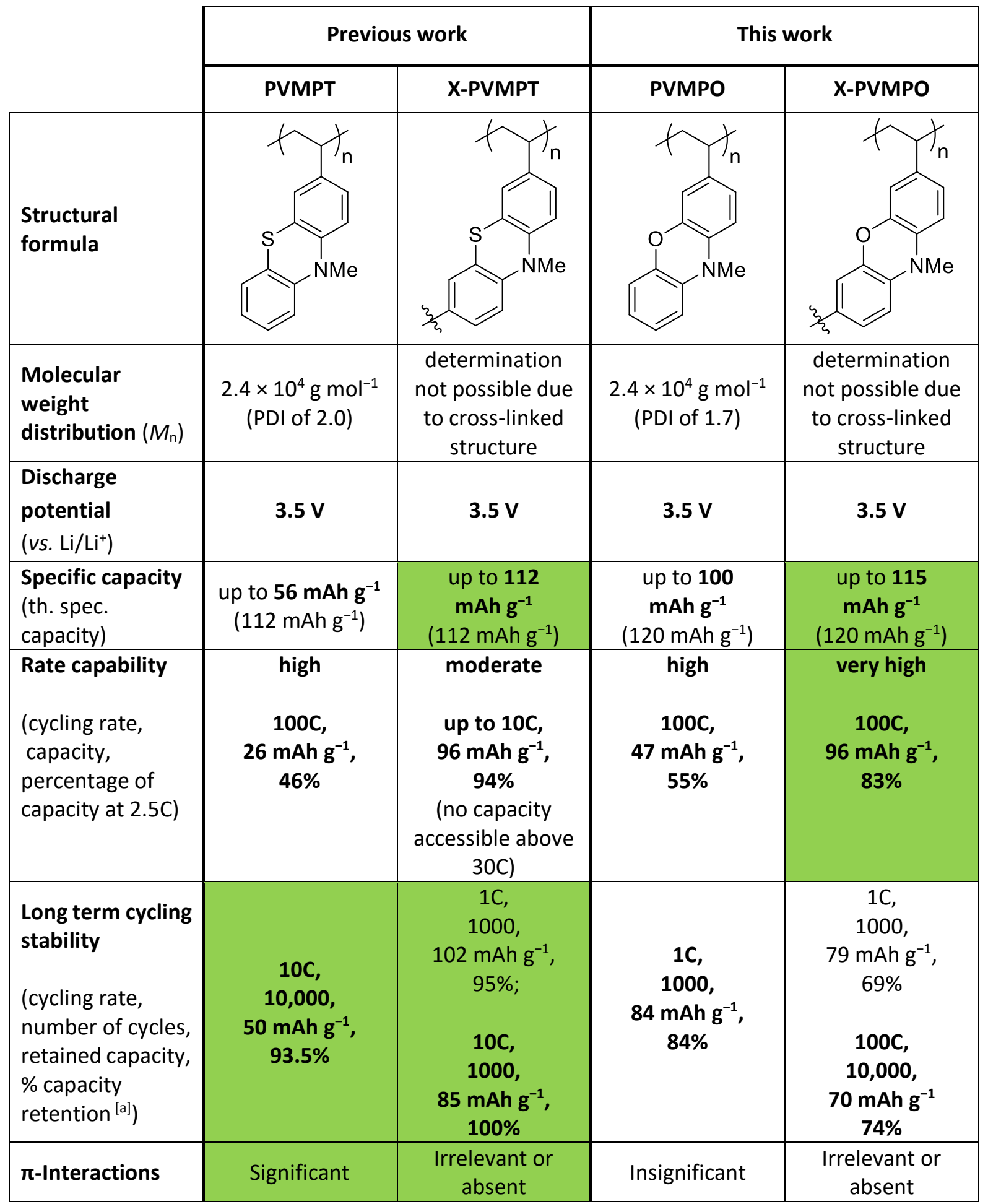

[a] Capacity retention compared to maximum achieved capacity during cycling. 


\section{References}

(1) Ahlrichs, R. TURBOMOLE V7.3, Forschungszentrum Karlsruhe GmbH, 2015.

(2) Eichkorn, K.; Treutler, O.; Öhm, H.; Häser, M.; Ahlrichs, R. Chem. Phys. Lett. 1995, 242 (6), 652660.

(3) Weigend, F. Phys. Chem. Chem. Phys. 2006, 8 (9), 1057-1065.

(4) Grimme, S.; Antony, J.; Ehrlich, S.; Krieg, H. J. Chem. Phys. 2010, 132 (15), 154104.

(5) Grimme, S.; Ehrlich, S.; Goerigk, L. J. Comput. Chem. 2011, 32 (7), 1456-1465.

(6) Becke, A. D.; Johnson, E. R. J. Chem. Phys. 2005, 123 (15), 154101.

(7) Johnson, E. R.; Becke, A. D. J. Chem. Phys. 2006, 124 (17), 174104.

(8) Grimme, S.; Brandenburg, J. G.; Bannwarth, C.; Hansen, A. J. Chem. Phys. 2015, 143 (5), 054107.

(9) Becke, A. D. J. Chem. Phys. 1993, 98 (7), 5648-5652.

(10) Stephens, P. J.; Devlin, F. J.; Chabalowski, C. F.; Frisch, M. J. J. Phys. Chem. 1994, 98 (45), $11623-$ 11627.

(11) Bühl, M.; van Wüllen, C. Chem. Phys. Lett. 1995, 247 (1-2), 63-68.

(12) Schleyer, P. V. R.; Maerker, C.; Dransfeld, A.; Jiao, H.; Van Eikema Hommes, N. J. R. J. Am. Chem. Soc. 1996, 118 (26), 6317-6318.

(13) Frisch, M. J.; Trucks, G. W.; Schlegel, H. B.; Scuseria, G. E.; Robb, M. A.; Cheeseman, J. R.; Scalmani, G.; Barone, V.; Petersson, G. A. ; Nakatsuji, H.; Li, X.; Caricato, M.; Marenich, A. V.; Bloino, J.; Janesko, B. G.; Gomperts, R.; Mennucci, B.; Hratchian, H. P.; Ortiz, J. V.; Izmaylov, A. F.; Sonnenberg, J. L.; Williams-Young, D.; Ding, F.; Lipparini, F.; Egidi, F.; Goings, J.; Peng, B.; Petrone, A.; Henderson, T.; Ranasinghe, D.; Zakrzewski, V. G.; Gao, J.; Rega, N.; Zheng, G.; Liang, W.; Hada, M.; Ehara, M.; Toyota, K.; Fukuda, R.; Hasegawa, J.; Ishida, M.; Nakajima, T.; Honda, Y.; Kitao, O.; Nakai, H.; Vreven, T.; Throssell, K.; Montgomery, Jr., J. A.; Peralta, J. E.; Ogliaro, F.; Bearpark, M. J.; Heyd, J. J.; Brothers, E. N.; Kudin, K. N.; Staroverov, V. N.; Keith, T. A.; Kobayashi, R.; Normand, J.; Raghavachari, K.; Rendell, A. P.; Burant, J. C.; Iyengar, S. S.; Tomasi, J.; Cossi, M.; Millam, J. M.; Klene, M.; Adamo, C.; Cammi, R.; Ochterski, J. W.; Martin, R. L.; Morokuma, K.; Farkas, O.; Foresman, J. B.; Fox, D. J. Gaussian 16, Gaussian, Inc., Wallingford CT, 2019.

(14) Zhao, Y.; Truhlar, D. G. J. Phys. Chem. A 2005, 109 (25), 5656-5667.

(15) D’Andrade, B. W.; Datta, S.; Forrest, S. R.; Djurovich, P.; Polikarpov, E.; Thompson, M. E. Org. Electron. 2005, 6 (1), 11-20.

(16) Kolek, M.; Otteny, F.; Schmidt, P.; Mück-Lichtenfeld, C.; Einholz, C.; Becking, J.; Schleicher, E.; Winter, M.; Bieker, P.; Esser, B. Energy Environ. Sci. 2017, 10 (11), 2334-2341.

(17) Otteny, F.; Kolek, M.; Becking, J.; Winter, M.; Bieker, P.; Esser, B. Adv. Energy Mater. 2018, 8 (33), 1802151. 
